\title{
Test-Analysis Correlation of the Single Stringer Bending Tests for the Space Shuttle ET-137 Intertank Stringer Crack Investigation
}

\author{
Dawn R. Phillips ${ }^{1}$, Joseph B. Saxon ${ }^{2}$, and Robert J. Wingate ${ }^{3}$ \\ NASA Marshall Space Flight Center, Huntsville, AL \\ Extended Abstract of Proposed Paper for the $53^{\text {rd }}$ AIAA/ASME/ASCE/AHS/ASC Structures, \\ Structural Dynamics, and Materials Conference, \\ April 23-26, 2012, Honolulu, Hawaii
}

Category: Structures

\section{INTRODUCTION}

On November 5, 2010, Space Shuttle mission STS-133 was scrubbed due to a hydrogen leak at the Ground Umbilical Carrier Plate (GUCP). After the scrub, a crack in the foam thermal protection system (TPS) was observed on the External Tank (ET) near the interface between the liquid oxygen (LOX) tank and the Intertank. When the damaged foam was removed, two 9-in. long cracks were found on the feet of Intertank stringer S7-2, and the stringer failure was the cause of the TPS crack. An investigation was conducted to determine the root cause of the cracks, establish a remedy/repair for the stringers, and provide flight rationale for the damaged tank, ET-137.

\section{BACKGROUND}

The Space Transportation System (STS) Super Lightweight ET (SLWT) is shown in Figure 1. The SLWT is comprised of two propellant tanks (an aft liquid hydrogen (LH2) tank and a forward LOX tank) and an Intertank. The Intertank serves as the structural connection between the two propellant tanks and also functions to receive and distribute all thrust loads from the solid rocket boosters (not shown in the figure). The Intertank is a stiffened cylinder structure consisting of eight mechanically joined panels (two integrally-stiffened, machined thrust panels to react the booster loads and six stringer-stiffened skin panels) [1]. There are one main ring frame, four intermediate ring frames, and forward and aft flange chords that mate to the respective propellant tanks. An example of the stringer, skin, and chord assembly on the LOX end of the Intertank is shown in Figure 2. The skin/stringer panels utilize external hat-section stringers that are mechanically attached with rivets along most of their length and with specialty fasteners, such as GP Lockbolts and Hi-Loks, at the forward and aft ends where the stringers attach to the flange chords (as shown in the Figure 2 inset).

\footnotetext{
${ }^{1}$ Aerospace Engineer, AIAA Senior Member.

2 Aerospace Engineer.

${ }^{3}$ Aerospace Engineer and Team Lead, AIAA Member.
} 


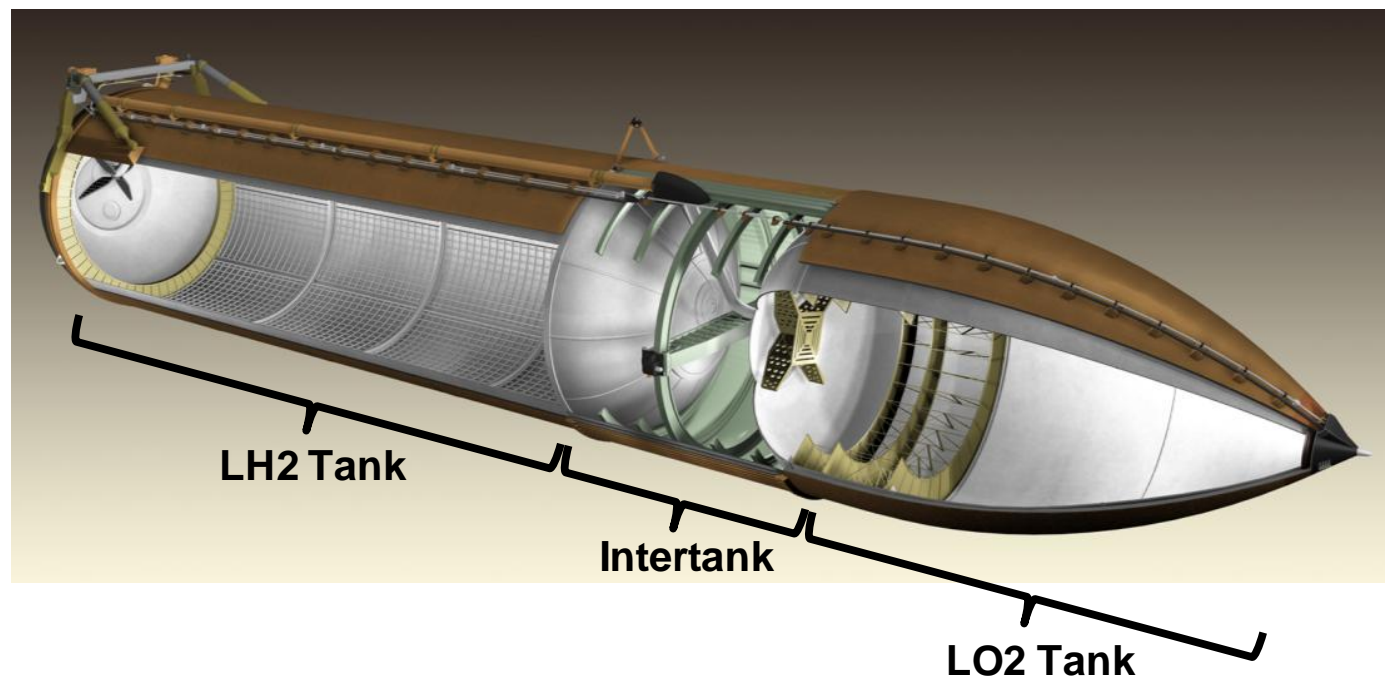

Figure 1. Super Lightweight External Tank.

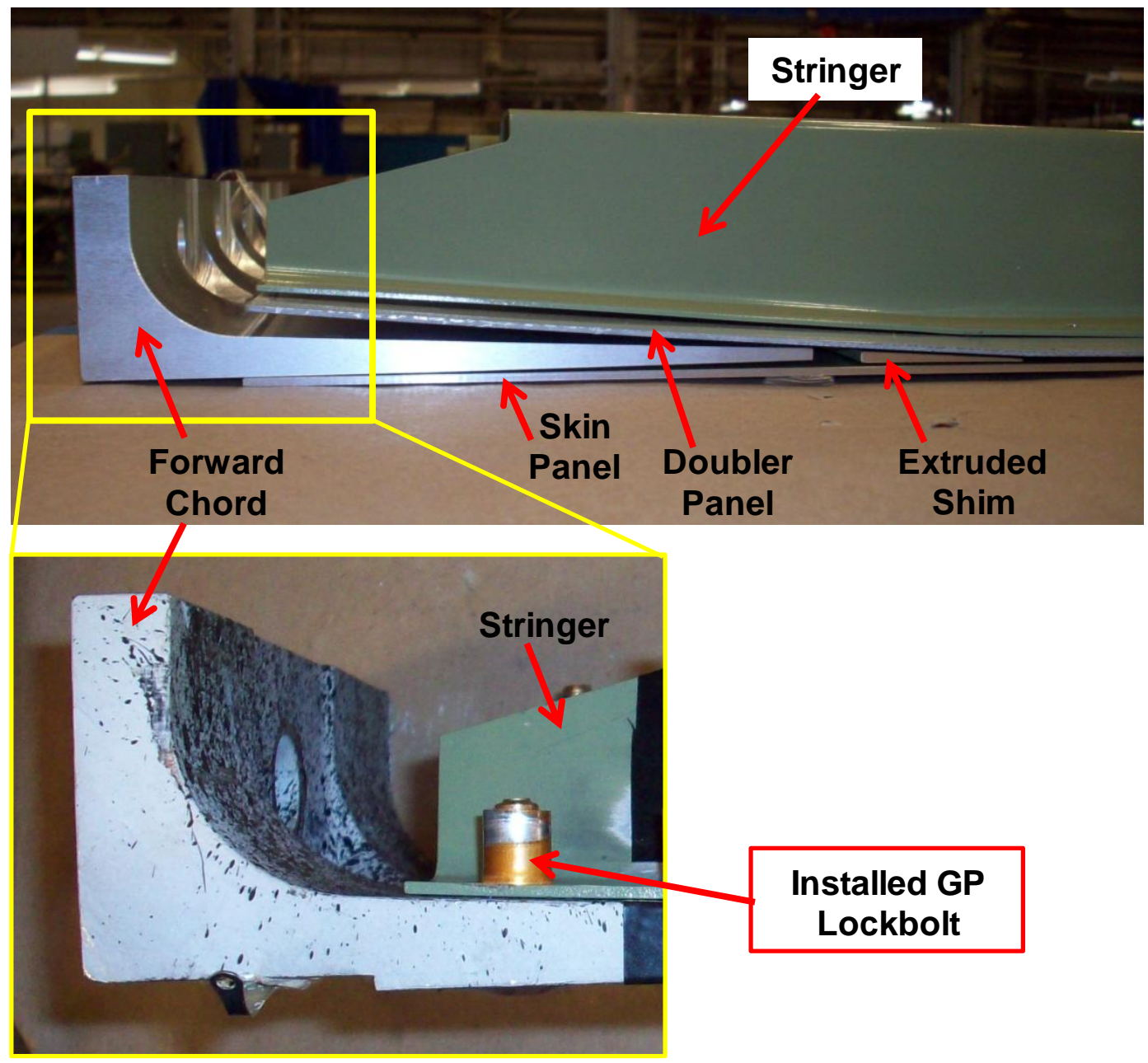

Figure 2. LOX end stringer, skin, and chord assembly. 
During the STS-133 Intertank stringer crack investigation, cracks were found on a total of five stringers. All of the cracks were at the LOX end, in the feet of the stringers, and near the forward fasteners (GP Lockbolts), as shown in Figure 3. Video of tanking for the November 5 launch attempt was used to determine that the TPS failure, and thus the stringer failure, occurred as the LOX liquid level crossed the LOX tank / Intertank interface ring frame. Hence, cryogenically-induced displacements were suspected as a contributing cause of the stringer cracks. To study the behavior of Intertank stringers subjected to similar displacements, static load tests of individual stringers, colloquially known as "single stringer bending tests" were performed. Approximately thirty stringers were tested, many of which were cut from the partially completed Intertank for what would have been ET-139 ${ }^{4}$ In addition to the tests, finite element (FE) analyses of the test configuration were also performed. In this paper, the FE analyses and test-analysis correlation for stringer test S6-8 are presented. Stringer S6-8 is a "short chord" configuration with no doubler panels.

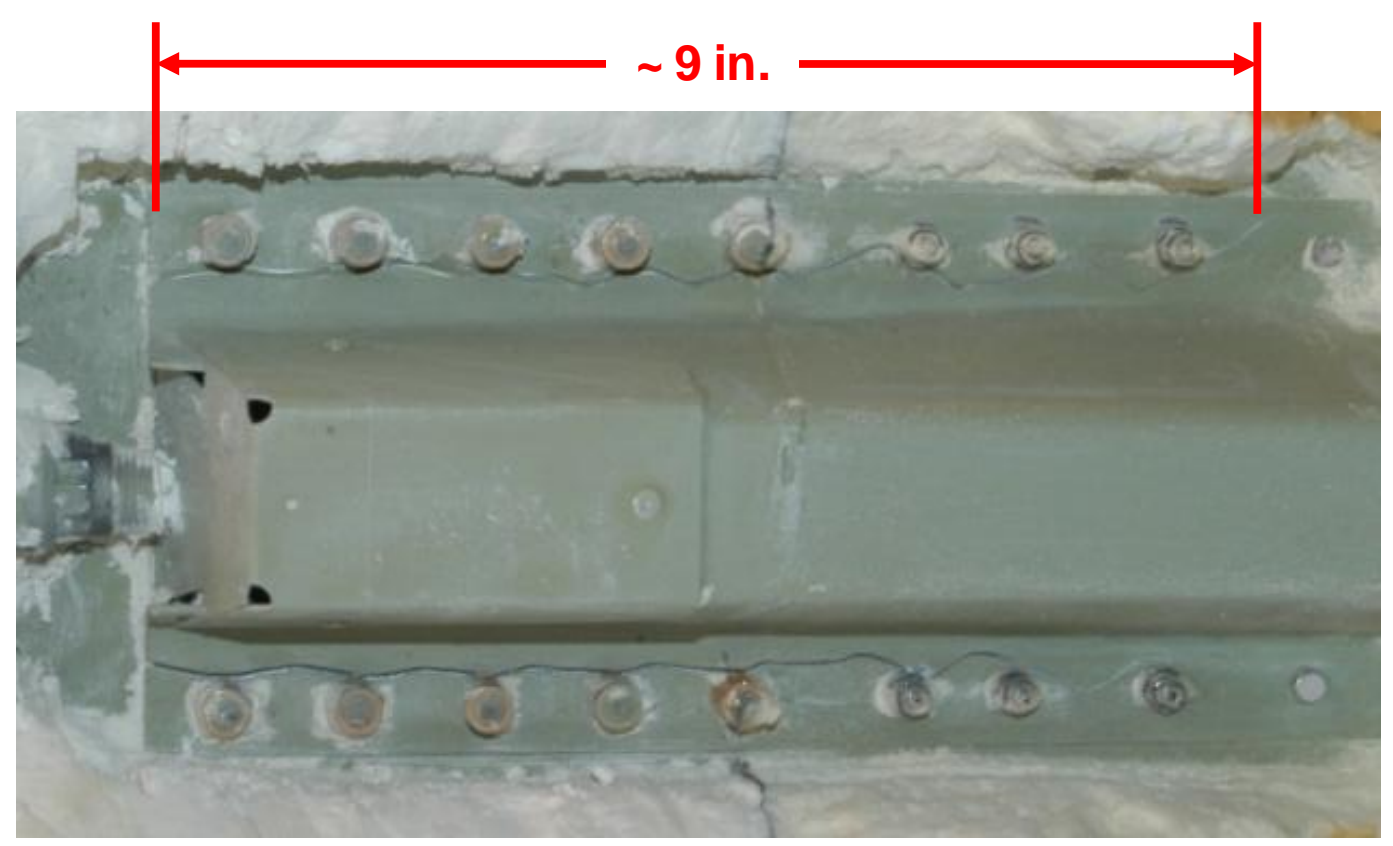

Figure 3. Cracks at LOX end of ET-137 stringer S7-2.

\begin{abstract}
ANALYSIS
The single stringer bending test configuration is shown in Figure 4. The test specimen is anchored to the test fixture at the aft end. At the forward end, the specimen is attached to the test fixture through a single bolt in the chord. The fixture at the forward end consists of two blocks mounted on linear bearings that allow for axial (i.e., the tank axial direction) and transverse (i.e., the tank radial direction) displacement but prevent free rotation of the chord. A specified rotation is applied to the chord by introducing a wedge-shaped shim between the chord and the fixture. A transverse load is applied to the fixture using a hydraulic jack to simulate the cryogenically-induced displacements. Two fulcra are mounted to the fixture on the skin side of

\footnotetext{
${ }^{4}$ Fabrication and assembly of ET-139 was halted at the direction of NASA when it was determined that the tank would not be needed to fly out the remaining missions of the STS.
} 
the specimen; the aft fulcrum is initially in contact with the specimen, while a small gap is initially present at the forward fulcrum. Linear variable-differential transformers (LVDTs) are mounted to both the fixture and the specimen, strain gages are installed on the stringer, and cameras are set up for photogrammetry measurements. The stringers are tested to failure.

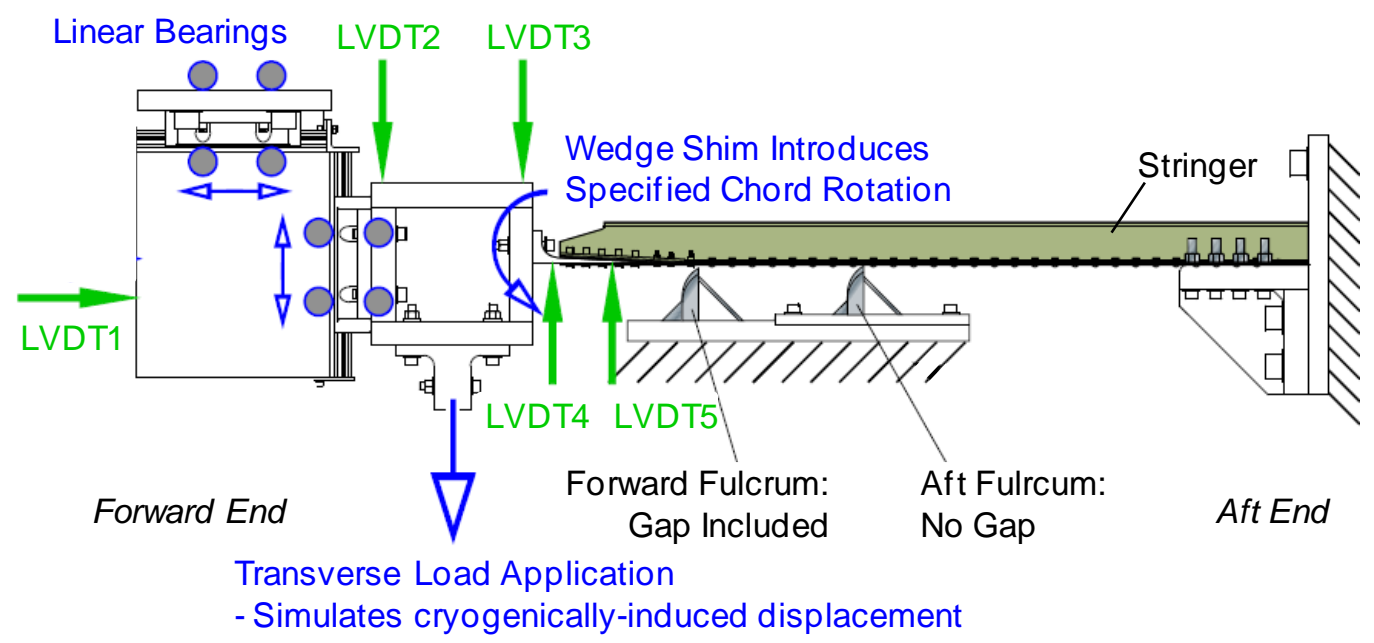

Figure 4. Single stringer bending test configuration.

The finite element model for S6-8 is presented in Figure 5. The model is a three-dimensional (3D) model with solid elements. Only half of the test set-up is modeled to take advantage of symmetry about the $\mathrm{X}-\mathrm{Z}$ plane. The load-application block of the forward fixture, with the wedge-shaped shim, is explicitly modeled in order to apply the chord rotation through a bolted connection (as in the actual test) and to track displacements and loads at the LVDT2, LVDT3, and applied load locations (as in the actual test). The fulcra are also explicitly modeled. The GP Lockbolts, Hi-Loks, and rivets, collectively referred to in this paper as the "stringer fasteners," are explicitly modeled using beam elements and spider constraints.

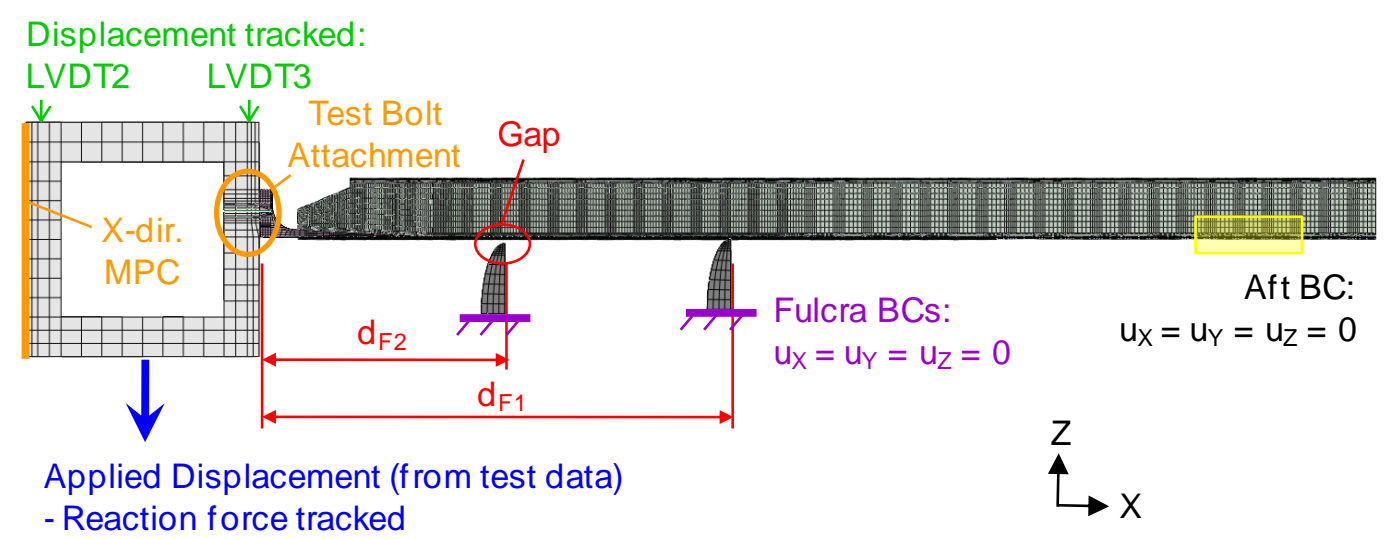

Figure 5. Finite element model of stringer S6-8 bending test configuration. 
A fixed boundary condition is assumed at the aft end of the model. On the forward face of the fixture, an X-direction multipoint constraint is included to reproduce the assumed displacement and rotation constraints of the actual test fixture. The chord is attached to the fixture through a bolt, called the "test bolt," which is modeled with beam elements, spider constraints, and an assumed preload. The fulcra are assumed to be rigid in the actual test fixture, and hence fixed boundary conditions are applied to the bottom of the fulcra. The distances, $\mathrm{d}_{\mathrm{F} 1}$ and $\mathrm{d}_{\mathrm{F} 2}$, from the forward chord face to the aft and forward fulcra, respectively, and the gap at the forward fulcrum were measured for each individual test and are explicitly included in the FE model. The transverse displacement measured at failure during the test is applied to the bottom of the forward fixture.

The finite element analyses are performed using the ABAQUS $5 /$ Standard v. 6.9-EF commercial finite element software [2]. Because bending is expected, four ABAQUS C3D8I ${ }^{6}$ solid brick elements are used through the thickness for the stringer, skin, chord, and extruded shim. The material properties are summarized in Table 1. The stringer fastener materials and preloads are summarized in Table 2. Contact, including friction, is modeled between the individual test specimen components (e.g., between the stringer/chord, skin/fulcra, chord/fixture). The analyses are performed in three steps: (1) preload is applied to the stringer fasteners, (2) preload is applied to the test bolt, and (3) transverse displacement is applied to the forward fixture.

Table 1. Material property summary for FE model of stringer test S6-8.

\begin{tabular}{|c|c|}
\hline Component & Material Model \\
\hline \hline Stringer & Aluminum, Elastic-plastic [3, 4] \\
\hline Skin & Aluminum, Elastic-plastic [3, 4] \\
\hline Chord & Aluminum, Elastic-plastic [3, 4] \\
\hline Extruded shim & Aluminum, Elastic-plastic [3, 4] \\
\hline Fulcra & Aluminum, Elastic \\
\hline Fixture & Steel, Elastic \\
\hline
\end{tabular}

Table 2. Stringer fastener summary for FE model of stringer test S6-8.

\begin{tabular}{|c|c|c|c|}
\hline Fastener & $\begin{array}{c}\text { Fastener numbers, } \\
\text { counting aft from chord }\end{array}$ & Material & Preload \\
\hline \hline GP Lockbolt & $1-3$ & A286, Elastic & Per specification [5] \\
\hline Hi-Lok & $4-6$ & A286, Elastic & Per specification [6] \\
\hline Rivet & Remaining & Aluminum, Elastic & Assumed \\
\hline
\end{tabular}

\section{RESULTS}

The global load-displacement response of the finite element model is compared to the test data in Figure 6. All of the plots are normalized by the LVDT3 displacement and transverse load

\footnotetext{
${ }^{5}$ ABAQUS is a registered trademark of Dassault Systèmes.

${ }^{6}$ The C3D8I solid element has 8 nodes with three degrees of freedom per node plus 13 additional element variables associated with the incompatible deformation modes. The estimated total number of unknowns for a given finite element mesh using C3D8I elements is roughly equal to three times the number of nodes plus 13 times the number of C3D8I solid elements [2].
} 
measured at failure during the test. The test data are represented by the open black circles. The initial response with zero slope represents the introduction of the chord rotation through the tightening of the test bolt, which also induces some transverse displacement. The first non-zero sloped region of the curve represents bending over the aft fulcrum, and the second sloped region represents bending over the forward fulcrum.

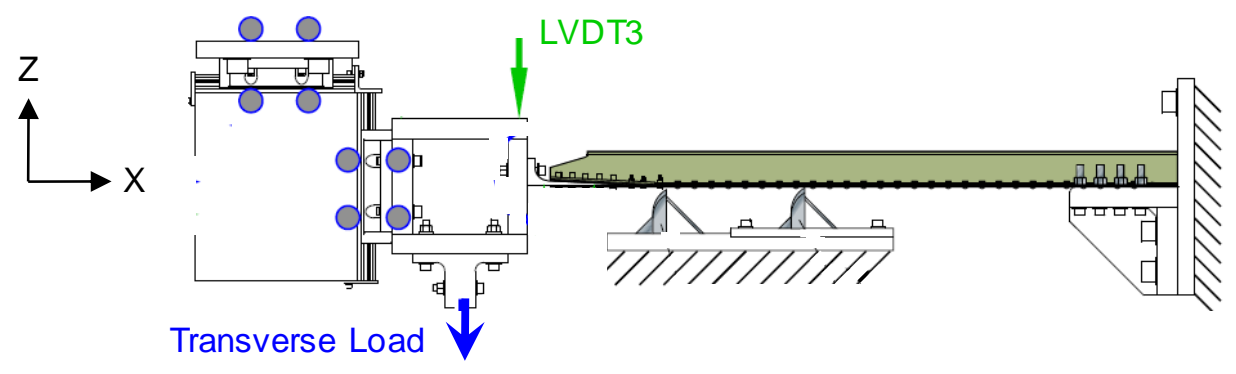

Load Vs. Displacement

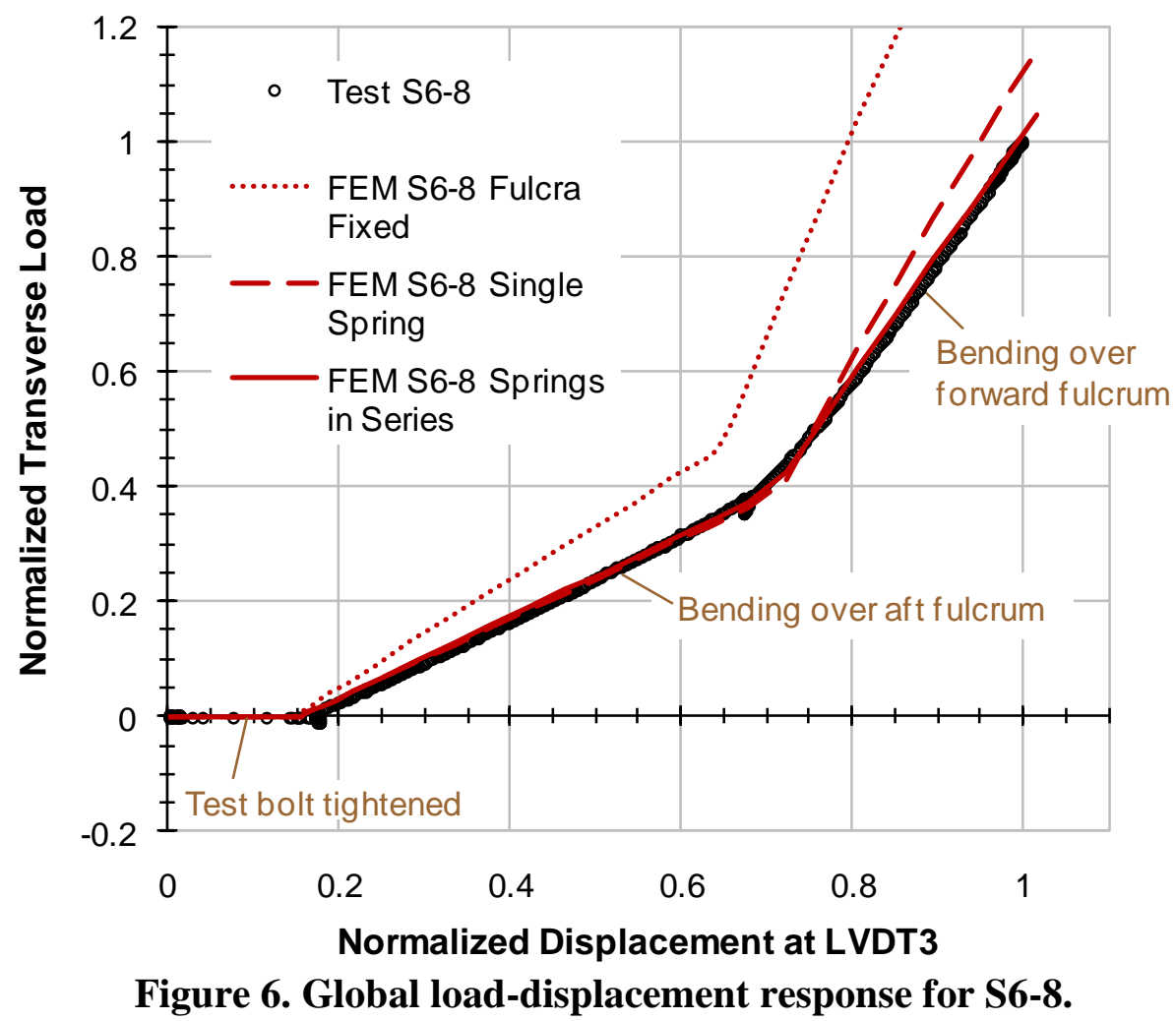

The dotted red line is the response from the FE model with assumed fixed boundary conditions for the fulcra. As shown by this line, the FE model is overly stiff in the $\mathrm{Z}$ direction. The source of the additional Z-direction stiffness is determined to be due to the rigid fulcra assumption. To account for compliance in the test fixture in the region where the fulcra are mounted, the boundary conditions for the fulcra in the FE model are modified. First, both fulcra are connected to a single spring with an assumed stiffness, as shown in Figure 7(a). The global loaddisplacement response for this configuration is shown by the red dashed line in Figure 6 . The 
results for bending over the aft fulcrum are very closely captured; however, the model is still overly stiff for bending over the forward fulcrum. Therefore, the model is modified again: a second spring in series is used for the forward fulcrum, as shown in Figure 7(b). The global load-displacement response for this configuration is shown by the solid red line in Figure 6. The correlation with the test data is excellent.

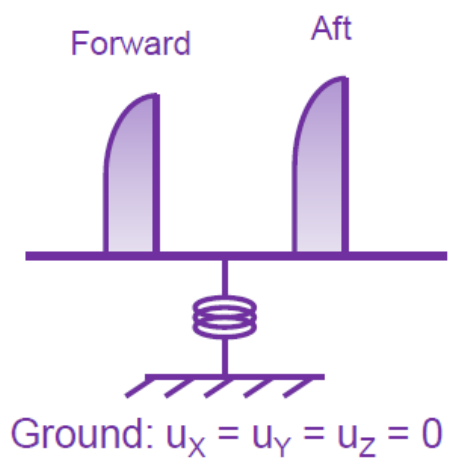

(a) Fulcra mounted to single spring

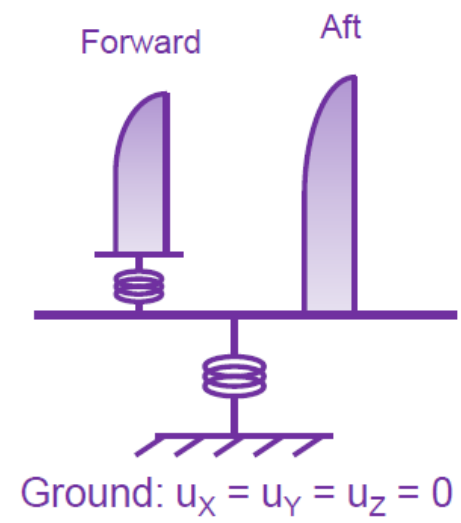

(b) Forward fulcrum mounted to second spring in series

Figure 7. Modified fulcra BCs.

A parallel and independent modeling and correlation effort is conducted for stringer S9-7, which has a standard length chord and a single doubler panel. The analyses are performed using the ANSYS $^{7}$ commercial finite element software. The analysis results for S9-7 show very similar trends as the analyses for S6-8.

In this paper, the details of the finite element analyses and test-analysis correlation for the single stringer bending test of stringer S6-8 will be presented. Comparisons and contrasts between the analyses and results for S6-8 and S9-7 will be made and used to discuss various challenges related to modeling for quickly-developed test programs. In addition, the analyses and results will be discussed as they related to other test and analysis efforts of the Intertank stringer crack investigation and the development of the flight rationale for ET-137.

\section{REFERENCES}

1. Anon. (1997): Space Shuttle External Tank System Definition Handbook, SLWT, Lockheed Martin - Michoud Space Systems Document No. LMC-ET-SE61-1, Volume I, Section 7, December 1997.

2. Anon. (2009): ABAQUS Analysis User's Manual: Volumes I - VI, Version 6.9, Dassault Systèmes Simulia Corp., Providence, RI.

\footnotetext{
${ }^{7}$ ANSYS is a registered trademark of SAS IP Inc.
} 
3. Pilet, J. and Geiman, W. (1997): Space Shuttle External Tank Stress Analysis, Lockheed Martin Report MMC-ET-SE05-439, December 1997.

4. Allen, P. (NASA/MSFC/EM20), Preliminary test data emailed to the author, 16 December 2010 and 23 March 2011.

5. McAllister (1997): Lockheed Martin Memorandum of Record (Memo no. SLWT-3070-97002) with Report on SLWT Intertank Al 2090 Stringer Cracking During Assembly, Special Investigation SI-96-S007, January 1997.

6. Anon. (2005): Lockheed Martin - Michoud Space Systems Standard Part Specification 25L9, Issue March 1975, Revision 8, July 2005.

\section{ACKNOWLEDGEMENTS}

The authors would like to gratefully acknowledge the engineers and technicians at the MSFC Materials and Environmental Test Complex (METCO) Hot Gas Facility for their contribution to constructing the test apparatus and performing the stringer tests and Mr. Todd Boles and Dr. Stanley Oliver for their work post-processing the photogrammetry data. 


\title{
Test-Analysis Correlation of the Single Stringer Bending Tests for the Space Shuttle ET-137 Intertank Stringer Crack Investigation
}

\author{
Dawn R. Phillips ${ }^{*}$, Joseph B. Saxon ${ }^{\dagger}$, and Robert J. Wingate ${ }^{\ddagger}$ \\ NASA Marshall Space Flight Center, Huntsville, AL
}

\begin{abstract}
Following the scrub of the November 5, 2010 launch attempt of Space Shuttle mission STS-133, cracks were found in the stringers on the Intertank of the External Tank, ET-137. A large investigation was conducted to determine the root cause of the cracks, establish a repair for the stringers, and provide data for the flight readiness assessment of the repaired tank. As part of the investigation, static load tests of individual stringer-skin sections and corresponding finite element analyses were performed. The details of these finite element analyses and the test-analysis correlation for these single stringer bending tests are presented. Comparisons and contrasts between the analyses and test results for two specific stringers are made and used to discuss challenges related to modeling for quickly-developed test programs; correlation of the finite element models to the test data was not trivial and is discussed. The analyses and test results are also discussed as they related to the development of the flight-worthiness rationale for ET-137 and the tanks for the remaining Shuttle missions. Lessons learned are identified.
\end{abstract}

\section{Introduction}

$\mathrm{O}$ November 5, 2010, Space Shuttle mission STS-133 was scrubbed due to a hydrogen leak at the Ground Umbilical Carrier Plate. After the scrub, a crack in the foam thermal protection system (TPS) was observed on the External Tank (ET) near the interface between the liquid oxygen (LOX) tank and the Intertank. When the damaged foam was removed, two 9-inch-long cracks were found on the feet of Intertank stringer identified as "S72 ," and the stringer failure was the cause of the TPS crack. A large investigation was immediately initiated, and analyses and testing were conducted to determine the root cause of the cracks, establish a remedy/repair for the stringers, and provide data for the flight readiness assessment of the repaired tank, ET-137.

\section{Background}

The Space Transportation System (STS) Super Lightweight ET (SLWT) is shown in Figure 1. The SLWT is comprised of two propellant tanks (an aft liquid hydrogen (LH2) tank and a forward LOX tank) and an Intertank. The Intertank serves as the structural connection between the two propellant tanks and also functions to receive and distribute all thrust loads from the solid rocket boosters (not shown in the figure). The Intertank is a stiffened cylinder structure consisting of eight mechanically joined panels (two integrally-stiffened, machined thrust panels to react the booster loads; and six stringerstiffened skin panels) [1]. The structure also has one main ring frame, four intermediate ring frames, and forward and aft flange chords that mate to the adjacent propellant tanks. An example of the stringer, skin, and

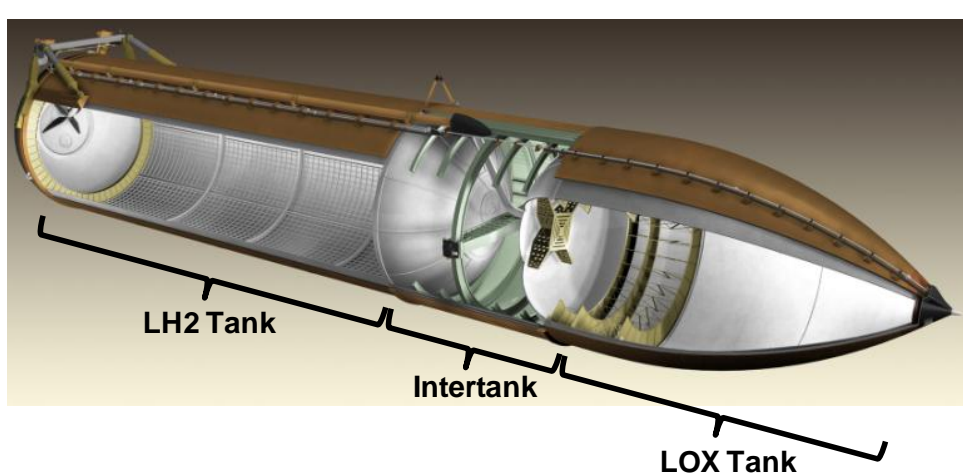

Figure 1. Super Lightweight External Tank.

\footnotetext{
*Aerospace Engineer, AIAA Senior Member, ASME Member.

$\dagger$ Aerospace Engineer.

¥ Aerospace Engineer and Team Lead, AIAA Senior Member.
} 
chord assembly on the forward end near the LOX tank (the LOX end) of the Intertank is shown in Figure 2. The skin/stringer panels utilize external hat-section stringers that are mechanically attached with rivets along most of their length and with specialty fasteners, such as GP Lockbolts and Hi-Loks, at the forward and aft ends where the stringers attach to the flange chords (as shown in the Figure 2 inset).

During the STS-133 Intertank stringer crack investigation, cracks were found on a total of five stringers. All of the cracks were similar to those shown in Figure 3, differing primary in length, occurring at the LOX end, in the feet of the stringers, and near the forward fasteners (GP Lockbolts). Launch pad video of tanking for the November 5 launch attempt was used to determine that the TPS failure, and thus the stringer failure, occurred as the LOX liquid level crossed the LOX tank / Intertank interface ring frame.
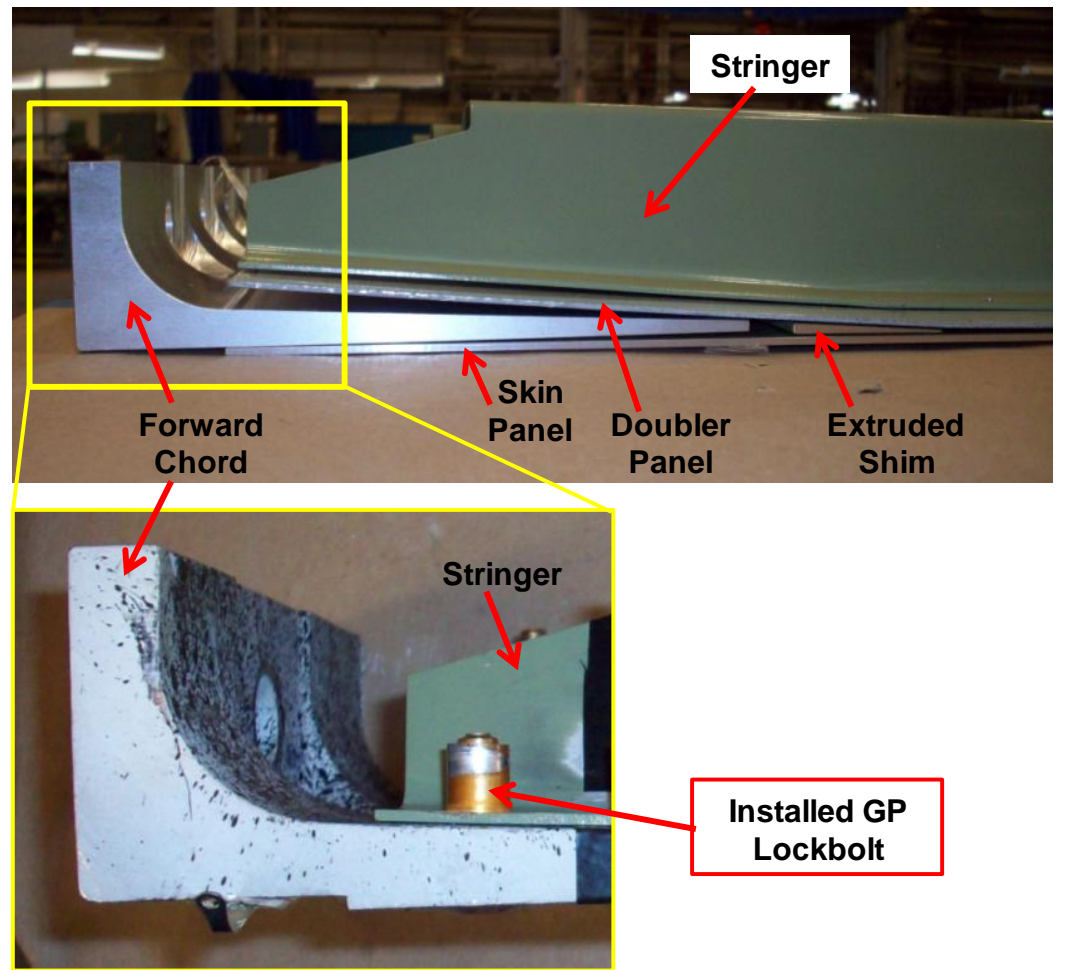

Figure 2. LOX end stringer, skin, and chord assembly.

Hence, cryogenically-induced displacements were suspected as a contributing cause of the stringer cracks. To study the behavior of Intertank stringers subjected to similar displacements, static load tests of individual stringer-skin sections, colloquially known as "single stringer bending tests," were performed. Approximately thirty stringers

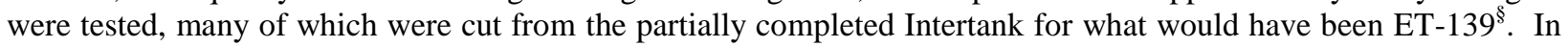
addition to the tests, finite element (FE) analyses of the test configuration were also performed.

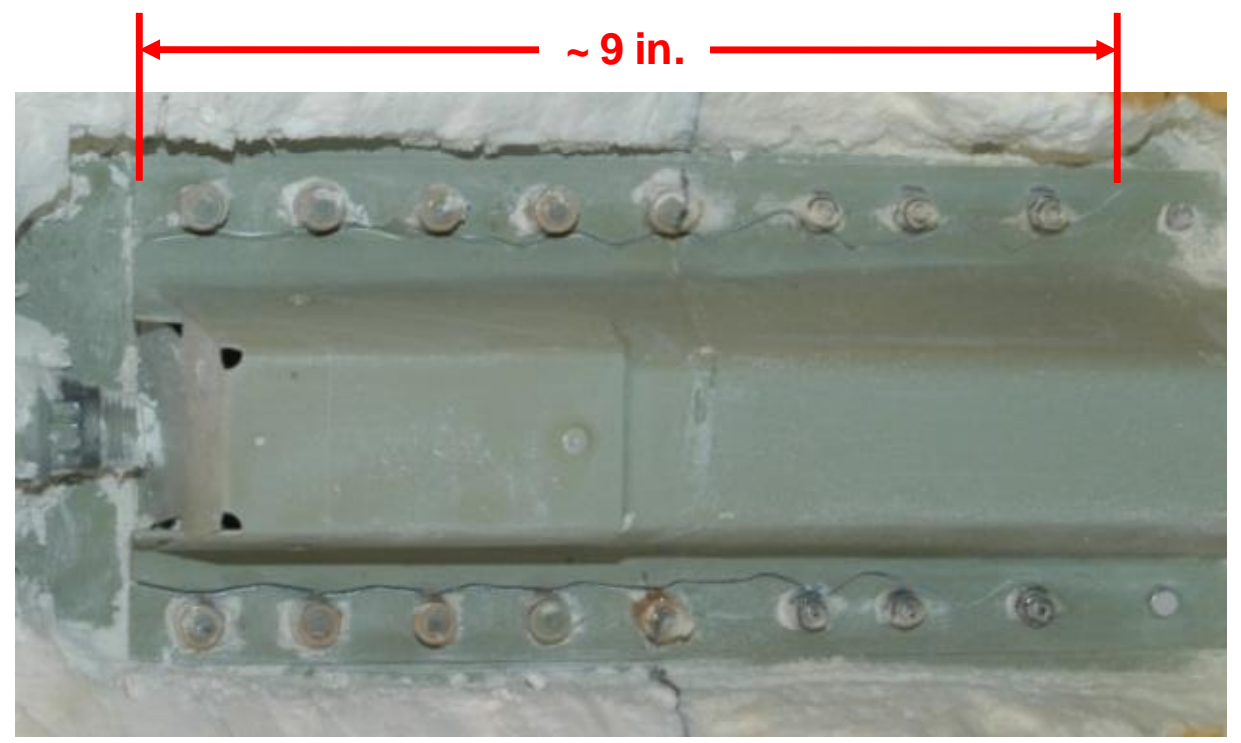

Figure 3. Cracks at LOX end of ET-137 stringer S7-2.

\footnotetext{
${ }^{\S}$ Fabrication and assembly of ET-139 was halted at the direction of NASA when it was determined that the tank would not be needed to fly out the remaining missions of the Space Shuttle Program.
} 
In this paper, the details of the finite element analyses and test-analysis correlation for the single stringer bending tests are presented. Comparisons and contrasts between the analyses and test results for two specific stringers are made and used to discuss various challenges related to modeling for quickly-developed test programs. In addition, the analyses and results are discussed as they related to the development of the flight-worthiness rationale for ET137 and the tanks for the remaining Shuttle missions.

\section{Single Stringer Bending Tests}

The single stringer bending test configuration is shown in Figure 4. Each single test specimen was approximately 40 inches long and consisted of a single stringer attached via the actual flight fasteners to an approximately 5-inch-wide cross-section of skin, extruded shim, and chord. The test specimen was anchored to the test fixture at the aft end. At the forward end, the specimen was attached to the test fixture through a single bolt in the chord. The fixture at the forward end consisted of two blocks mounted on linear bearings that allowed for axial (i.e., the tank axial direction) and transverse (i.e., the tank radial direction) displacement but prevented free rotation of the chord. A specified rotation, measured during a tanking test that was performed on December 17, 2010 [2], was applied to the chord by introducing a wedge-shaped shim between the chord and the load block (see the Figure 4 inset). A transverse load was applied to the load block using a hydraulic jack to simulate the cryogenicallyinduced displacements. Two fulcra were mounted to the fixture on the skin side of the specimen; the aft fulcrum was initially in contact with the specimen, while a small gap was initially present at the forward fulcrum. Linear variable differential transformers (LVDTs) were mounted to both the fixture and the specimen, strain gages were installed on the stringer, and cameras were set up for photogrammetry measurements. The stringers were tested to failure.
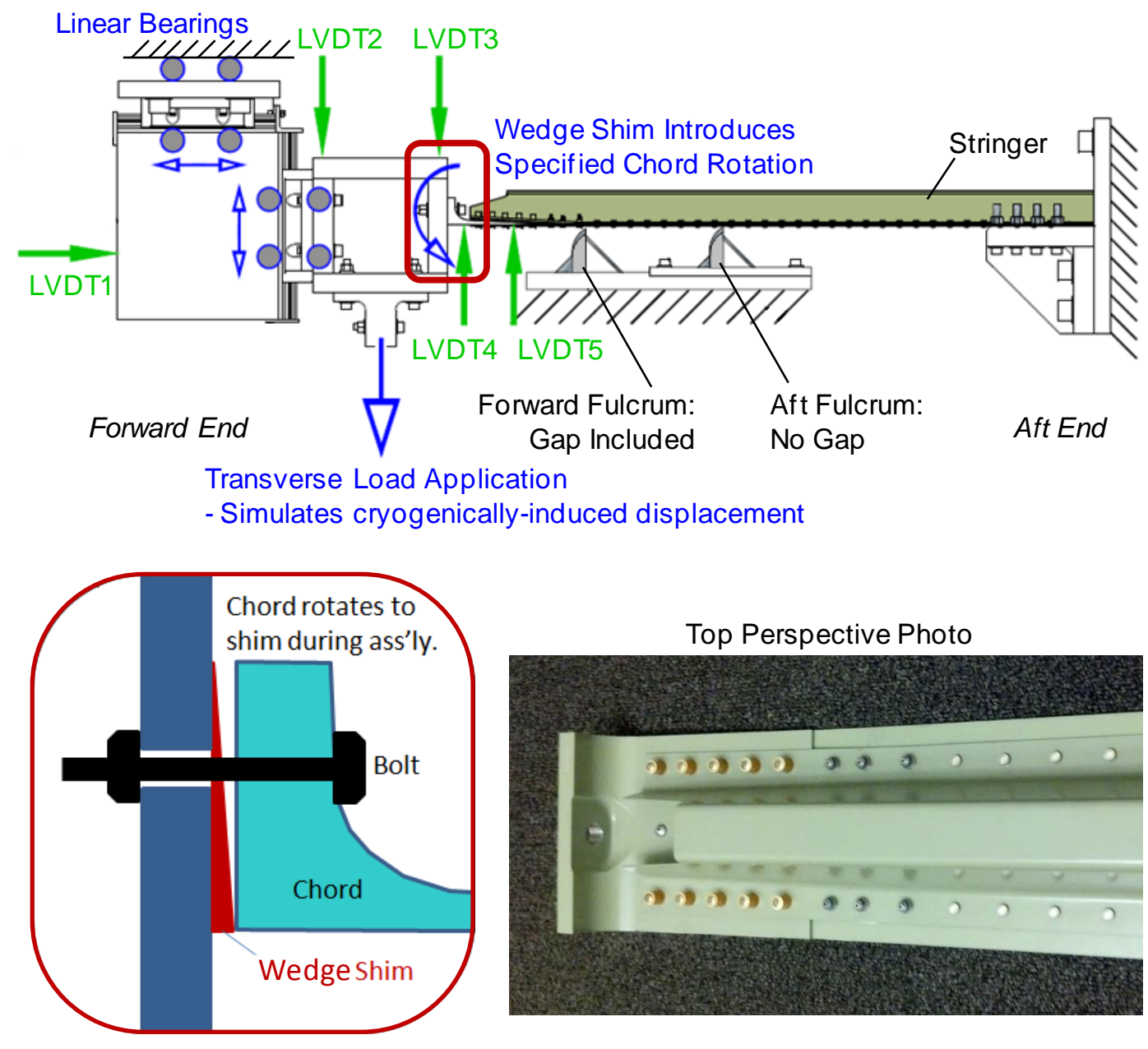

Figure 4. Single stringer bending test configuration.

American Institute of Aeronautics and Astronautics 
All of the Intertank flange chords have the same basic L-section shape, as shown in Figure 5, but the length of the axial leg (under the stringers) is longer for some chords than for others. Specifically, the forward chords of the four stringer panels adjacent to the thrust panels have a longer axial leg to accommodate the doubler skins on those panels. These chords are called "long chords" (Figure 5(a)). The forward chords on the remaining two stringer panels and the aft chords for all of the stringer panels have a shorter length axial leg. These chords are called "short chords" (Figure 5(b)). Bending tests were performed for both long-chord and short-chord configurations.

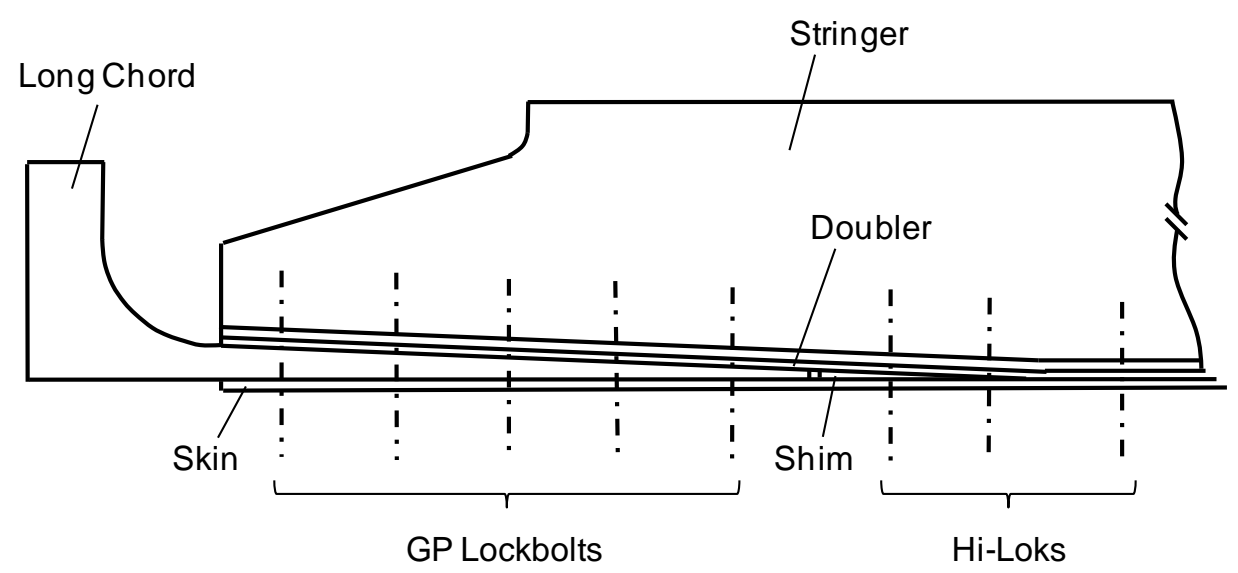

(a) Long Chord

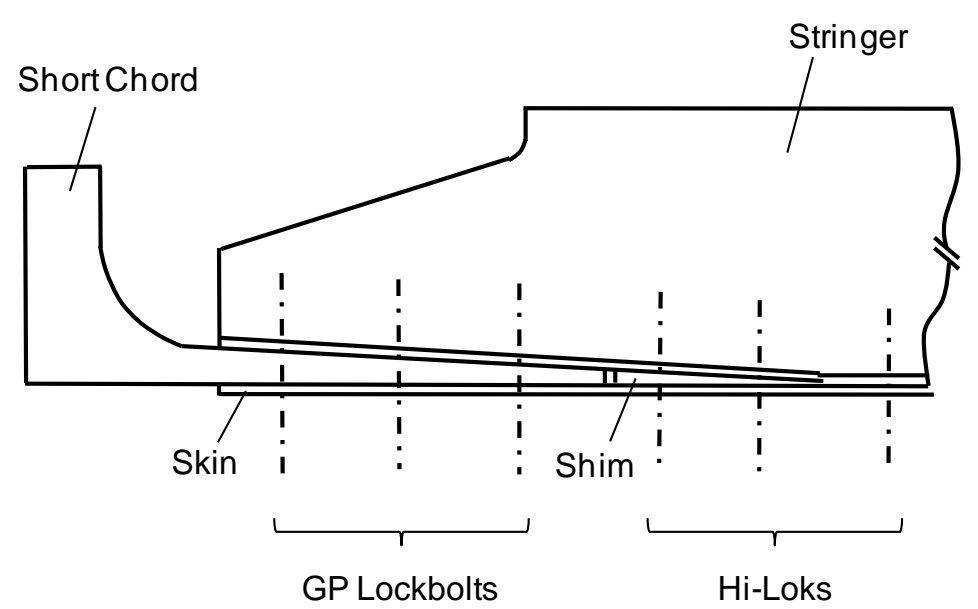

(b) Short Chord

Figure 5. Long- and short-chord configurations.

\section{Finite Element Analysis}

Two parallel FE analysis efforts were performed somewhat independently by two different analysts. One analyst modeled a long-chord configuration (test specimen designated S9-7), and the other modeled a short-chord configuration (test specimen designated S6-8). The details of these two analyses are described in Table 1 and the paragraphs that follow.

Table 1. Finite element analyses performed.

\begin{tabular}{|c|c|c|}
\hline & Long Chord & Short Chord \\
\hline \hline Corresponding test specimen & S9-7 & S6-8 \\
\hline Analysis code & ANSYS v12 & ABAQUS v6.9-EF \\
\hline FEM representation of fulcra & Gap elements & Meshed geometry \\
\hline
\end{tabular}


The finite element models for stringers S9-7 and S6-8 are presented in Figure 6. Both models were threedimensional (3D) models with solid elements. For S9-7, the chord, extruded shim, and skin were modeled as a single part, while for S6-8, each part was modeled separately. Only half of the test set-up was modeled to take advantage of symmetry about the X-Z plane. The load-application block of the forward fixture, with the wedgeshaped shim, was explicitly modeled with meshed geometry to realistically model the contact and preload at the bolted block/shim/chord interface and also to track displacements and loads at the LVDT3 and applied load locations (as in the actual test). The GP Lockbolts, Hi-Loks, and rivets, collectively referred to in this paper as the "stringer fasteners," were explicitly modeled using beam elements, spider constraints, and preloads.

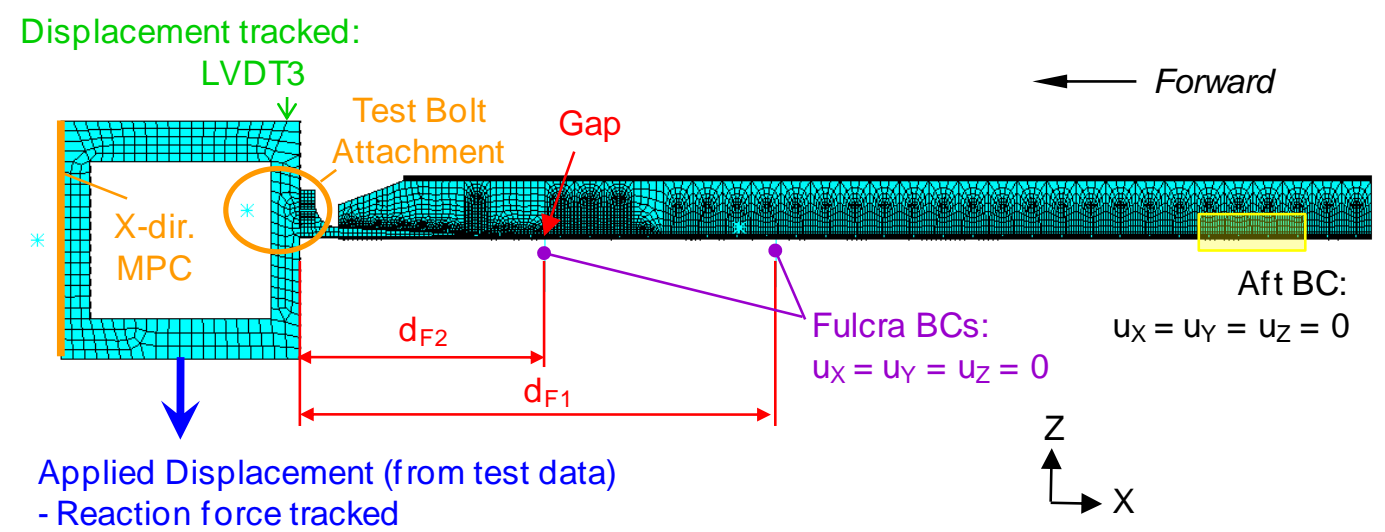

(a) S9-7

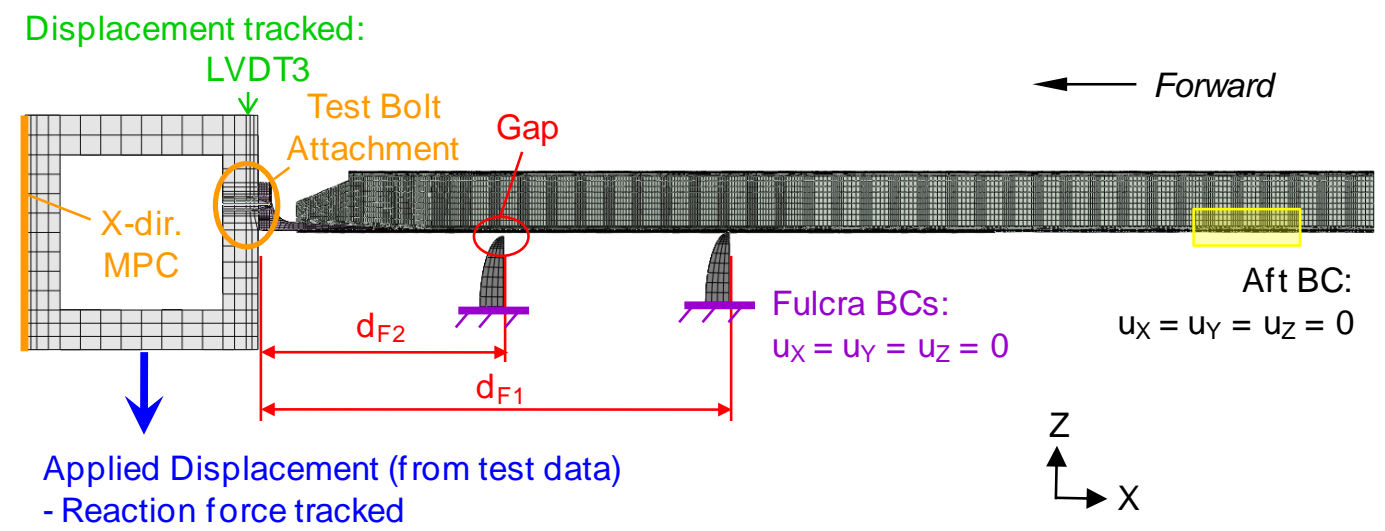

(b) S6-8

Figure 6. Finite element models of stringer bending test configurations.

A fixed boundary condition was assumed at the aft end of both models. On the forward face of the load block, an X-direction multipoint constraint was included to reproduce the free translation and fixed rotation constraints provided by the actual test fixture. The chord was attached to the load block through a bolt, called the "test bolt," which was modeled with beam elements, spider constraints, and a preload estimated from the known torque. The fulcra were initially assumed to be rigid in the actual test fixture, and hence fixed boundary conditions were applied to the bottom of the fulcra. The gap at the forward fulcrum was measured for each individual test and was explicitly included in the FE models. The transverse displacement measured at failure during the test was enforced at the load block to deflect the stringer over the fulcra.

The FE material properties are summarized in Table 2. The stringer fastener materials and preloads are summarized in Table 3. Contact, including friction, was modeled between the individual test specimen components (e.g., stringer to chord-skin, chord to load block, etc.). 
Table 2. Material property summary for FE models of stringer tests.

\begin{tabular}{|c|c|c|}
\hline \multirow{2}{*}{ Component } & \multicolumn{2}{|c|}{ Material Model } \\
\cline { 2 - 3 } & S9-7 & S6-8 \\
\hline \hline Fulcra & n/a (gap elements) & Aluminum, Elastic \\
\hline Stringer & Aluminum, Elastic-plastic [3, 4] \\
\hline Skin & Aluminum, Elastic-plastic [3, 4] \\
\hline Chord & Aluminum, Elastic-plastic [3, 4] \\
\hline Extruded shim & Aluminum, Elastic-plastic [3, 4] \\
\hline Load block & Steel, Elastic \\
\hline
\end{tabular}

Table 3. Stringer fastener summary for FE models of stringer tests.

\begin{tabular}{|c|c|c|c|c|c|}
\hline \multirow{2}{*}{ Fastener } & \multicolumn{2}{|c|}{$\begin{array}{c}\text { Fastener numbers, counting } \\
\text { aft from chord (see Fig. 5) }\end{array}$} & \multicolumn{2}{|c|}{ Material } & \multirow{2}{*}{ Preload } \\
\cline { 2 - 5 } & S9-7 & S6-8 & S9-7 & S6-8 & Per specification [5] \\
\hline \hline GP Lockbolt & $1-5$ & $1-3$ & \multicolumn{2}{|c|}{ Steel, Elastic } & Per specification [6] \\
\hline Hi-Lok & $6-8$ & $4-6$ & \multicolumn{2}{|c|}{ Steel, Elastic } & Assumed \\
\hline Rivet & \multicolumn{2}{|c|}{ Remaining } & Steel, Elastic & Alum., Elastic & \\
\hline
\end{tabular}

For S9-7, the interaction of the test specimen with the fulcra was modeled with gap elements. The analyses were performed using the ANSYS ${ }^{* *}$ v12 commercial finite element software [7]. Solid185 elements were used - two through the thickness for the stringer, and at least two through the thickness for the skin, chord, and extruded shim assembly. The analyses were performed in eight steps:

(1) Displacement applied to stringer fasteners to exactly close gap between stringer and skin

(2) Full preload applied to stringer fasteners

(3) Stringer fastener preloads locked with relative deflections

(4) Displacement applied to test bolt to close gap between chord and load block

(5) Full preload applied to test bolt

(6) Test bolt preload locked with relative deflection

(7) Transverse displacement of 0.5 inches applied to load block (similar to test procedure)

(8) Remaining transverse displacement to test value applied to load block

Note that applying the preload in two steps was a precaution against convergence problems but was not strictly necessary.

For S6-8, the fulcra were explicitly modeled with meshed geometry, and contact with friction was included between the test specimen and the fulcra. The analyses were performed using the ABAQUS ${ }^{\dagger \dagger} / S_{\text {Standard v. } 6.9-\mathrm{EF}}$ commercial finite element software [8]. Because bending was expected, four $\mathrm{C} 3 \mathrm{D} 8 \mathrm{I}^{\mathrm{H}}$ solid brick elements were used through the thickness for each of the stringer, skin, chord, and extruded shim. The analyses were performed in three steps:

(1) Preload applied to stringer fasteners

(2) Preload applied to test bolt

(3) Transverse displacement applied to load block

\section{Results}

The global load-displacement response of the FE model for S9-7 is compared to the corresponding test data in Figure 7. The test data are represented by the solid black line. The initial response with zero slope represents the introduction of the chord rotation through the tightening of the test bolt, which also induces some transverse displacement. The first non-zero sloped region of the curve represents bending over the aft fulcrum, and the second sloped region represents bending over the forward fulcrum.

\footnotetext{
*** ANSYS is a registered trademark of SAS IP Inc.

${ }^{\dagger \dagger}$ ABAQUS is a registered trademark of Dassault Systèmes.

$\$$ The C3D8I solid element has 8 nodes with three degrees of freedom per node plus 13 additional element variables associated with the incompatible deformation modes. The estimated total number of unknowns for a given finite element mesh using C3D8I elements is roughly equal to three times the number of nodes plus 13 times the number of C3D8I solid elements [8].
} 


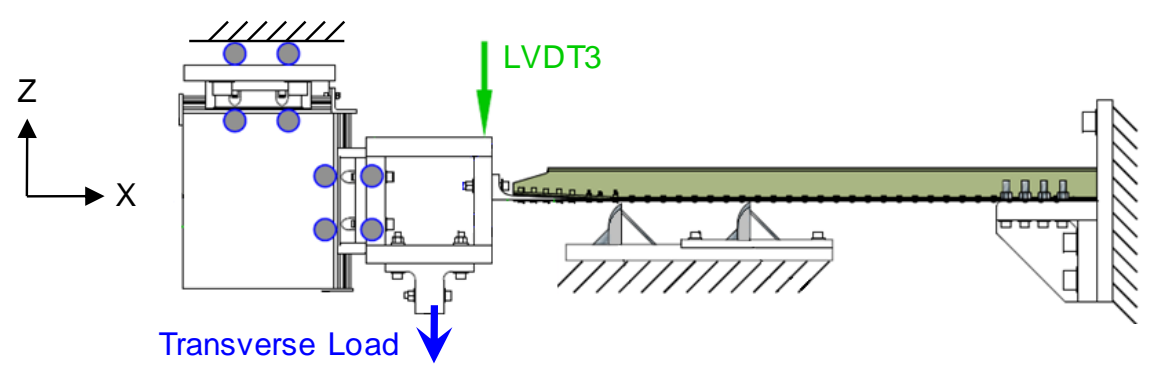

Load Vs. Displacement

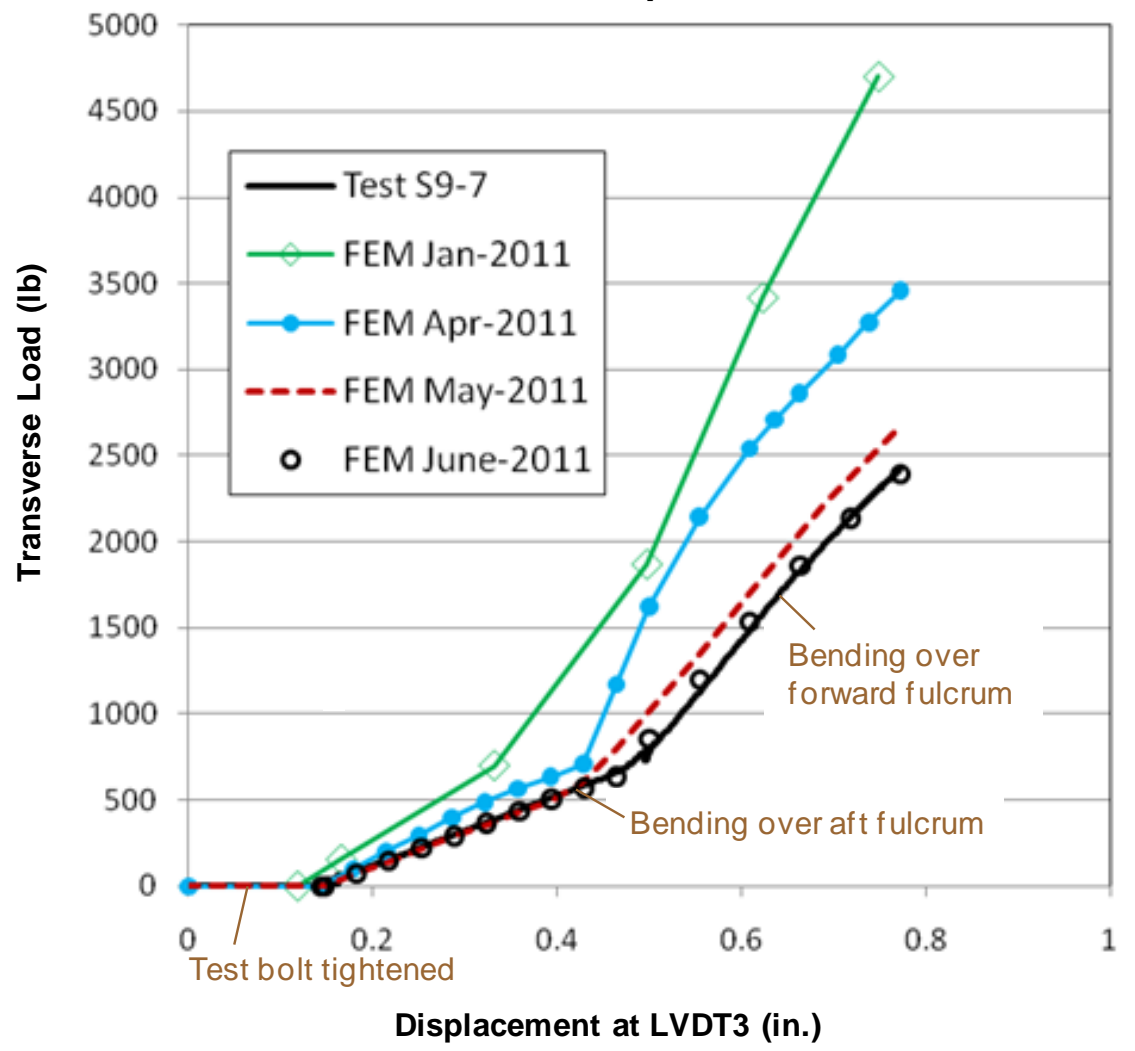

Figure 7. Global load-displacement response for S9-7.

The figure shows how correlation was improved as modeling assumptions were changed. The green curve labeled Jan-2011 shows results from an earlier model without fully developed fastener representations. The blue curve labeled Apr-2011 shows the results for the modeling details described in the previous section with the assumed fixed BCs for the fulcra. As shown by this line, the FE model was overly stiff in the $\mathrm{Z}$ direction. The source of the additional Z-direction stiffness was determined to be due to the rigid fulcra assumption. This conclusion was supported by limited test data obtained late in the test program. To account for compliance in the test fixture in the region where the fulcra were mounted, the boundary conditions for the fulcra in the FE model were modified. First, both fulcra were connected to a single spring with an assumed stiffness, $k$, as shown in Figure 8(a). Additionally, the elastic modulus of the stringer-skin aluminum was tweaked to match that from data from a parallel materials testing effort [4]. The value for $k$ was tuned until the best possible correlation to the test data was achieved. The global load-displacement response for this configuration is shown by the red dashed line labeled May-2011 in Figure 7. The results for bending over the aft fulcrum were very closely captured; however, the model was still overly stiff for bending over the forward fulcrum. Therefore, the model was modified again: a second spring in series was used for the forward fulcrum, as shown in Figure 8(b), with $k_{1}$ initially equal to $k$, and the assumed stiffness values for $k_{1}$ and $k_{2}$ were tuned until the best possible correlation to the test data was achieved. The global load-displacement response for this configuration is shown by the black open circles labeled June-2011

American Institute of Aeronautics and Astronautics 


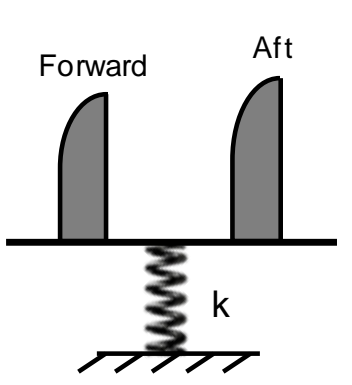

Ground: $\mathrm{uX}_{\mathrm{X}}=\mathrm{u}_{\mathrm{Y}}=\mathrm{u}_{\mathrm{Z}}=0$

(a) Fulcra mounted to single spring

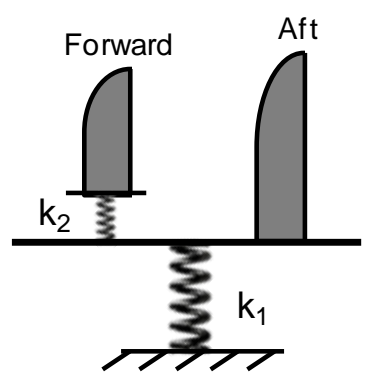

Ground: $\mathrm{uX}_{\mathrm{X}}=\mathrm{u}_{\mathrm{Y}}=\mathrm{u}_{\mathrm{Z}}=0$

(b) Forward fulcrum mounted to second spring in series

Figure 8. Modified fulcra BCs.

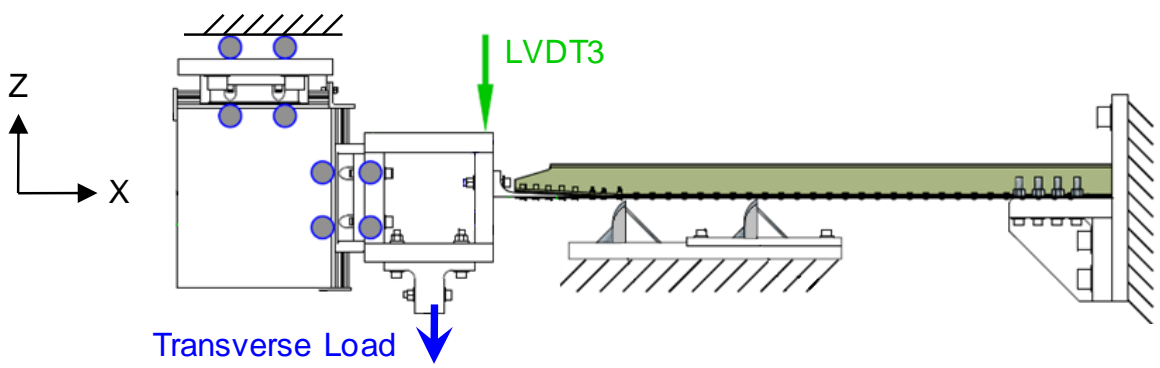

\section{Load Vs. Displacement}

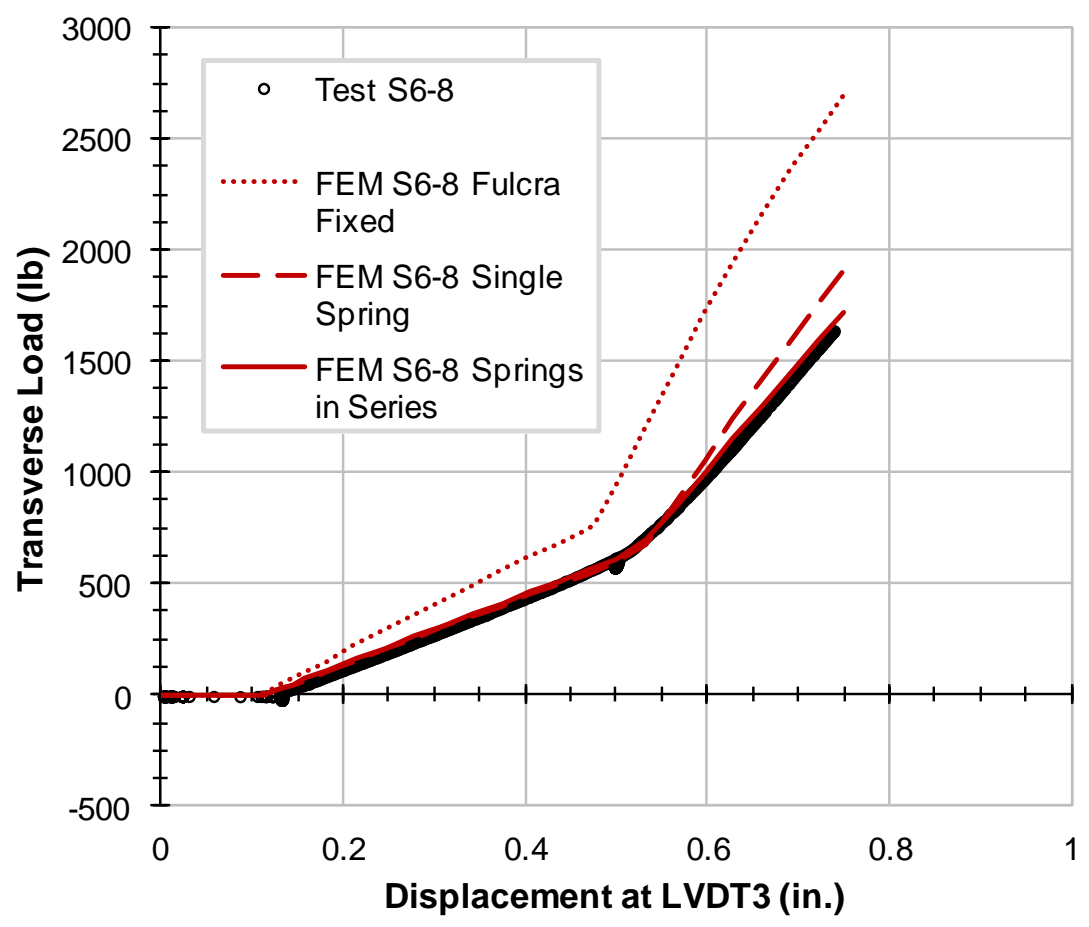

Figure 9. Global load-displacement response for S6-8.

American Institute of Aeronautics and Astronautics 
Figures 10 and 11 present strain gage comparisons from the correlated FE models (i.e., with the fulcra mounted on springs in series) for S9-7 and S6-8, respectively. The correlation with the test data is excellent.

Figure 12 presents photogrammetry comparisons from the correlated FE model for S6-8. The correlation with the test data is excellent.

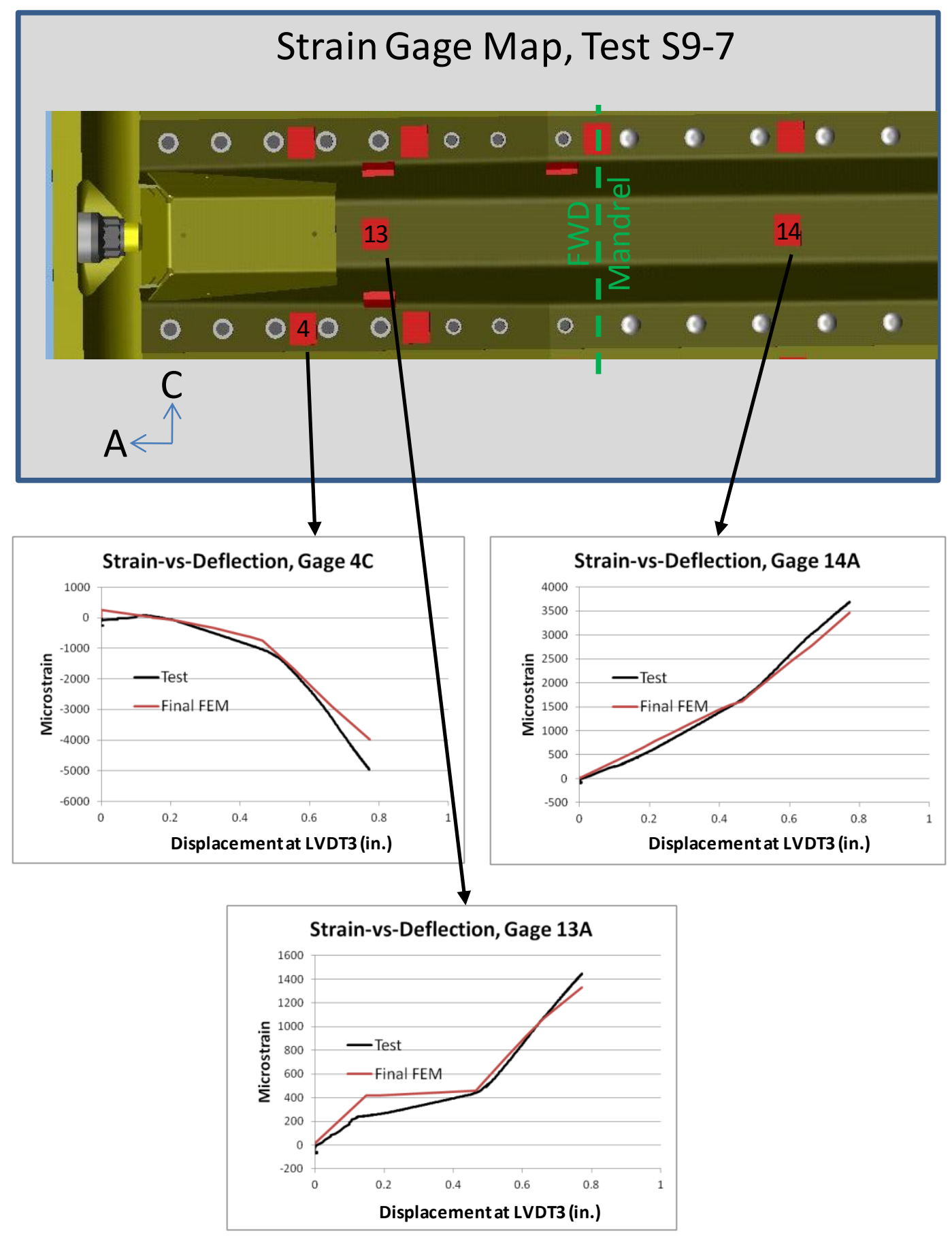

Figure 10. Strain gage comparisons for S9-7.

American Institute of Aeronautics and Astronautics 


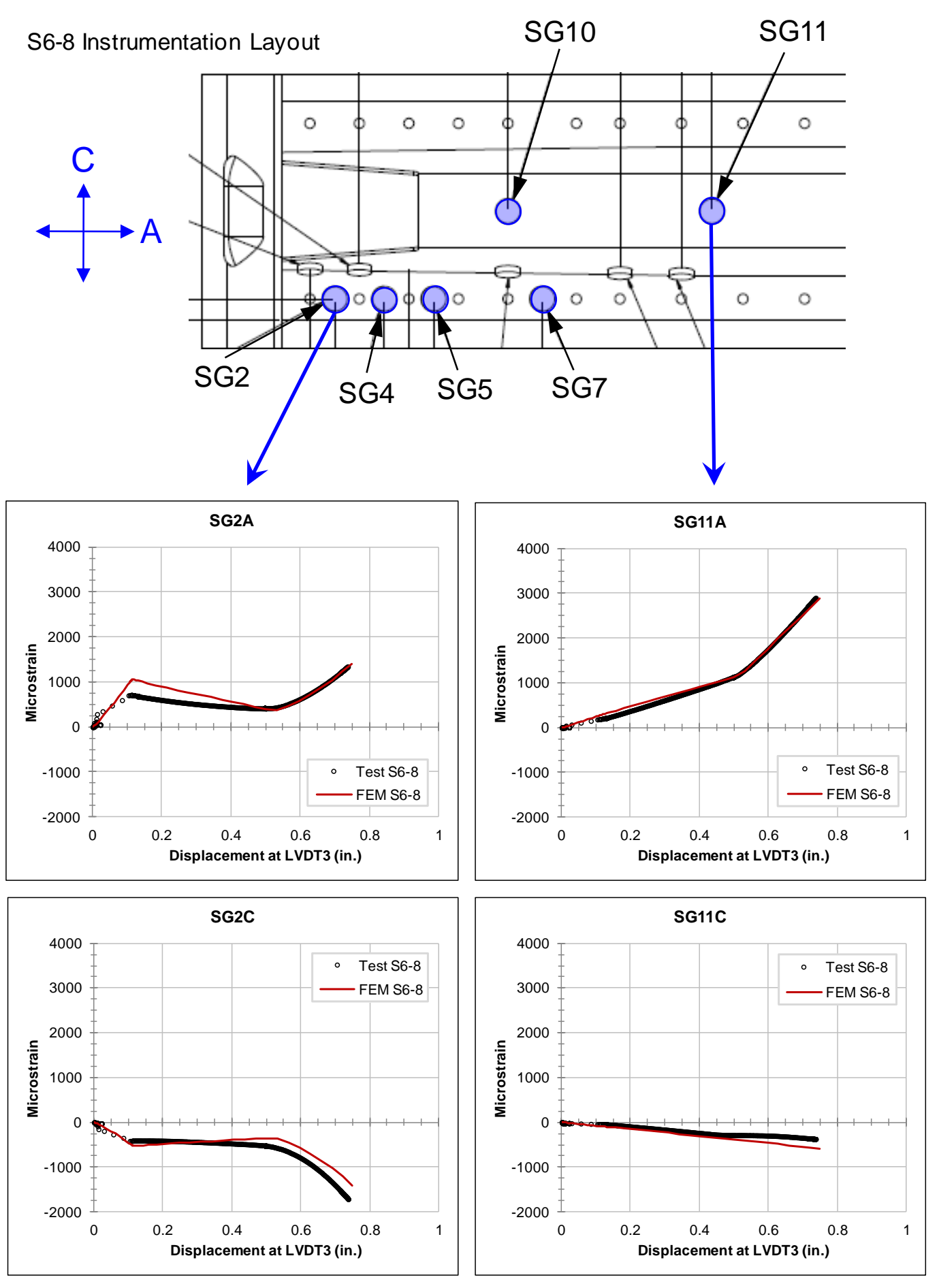

Figure 11. Strain gage comparisons for S6-8. 


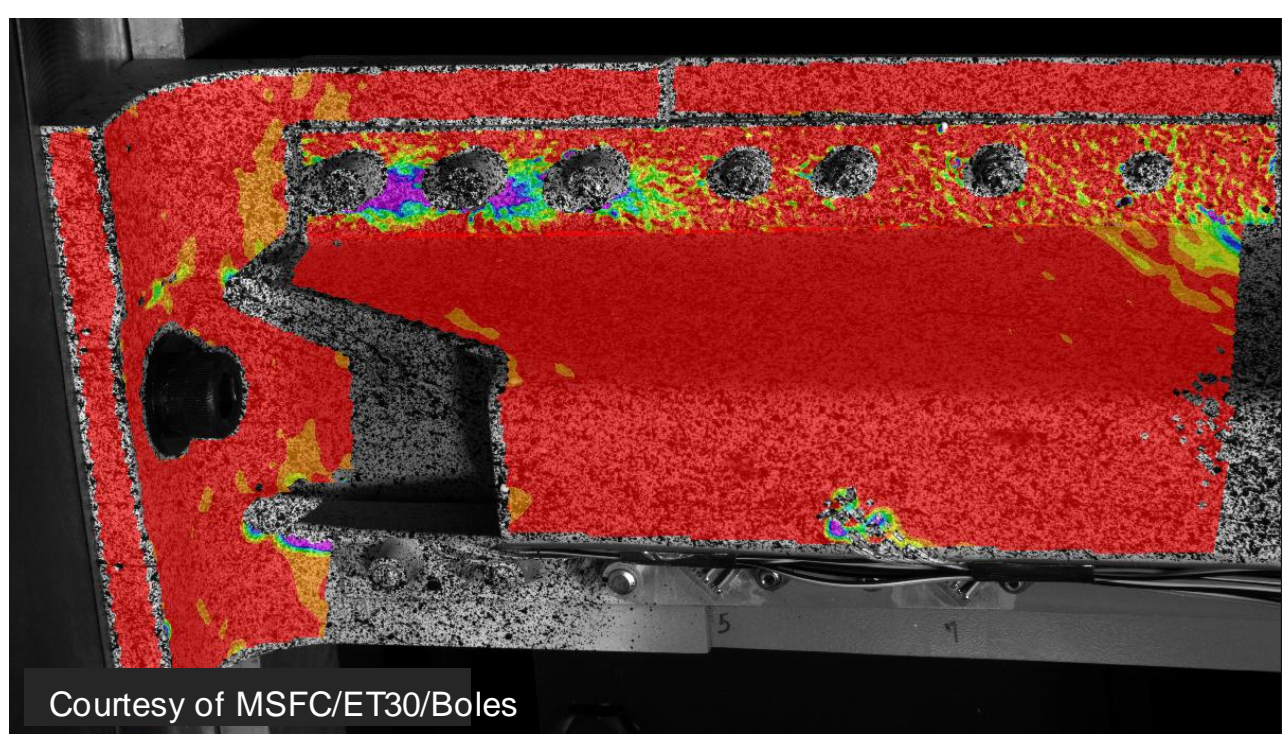

(a) Test

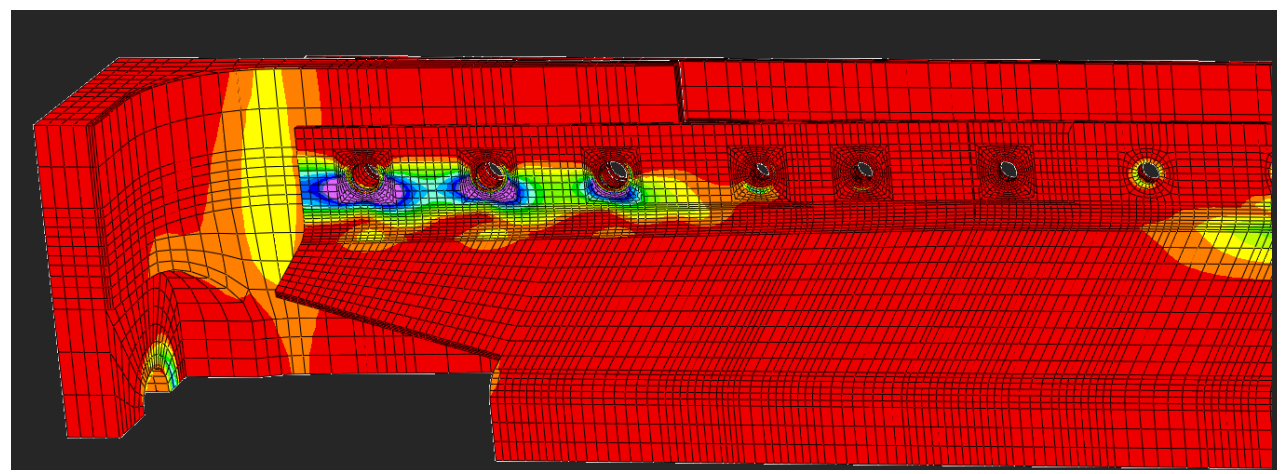

(b) FEM

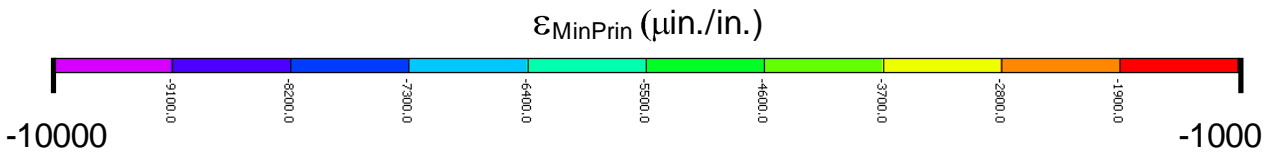

Figure 12. Photogrammetry comparison for S6-8: minimum principal strain at imminent failure.

\section{Further Correlation Efforts}

Achieving the excellent correlation between the finite element analyses and the test data discussed so far in this paper was not a trivial task. In fact, initial model correlation to the test data was much poorer than expected. As the analysis effort proceeded, systematic implementation of a series of modeling fidelity changes (not discussed in this paper) improved the correlation, but not to an acceptable level. These modeling changes ultimately culminated in an epiphany that the fulcra boundary condition may have been the issue. The boundary conditions at the fulcra for both the FE models of S9-7 and S6-8 were then modified and independently tuned to the stiffness values reported earlier in this paper. The tuned stiffness values for both models are very similar, indicating that the spring-supported boundary condition at the fulcra was not a problem-specific fix, but rather the key to achieving correlation with the test data. That the tuned stiffness values for both models are not exactly the same is likely due to differences in the models: different FE codes, slightly different modulus values, different meshes, and different element formulations. The boundary condition finding is explored further by examining the fundamental assumptions of the analysis and the analysis correlation to test data from a repaired stringer. 


\section{A. Fundamental Assumptions of the Analysis}

As mentioned previously, the key to analysis correlation to the single stringer bending test data turned out to be the correct application of boundary conditions at the two fulcra. After many iterations with the 3D solid model, it became increasingly evident, as originally thought, that the behavior of the stringer should approximate that of a simple beam with appropriate boundary conditions. For example, for bending over the aft fulcrum up until the point of contact with the forward fulcrum, the test resembled the simple beam depicted in Figure 13. The beam is simply supported at one end, has an applied rotation and load at the other end, and is propped by a spring in the middle.

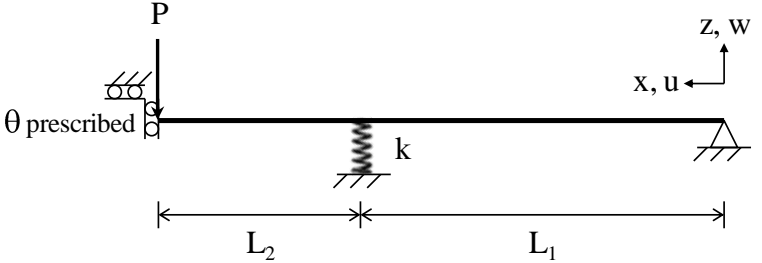

Figure 13. Simple beam resembling test configuration.

To confirm this idea for stringer S6-8, a simple finite element model, consisting of 1D beam elements, was constructed. The beam element cross-section was rectangular with a moment of inertia equivalent to that of the stringer-skin cross-section, as shown in Figure 14. The fulcra boundary condition definition included two springs in series, as discussed for the 3D solid model. The gap at the forward fulcrum was represented with a single gap element. Linear, elastic analysis with incremental load steps was performed.

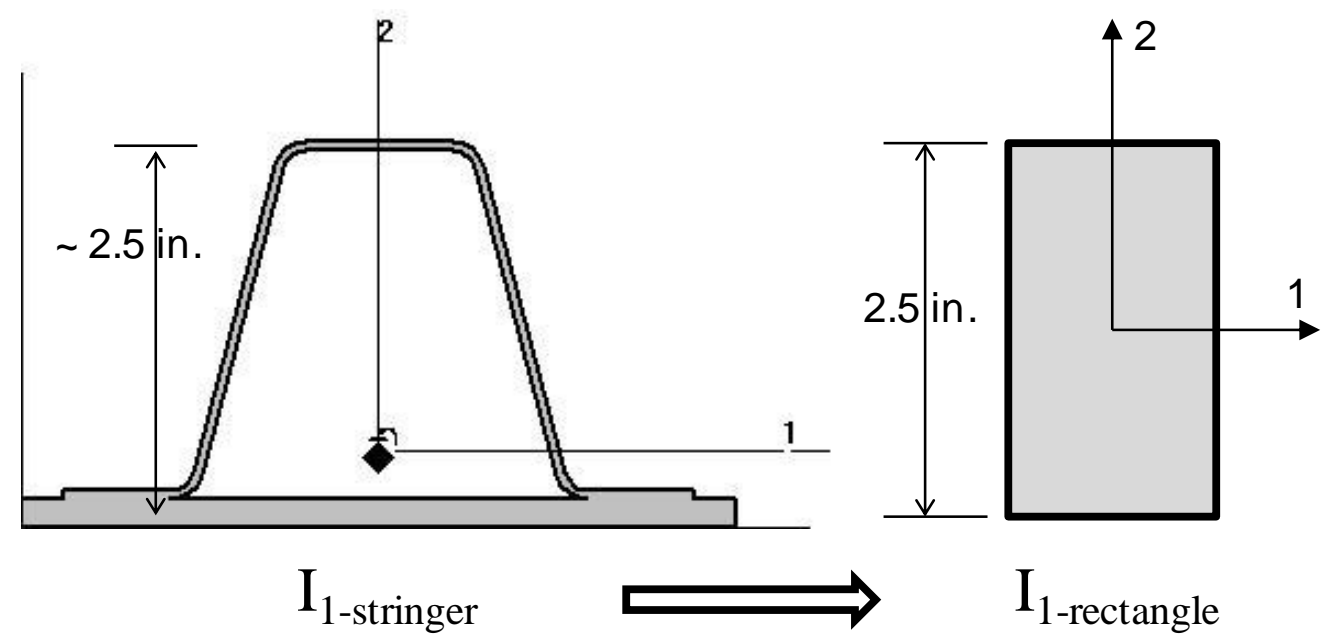

Figure 14. Cross-sections and moments of inertia for simple 1D finite element model of S6-8.

The FE results for load vs. displacement are compared to the test data for S6-8 in Figure 15. The results for the model with the single spring and rigid fulcra boundary conditions are also presented in the figure. While the simplified model does not correlate well with the test data, some important observations are made. First, the model captures the two kinks in the load-displacement curve where bending over the fulcra occurs. Second, the results are on the same order of magnitude as the test data and the various permutations of the 3D solid FE models. Third, the three boundary conditions show the same trend as observed from the 3D solid models; i.e., the correlation improves as the $\mathrm{BC}$ is modified from the rigid assumption to include the springs in series. Finally, note that the initial flat regions of the FE curves, which represent the tightening of the test bolt and rotation of the chord against the wedgeshaped shim of the load block, overshoot that of the test data. This result is easily explained. The simplified FE model assumes a constant cross-section, consistent with the stringer-skin cross-section, along the entire length of the test specimen, thus ignoring the contribution of the chord to the moment of inertia at the forward end of the test specimen.

To improve the correlation of the simple FE model to the test data, the model was modified to use three separate cross-sections. The beam elements representing a majority of the length of the skin-stringer used a box-shaped cross-section with a moment of inertia consistent with that of the actual cross-section. Similarly, the beam elements over the forward end of the chord and the transition region between the chord and stringer used rectangular crosssections with moments of inertia consistent with their respective 3D counterparts. The FE results for this model are compared to the test data in Figure 16. The correlation is very good, demonstrating that the simple model with appropriate boundary conditions captured the global behavior well. 
Load Vs. Displacement

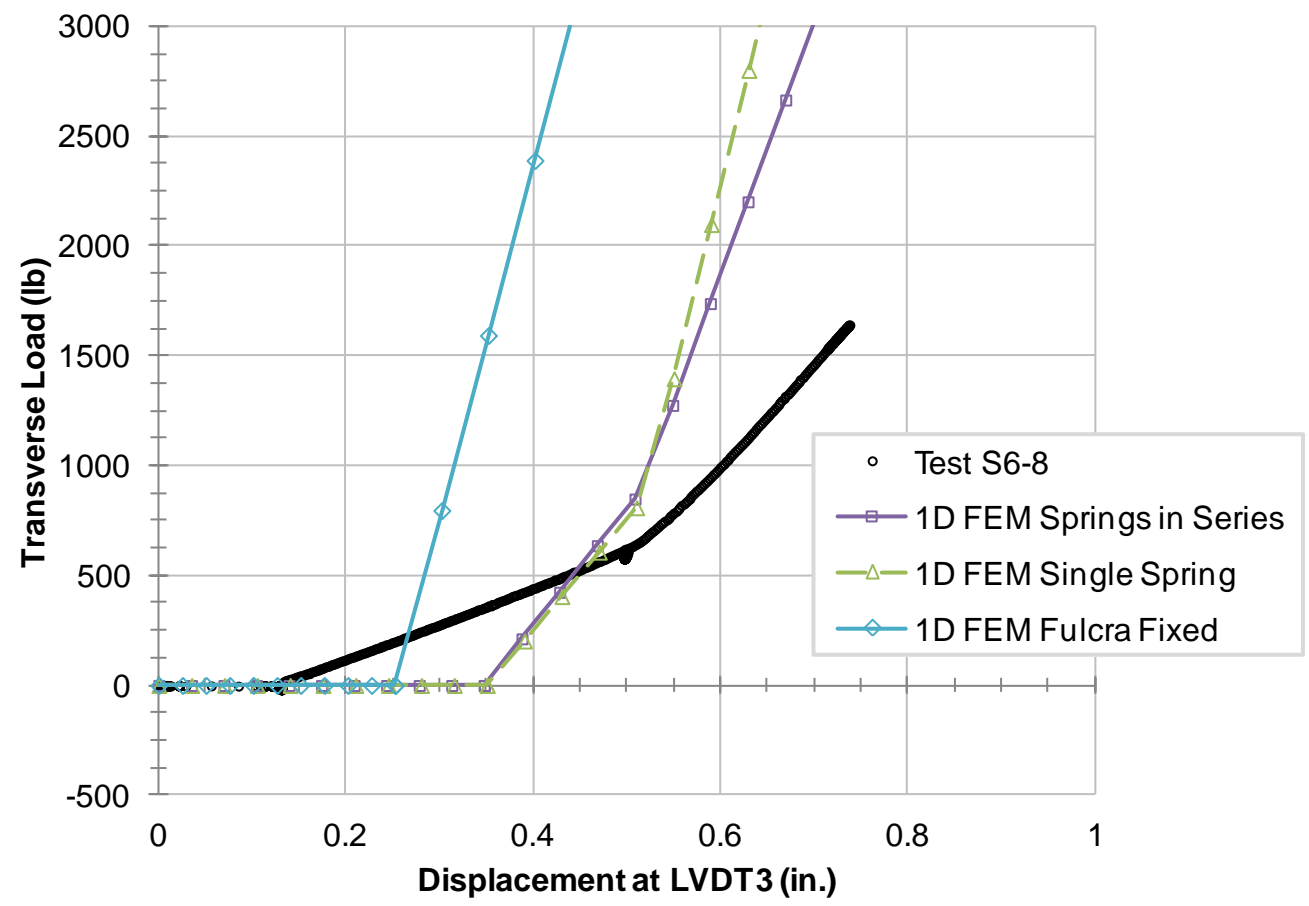

Figure 15. FE comparison of simple model of S6-8 to test data for load vs. displacement.

Load Vs. Displacement

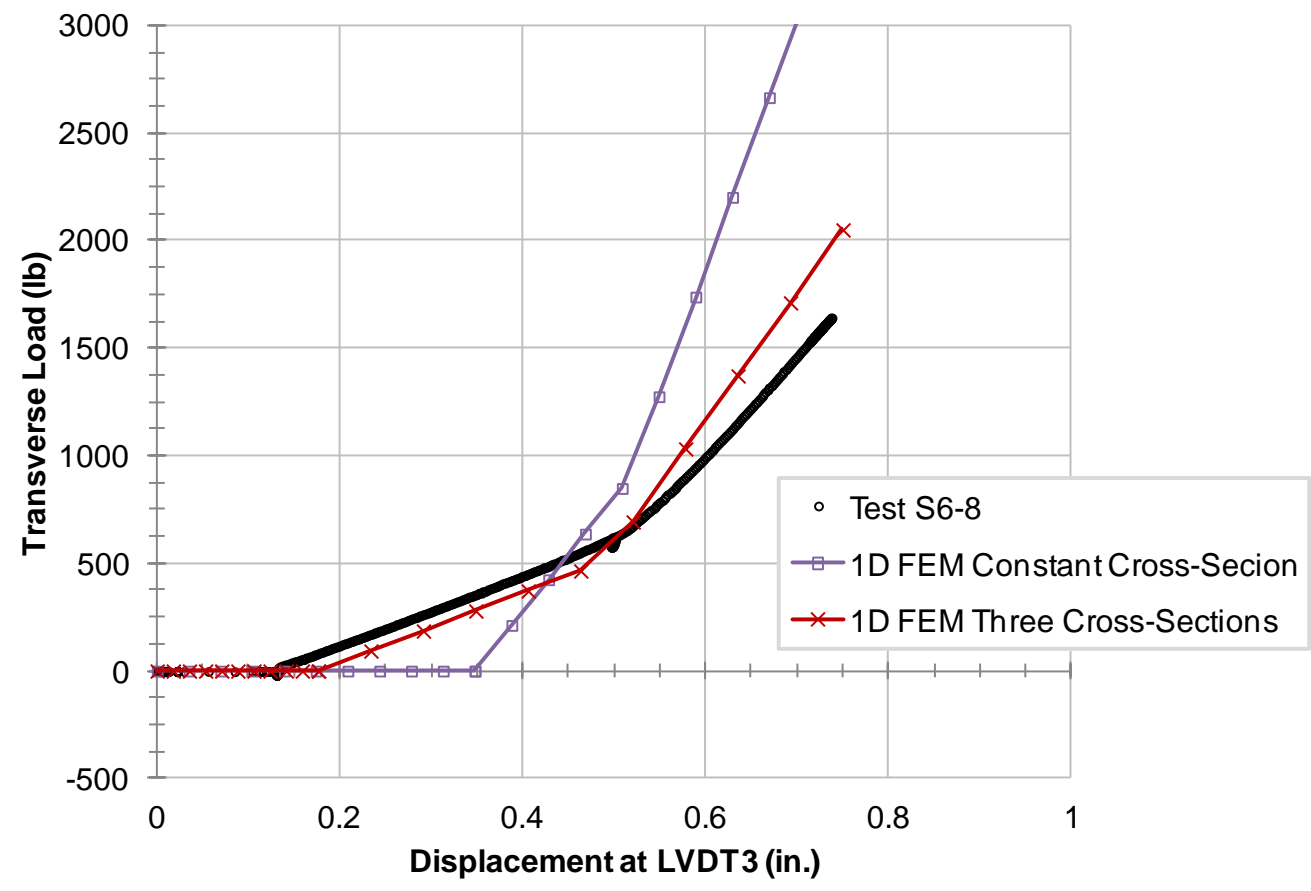

Figure 16. FE comparison of simple model with three cross-sections to test data for load vs. displacement. 


\section{B. Radius Block Repair and Analysis Correlation}

ET-137 was repaired by installing radius blocks on all of the stringers on the LOX end of the Intertank. The radius block repair is shown in Figure 17. Radius blocks are pieces of aluminum installed on top of the stringer feet and intended to increase the capability of the stringers to prevent cracking due to the cryogenicallyinduced displacements.

As part of the single stringer bending tests, stringers with radius blocks installed, including the short-chord stringer S8-8, were also tested. To create an FE model for the S8-8 bending test, the correlated FE model for S68 was modified to include radius blocks, and the analysis was repeated. The global load-displacement response, strain gage comparisons, and photogrammetry comparisons are presented in Figures 18, 19, and 20, respectively. The correlation with the test data is excellent. These results further confirm that the compliant fulcra $\mathrm{BC}$ is not a problem-specific fix, but rather the key to achieving correlation with the test data.

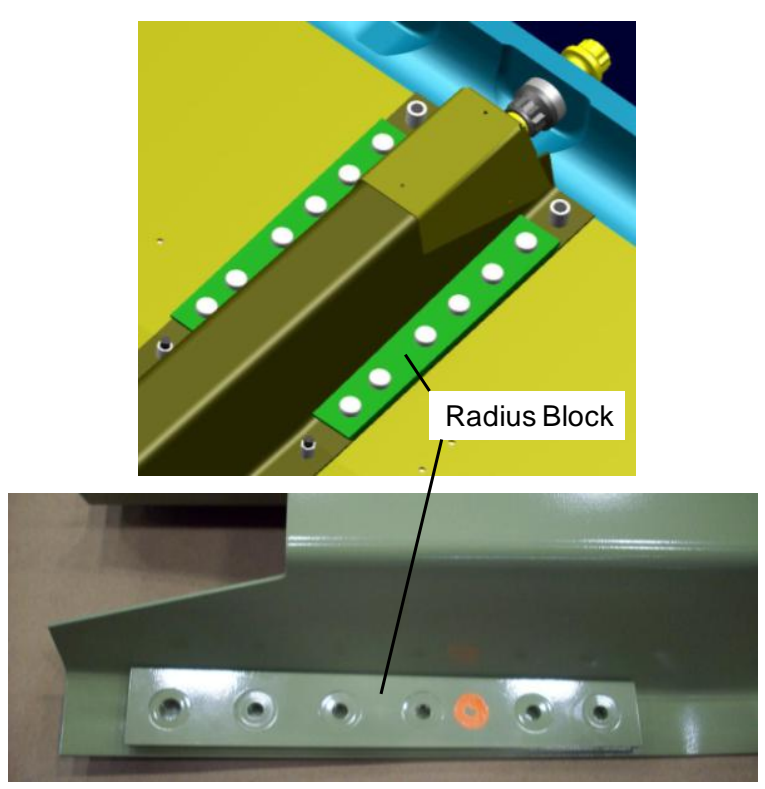

Figure 17. Radius block repair.
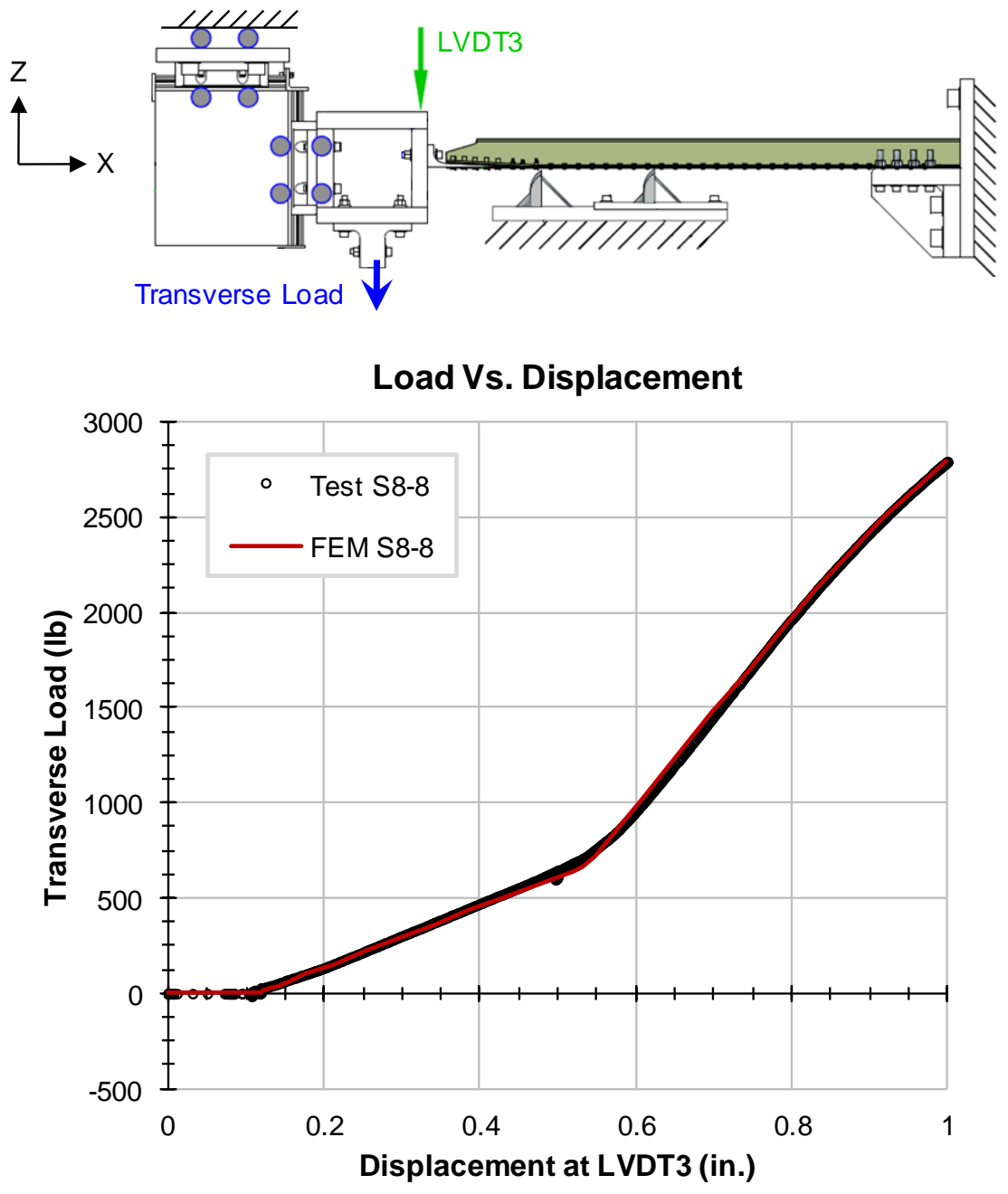

Figure 18. Global load-displacement response for S8-8.

American Institute of Aeronautics and Astronautics 


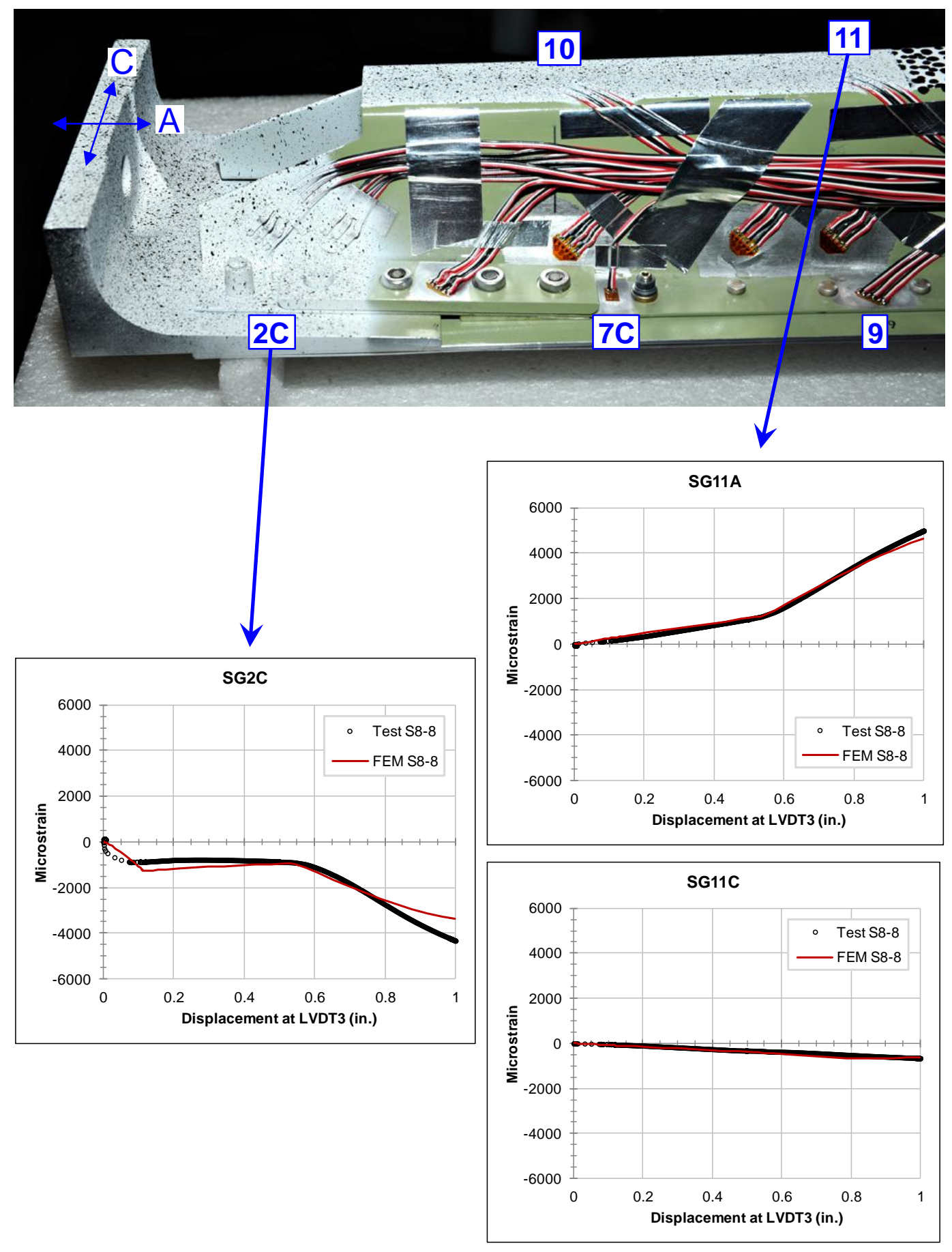

Figure 19. Strain gage comparisons for $\mathbf{S 8 - 8}$.

American Institute of Aeronautics and Astronautics 


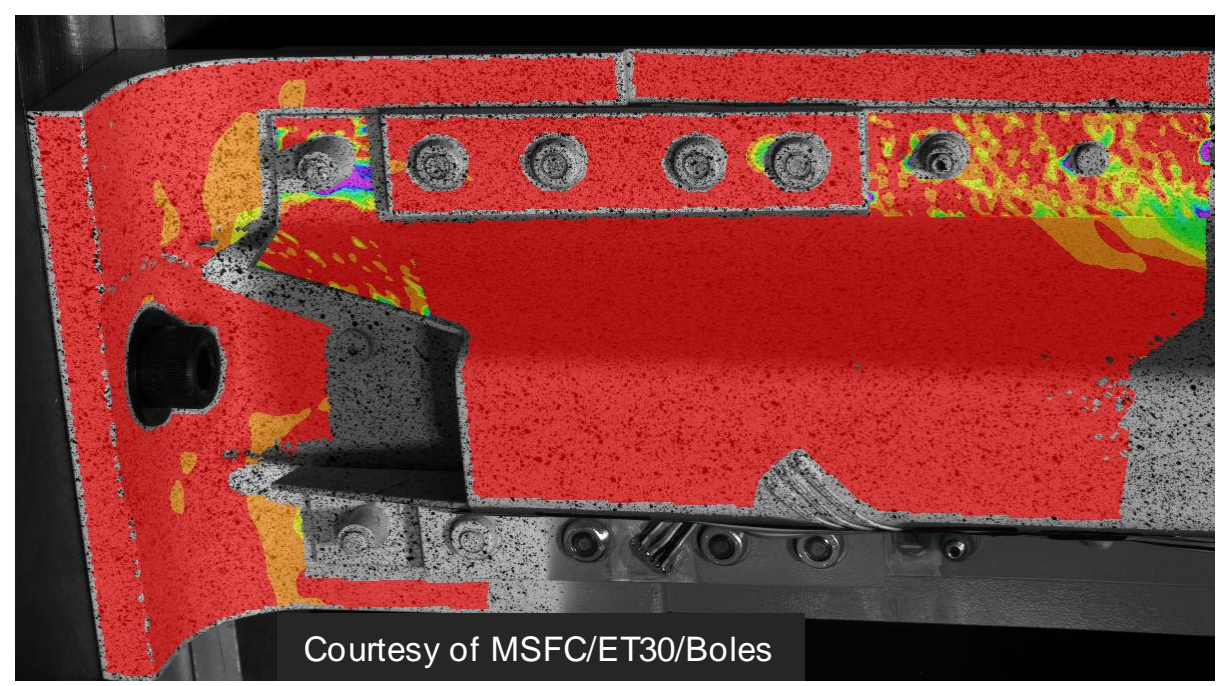

(a) Test

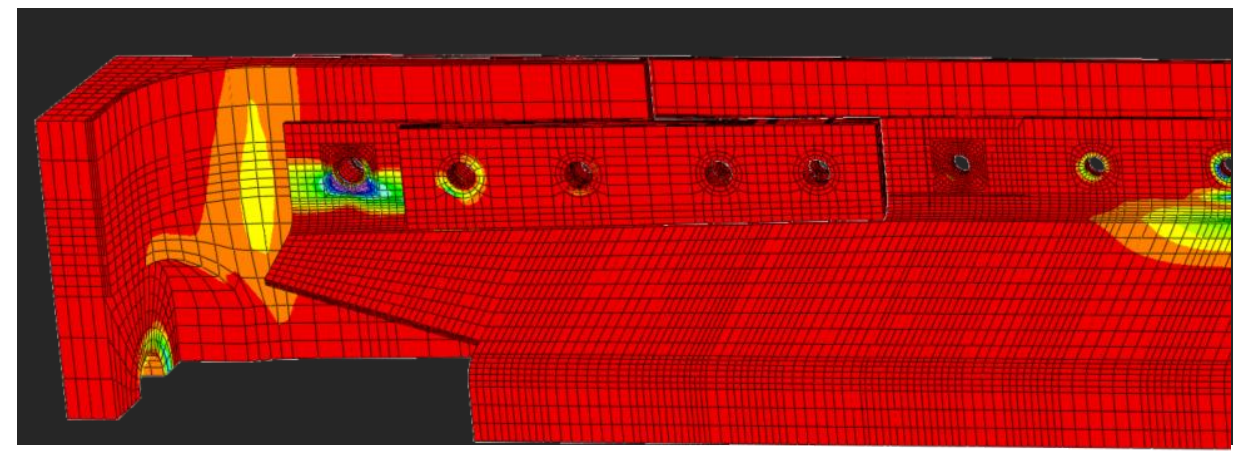

(b) FEM

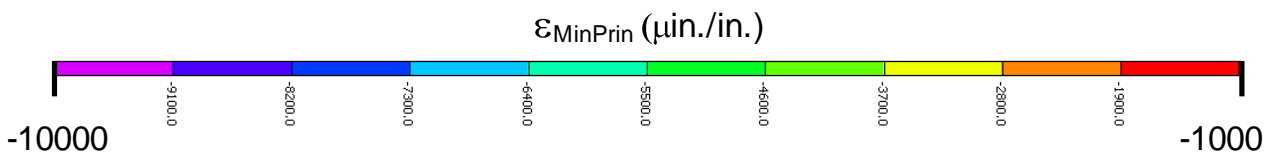

Figure 20. Photogrammetry comparison for S8-8: minimum principal strain at 0.75 -in. LVDT3 displacement (imminent failure of S6-8).

\section{Discussion}

The ET-137 stringer crack investigation was a fast-paced effort that involved multiple organizations within NASA and the Shuttle Program prime contractors, with many studies invoking both test and analysis. The change in focus of both the test program and the correlation effort as they related to the overall stringer crack investigation is discussed next.

\section{A. Test Program Focus Change}

The original purpose of the single stringer bending tests was to provide data to validate finite element models of single stringers subjected to various prelaunch and flight loading conditions. However as previously discussed, the test-analysis correlation effort proved to be more difficult than anticipated. Concurrently, the objectives of the test program began to evolve.

During early tests, it was observed that when stringers fabricated from what was known as suspect material [9] were tested to failure, the failures experienced on ET-137 could be accurately reproduced. Thus, the primary test focus changed to become a study of the relative performance of stringers subjected to repeatable load conditions.

American Institute of Aeronautics and Astronautics 
The single stringer bending test results were used to create a test bed to comparatively demonstrate the capability of stringers fabricated from suspect and nominal materials, each with and without radius blocks [9]. The findings and conclusions of the test program were able to stand alone in the flight readiness assessment for STS-133 [10].

\section{B. Test-Analysis Correlation Timeline}

The correlation of the FE analyses to the single stringer bending test data was actually completed after ET-137 flew. As mentioned previously, the findings of the test program stood alone in the flight readiness assessment for STS-133. However, because there were still two tanks to fly, ET-122 and ET-138, both of which were also modified to include radius blocks, the test-analysis correlation effort was continued in order to improve understanding of the tank behavior and the effects of the radius block repair.

The effect of the radius blocks is demonstrated in Figure 21. The strain at imminent failure of S6-8 (see Figure 12) is compared to the strain of S8-8 for the same applied transverse displacement (see Figure 20). Note the decrease in strain around the forward-most fastener. The extent of the area of high microstrain is much smaller for the stringer with the radius block, and the strain level over part of that area decreases from approximately -10000 microstrain to as low as -5000 microstrain. Also note the additional capability demonstrated by comparing the loaddisplacement results; the stringer with the radius block carried more load before rupture.
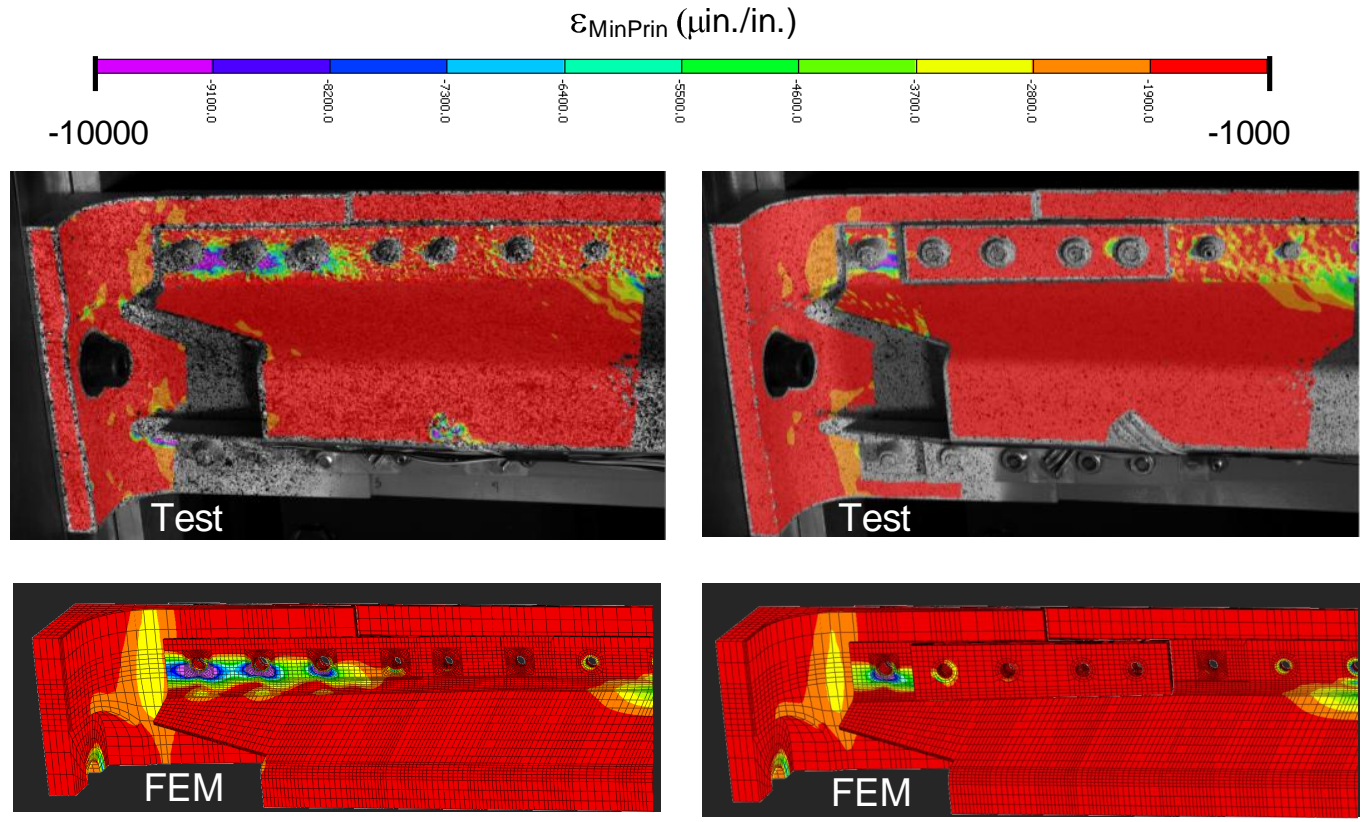

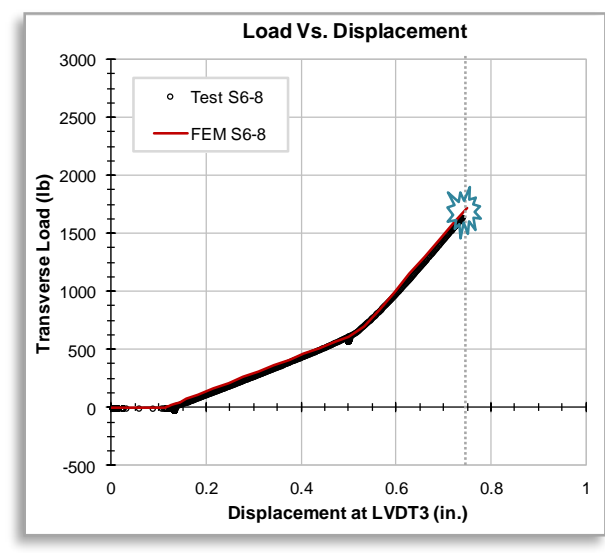

(a) S6-8 (No Radius Blocks)

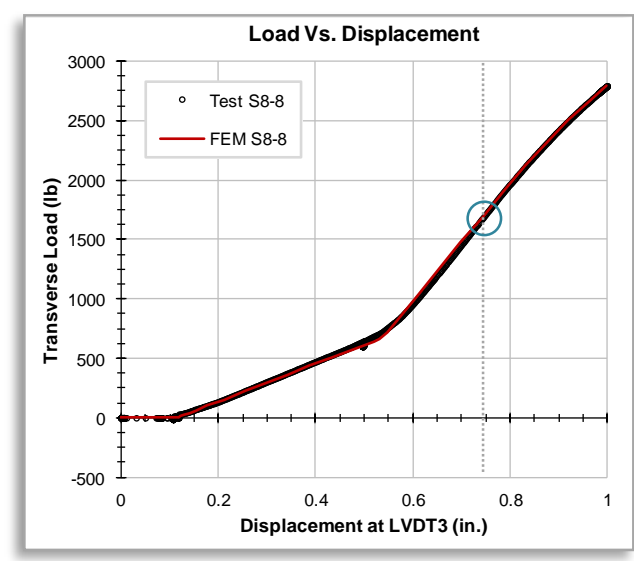

(b) S8-8 (With Radius Blocks)

Figure 21. Effect of radius blocks: minimum principal strain at 0.75 -in. LVDT3 displacement (imminent failure of S6-8). 
Through diligently pursuing the sources of the initial poor correlation, excellent correlation to the test data was eventually obtained. These results were available to further bolster the structural verification of the ETs for the remaining two flights of the Shuttle Program, STS-134 and STS- 135.

\section{Challenges and Lessons Learned}

When the ET-137 stringer crack investigation began, the many NASA and contractor participants ramped up very quickly to work toward solving the problem. The single stringer bending test was proposed early on, while concurrently, 3D solid finite element models for flight loading conditions were built and analyses began, with particular interest in studying the through-thickness strains. These flight models were for the long-chord stringer configuration and were to be validated by the testing effort; therefore, the corresponding model was used for the test analysis of S9-7. The instrumentation of the tests included several strain gages in areas of interest related to the observed failure on ET-137. The goal was to correlate measured strains with analytical test predictions.

The correlation of the finite element models to the test data was not trivial. Comparisons to the strain gage data could not be made because the global load-displacement response could not be reproduced. Boundary conditions were challenged. Both the analytical BCs at the forward and aft ends of the stringer were systematically modified, with marginal success in improving the correlation. The fulcra BCs were also peripherally challenged; both the shape of the fulcra contour that contacted the skin and the corresponding contact definitions were studied. However, the assumption that the fulcra were rigid within the test fixture seemed appropriate following a visual inspection of the fixture, and the assumption was not challenged until a subsequent test for a different loading condition returned LVDT displacements that suggested the fulcra had some compliance.

Many experienced test engineers and analysts worked the test-analysis correlation, and still, one of the fundamental assumptions of the test set-up turned out to be wrong. The lesson learned, as in many analysis efforts, is to not take boundary conditions for granted. Challenge everything - systematically verify key inputs and assumptions. In addition, concerning the test set-up, it would have been prudent to verify the boundary conditions with actual test measurements; i.e., an LVDT could have been placed over the fulcra. Also, even in the midst of the fast pace of the investigation, it may have been prudent to take a step back and exercise simpler finite element models (such as 1D beam models) to gain understanding of the fundamental behavior of the test set-up; when using detailed FE models with many features such as contact physics, plasticity, fastener modeling, etc., the tendency is to focus on those features as the source of error accumulation and poor correlation rather than focusing on basic features such as boundary conditions.

Finally, the photogrammetry data turned out to be incredibly useful test data. The strain and displacement distributions could be directly compared to those from FE analyses for an overall picture of the level of correlation. The photogrammetry strain distributions were helpful in assessing whether the strain gages were in high-gradient areas, which is helpful when attempting to correlate predicted strains to gage data - in high strain gradient areas, slight differences in where analytical results are extracted versus where the gage is actually mounted can greatly affect correlation.

\section{Concluding Remarks}

Following the scrub of the initial launch attempt of STS-133, cracks were found in the stringers on the Intertank of the External Tank, ET-137. A large investigation was conducted to determine the root cause of the cracks, establish a remedy/repair for the stringers, and provide data for the flight readiness assessment of the repaired tank. As part of the investigation, static load tests of individual stringers were performed. In addition to these single stringer bending tests, finite element analyses of the test configuration were also performed.

This paper presents the details of the finite element analyses and test-analysis correlation for the single stringer bending tests. Three-dimensional, solid finite element models were used for two different stringer configurations in parallel analysis efforts. Correlation of the finite element models to the test data was not trivial. Initially, the global load-displacement response could not be reproduced. Systematic implementation of a series of modeling fidelity changes ultimately culminated in an epiphany that one of the assumed rigid boundary conditions was the issue. This boundary condition was modified to include springs and then individually tuned within each of the parallel analysis efforts to reproduce the global load-displacement response. The final tuned spring stiffness used for both models was similar, indicating that the spring-supported boundary condition was not a problem-specific fix, but rather the key to achieving correlation with the test data. Additional analyses of the test configuration using one-dimensional beam elements also confirmed this finding. 
The test-analysis correlation of the single stringer bending tests was actually completed after ET-137 flew. ET137 was repaired by installing radius blocks on all of the stringers on the LOX end of the Intertank. The flight rational for the tank with the radius block repair was developed from the single stringer bending test results, results from separate flight analyses, and results from other test and analysis efforts. Because there were still two tanks to fly, ET-122 and ET-138, both of which were also modified to include radius blocks, the test-analysis correlation effort was continued in order to improve understanding of the structural behavior, the fundamental assumptions of the analyses, and the effects of the radius block repair. The eventual results from the correlation effort presented in this paper were available to further bolster the structural verification of the ETs for the remaining two flights of the Shuttle Program, STS-134 and STS-135.

\section{Epilogue}

On February 18, 2011, at Kennedy Space Center, results from the stringer bending tests and the related studies were presented to NASA's top management at the STS-133 Flight Readiness Review. At day's end, the Review Board unanimously declared STS-133 was "Go for Flight." This was not a declaration that all questions were completely resolved. Rather, it was a judgment that related risks were reduced to an acceptable level. It serves as a reminder that space flight remains a risky business. Less than a week later, on February 24, 2011, STS-133 launched the Space Shuttle Discovery on her final mission. Within six months, Shuttles Endeavour and Atlantis also flew their final missions, both with the radius block repair on their ETs, bringing the Space Shuttle Program to a close.

\section{Acknowledgements}

The authors would like to gratefully acknowledge the engineers and technicians at the MSFC Materials and Environmental Test Complex (METCO) Hot Gas Facility for their contribution to constructing the test apparatus

and performing the stringer tests and Mr. Todd Boles and Dr. Stanley Oliver for their work post-processing the photogrammetry data.

\section{References}

1. Anon. (1997): Space Shuttle External Tank System Definition Handbook, SLWT, Lockheed Martin - Michoud Space Systems Document No. LMC-ET-SE61-1, Volume I, Section 7, December 1997.

2. S. T. Oliver (2012); "STS-133/ET-137 Tanking Test Photogrammetry Assessment," paper accepted for presentation at the $53^{\text {rd }}$ AIAA SDM Conference, Honolulu, HI, 23-26 April 2012, Paper No. TBD.

3. J. Pilet and W. Geiman (1997): Space Shuttle External Tank Stress Analysis, Lockheed Martin Report MMC-ET-SE05-439, December 1997.

4. P. Allen (NASA/MSFC/EM20), Preliminary test data emailed to the author, 16 December 2010 and 23 March 2011.

5. J. T. McAllister (1997): Lockheed Martin Memorandum of Record (Memo no. SLWT-3070-97-002) with Report on SLWT Intertank Al 2090 Stringer Cracking During Assembly, Special Investigation SI-96-S007, January 1997.

6. Anon. (2005): Lockheed Martin-Michoud Space Systems Standard Part Specification 25L9, Issue March 1975, Revision 8, July 2005.

7. ANSYS Users' Manual, ANSYS, Inc., available online at http://www.ansys.com.

8. Anon. (2009): ABAQUS Analysis User's Manual: Volumes I - VI, Version 6.9, Dassault Systèmes Simulia Corp., Providence, RI.

9. J. B. Saxon, G. R. Swanson, W. P. Ondocsin, T. F. Boles, and R. J. Wingate (2012): "Stringer Bending Test Helps Diagnose and Prevent Cracks in the Space Shuttle's External Tank," paper accepted for presentation at the 53 ${ }^{\text {rd }}$ AIAA SDM Conference, Honolulu, HI, 23-26 April 2012, Paper No. TBD.

10. R. J. Wingate (2012): "Stress Analysis and Testing at the Marshall Space Flight Center to Study Cause and Corrective Action of Space Shuttle External Tank Stringer Failures," paper accepted for presentation at the $53^{\text {rd }}$ AIAA SDM Conference, Honolulu, HI, 23-26 April 2012, Paper No. TBD. 


\title{
Test-Analysis Correlation of the Single Stringer Bending Tests for the Space Shuttle ET-137 Intertank Stringer Crack Investigation
}

\author{
Dawn R. Phillips, \\ Joseph B. Saxon, and Robert J. Wingate \\ NASA Marshall Space Flight Center
}




\section{Outline}

- Single stringer bending test description, tests chosen for correlation

- Finite element analysis description

- Test-analysis correlation results

- Further correlation efforts

- Timeline, lessons learned

- Summary 


\section{External Tank Intertank Stringers}
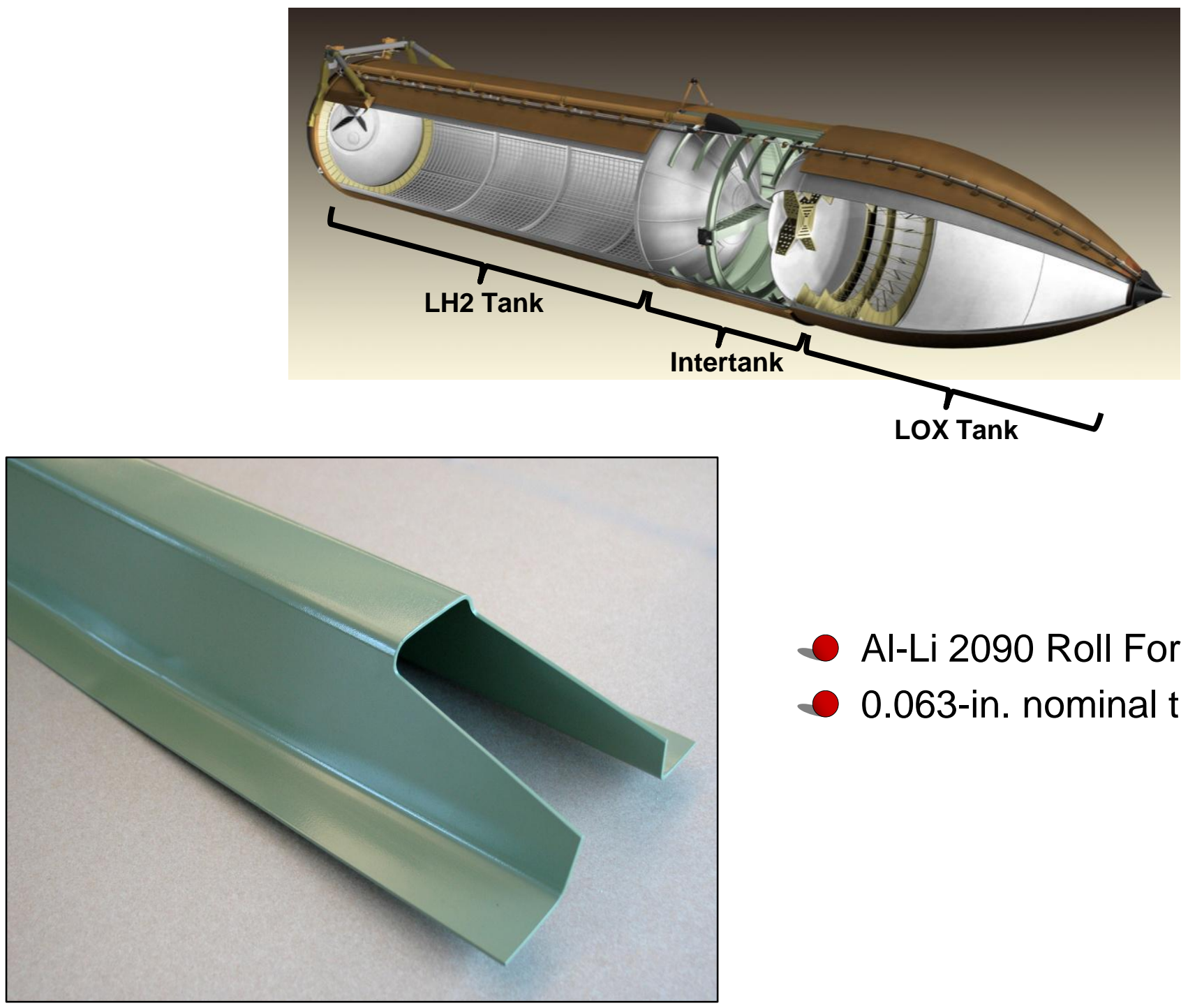

- Al-Li 2090 Roll Formed Hat Stringers

0.063-in. nominal thickness 


\section{Single Stringer Bending Tests}

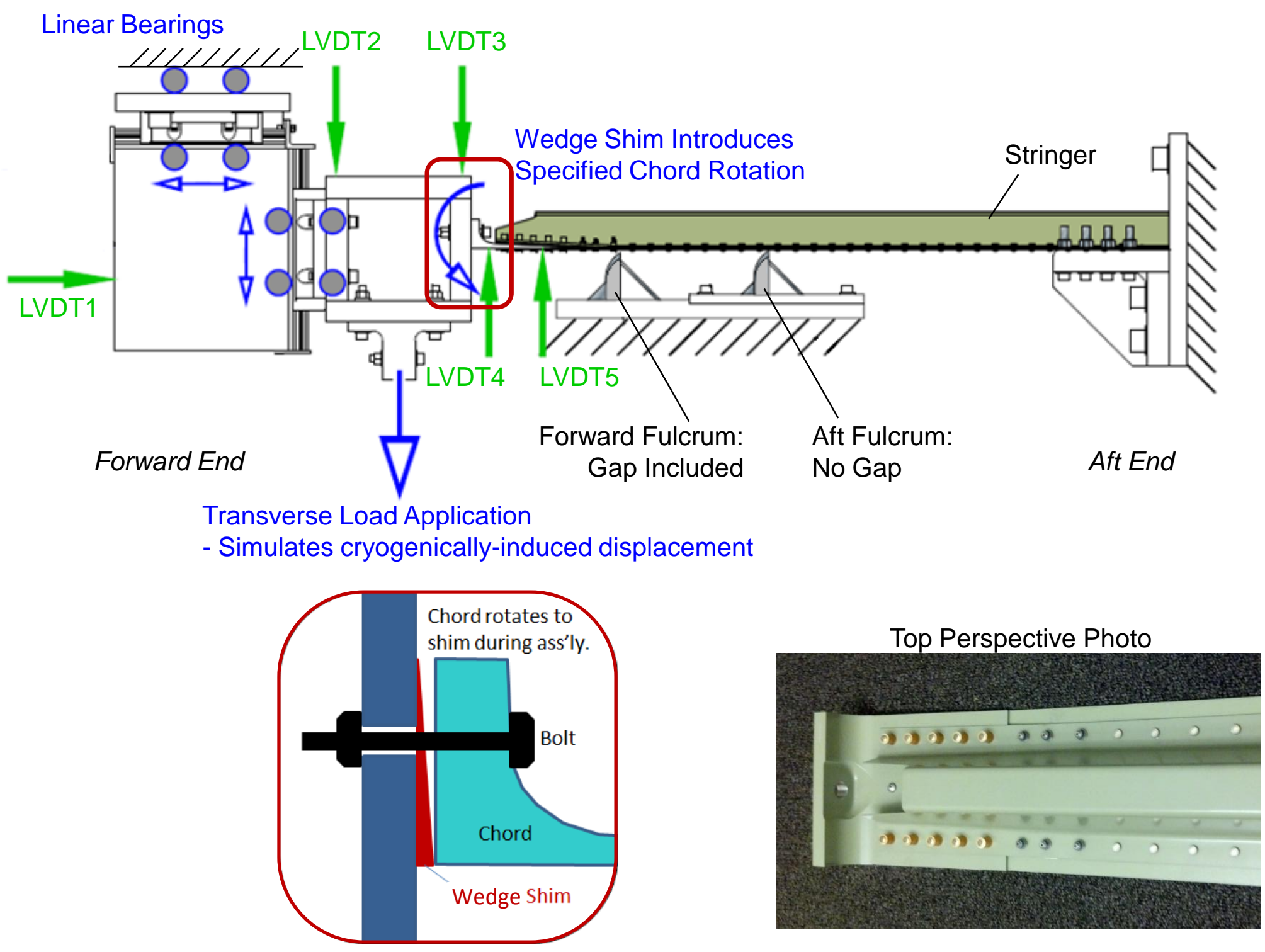




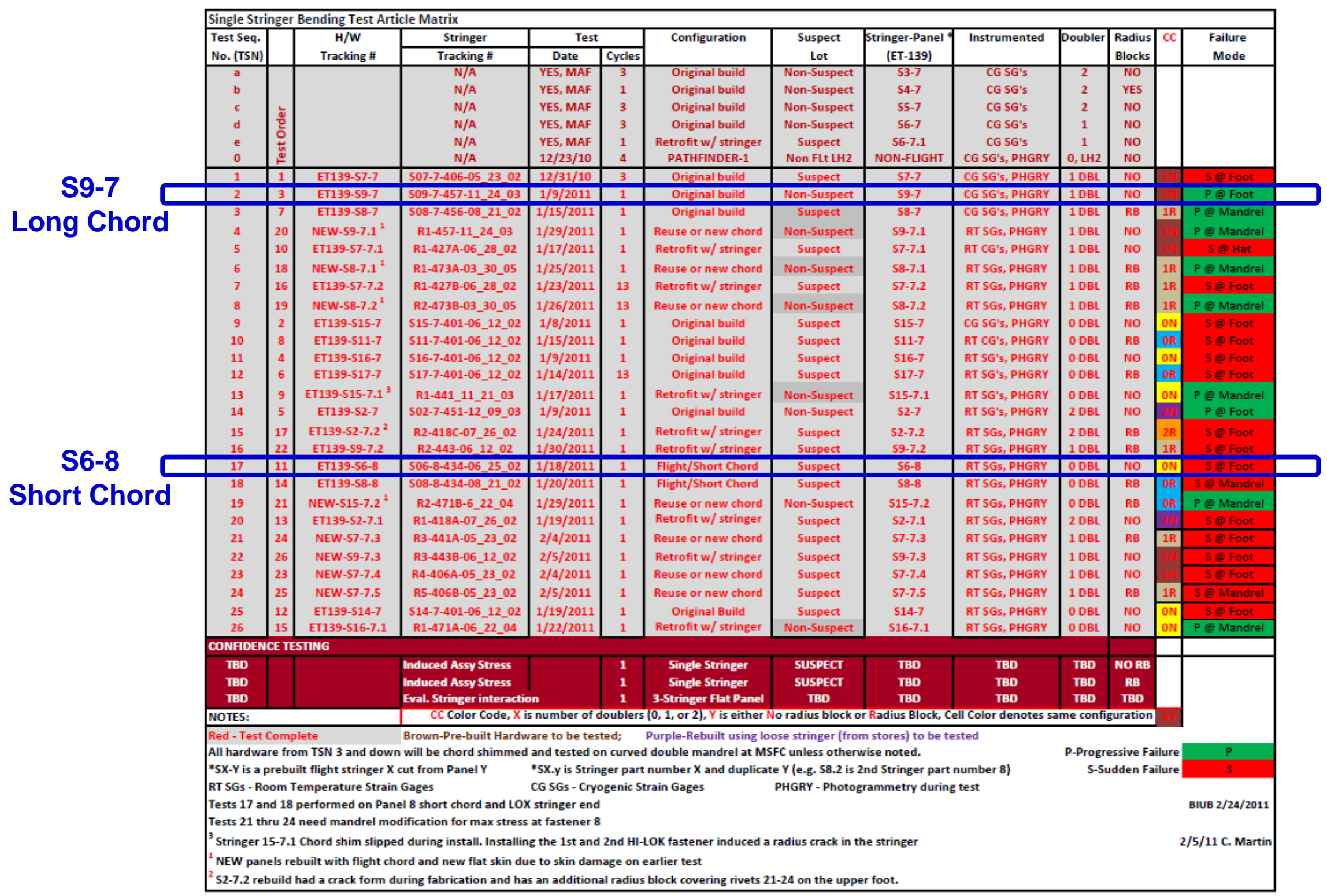




\section{Long Chord vs. Short Chord}

S9-7: Long Chord

- Most LOX-end

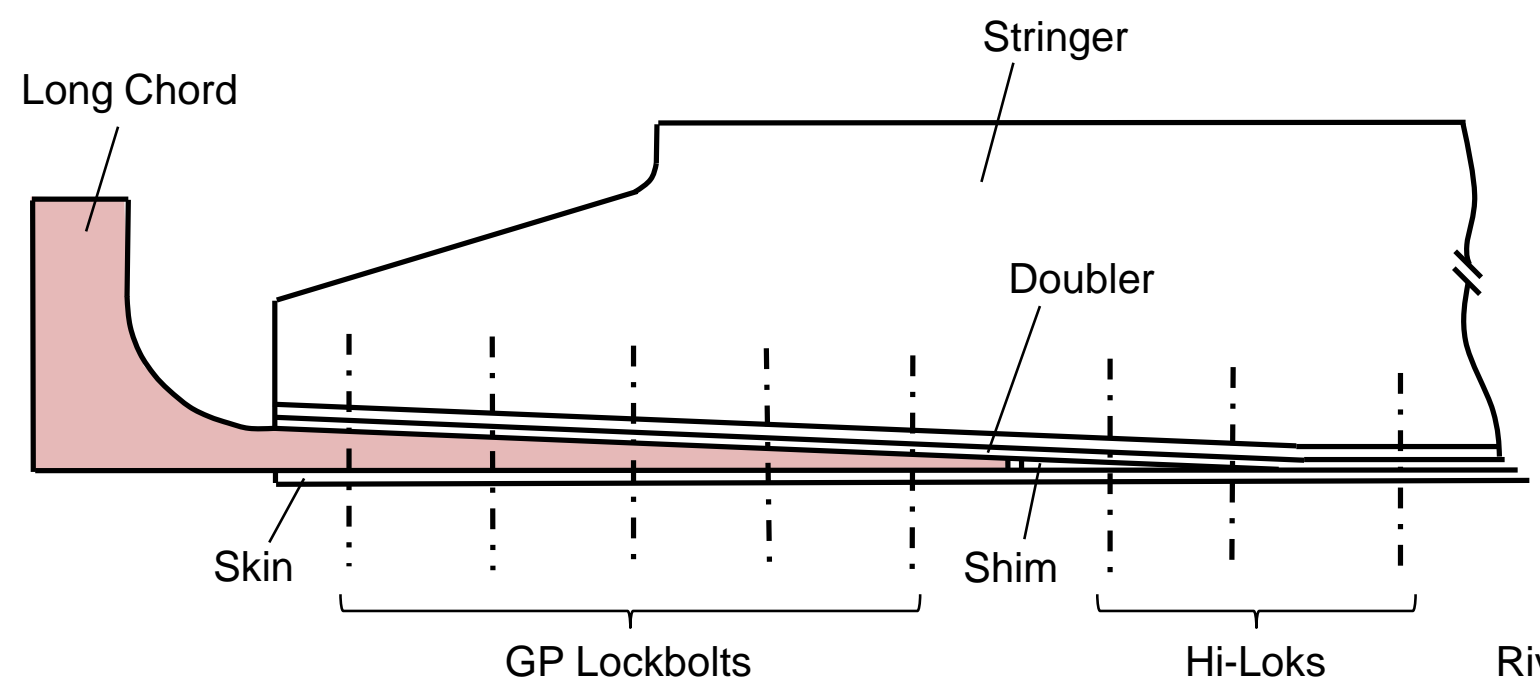

\section{S6-8: Short Chord}

- Some LOX-end

- All LH2-end

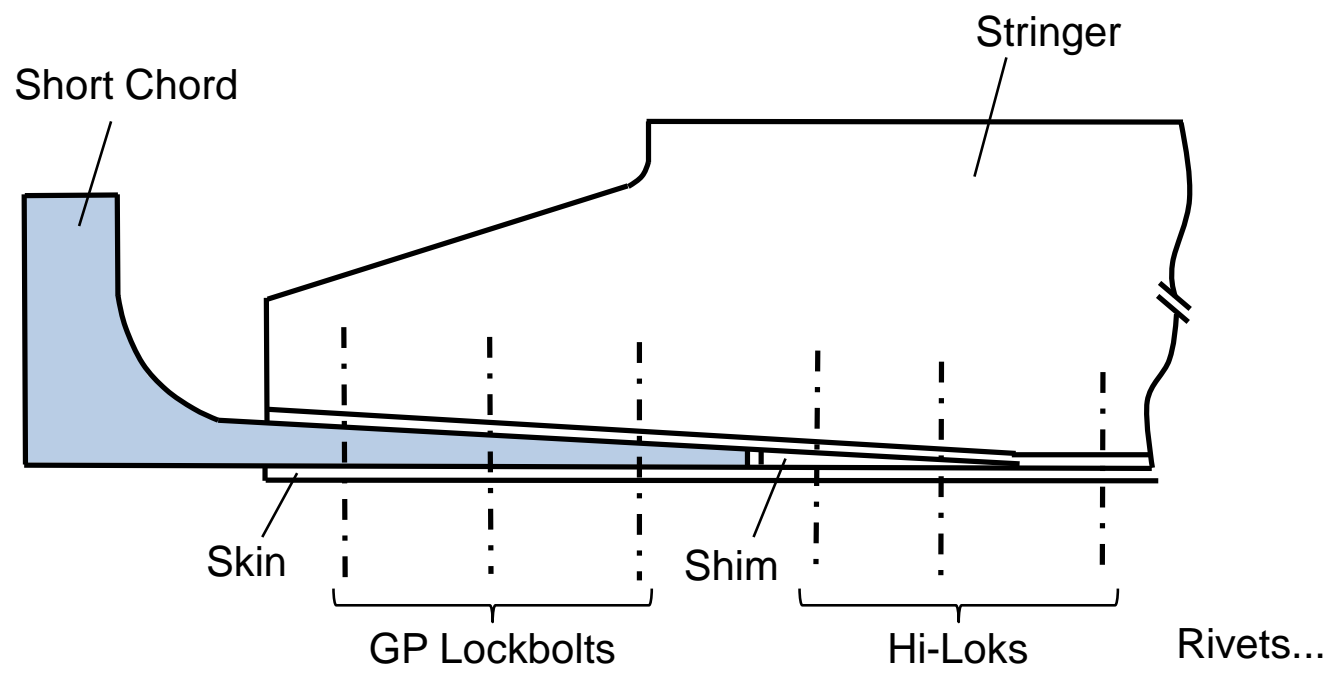




\section{S6-8 (Short Chord) in Test Frame}
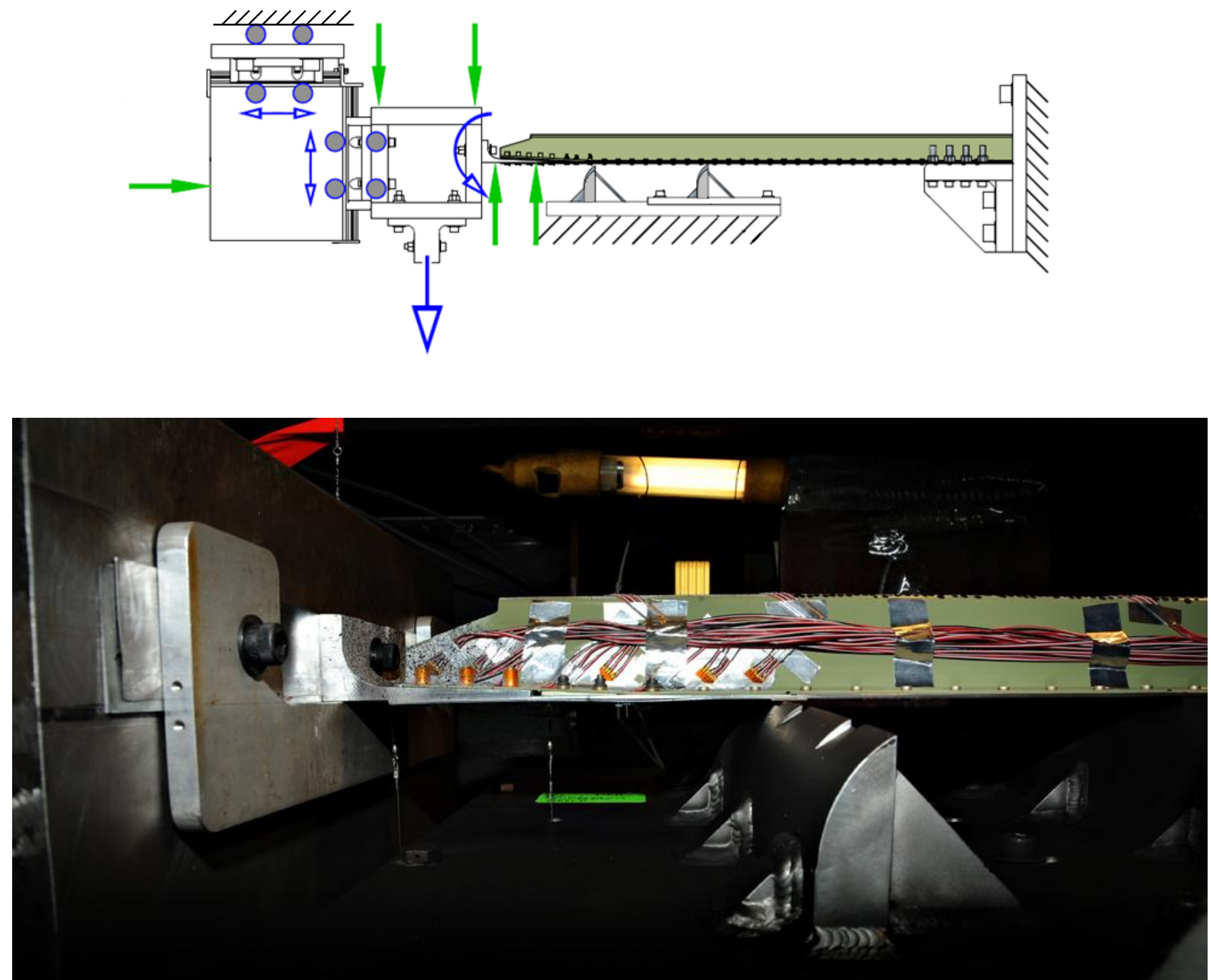


\section{Finite Element Analysis}

\section{Both}

3D, half-symmetry

- Nonlinear, elastic-plastic

- Fasteners as beam elements $\mathrm{w} /$ spider constraints

- Contact included

- Basic 3-step procedure:

- Preload to stringer fasteners

- Preload to test bolt

- Displacement to load block

\section{S9-7 (Long Chord)}

Analyst: Joe ANSYS v12

Solid185 elements, $2 \mathrm{ttt}$

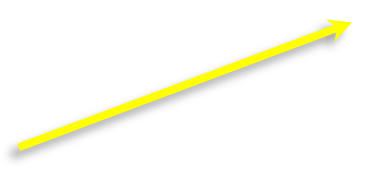

Fulcra as gap elements

\section{S6-8 (Short Chord)}

- Analyst: Dawn

- ABAQUS v6.9-EF

- C3D8I elements, 4ttt

- Fulcra as meshed geometry
Somewhat independent parallel analysis efforts: $\rightarrow$ Different stringer geometries, different analysts, different FE models, different analysis codes, etc...

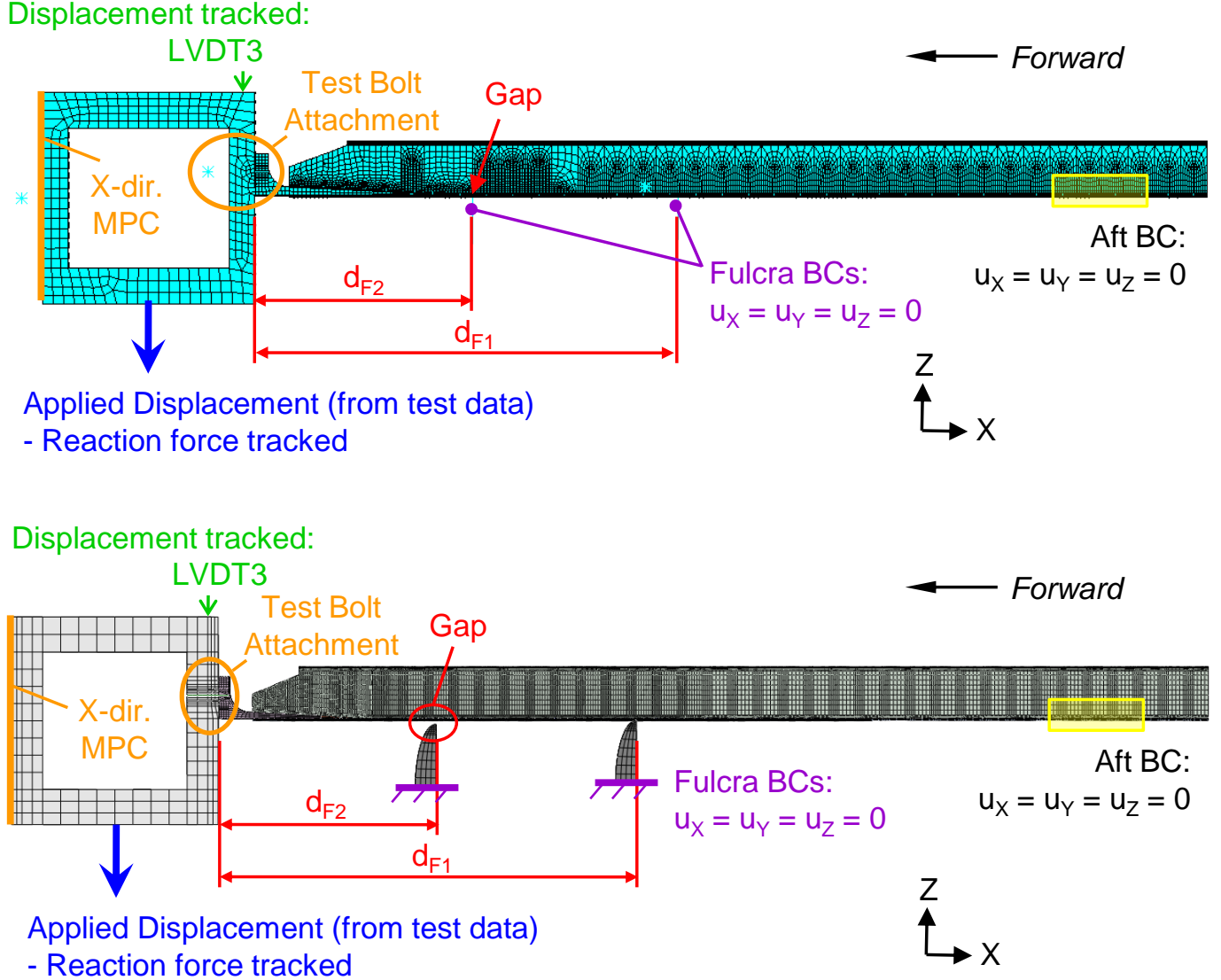




\section{S9-7 (Long) Global Load-Displacement Results}
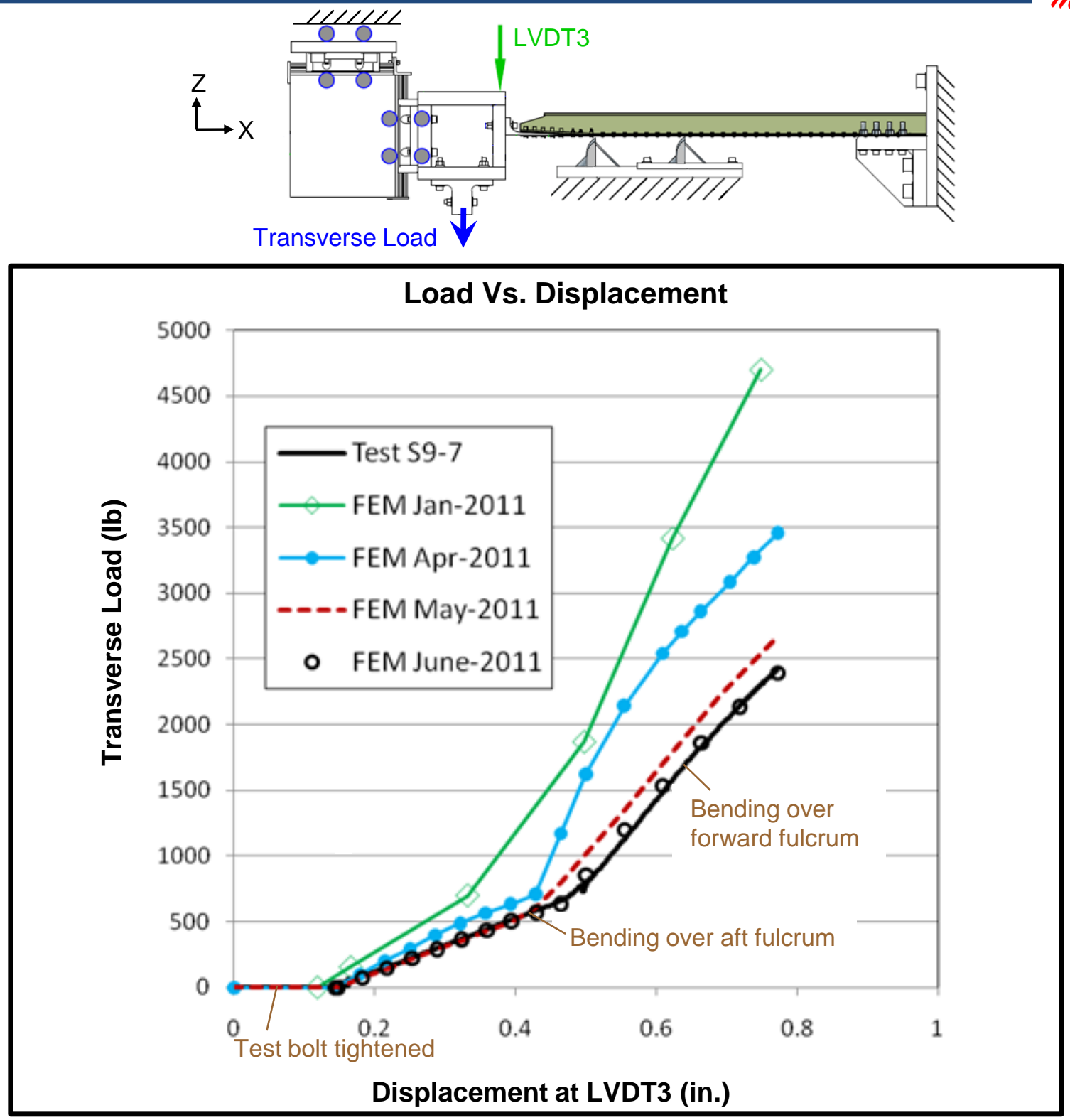


\section{Key To Correlation: Fulcra BCs}

Original assumption - fulcra rigidly mounted

$\rightarrow$ FE model overly stiff in $Z$ direction
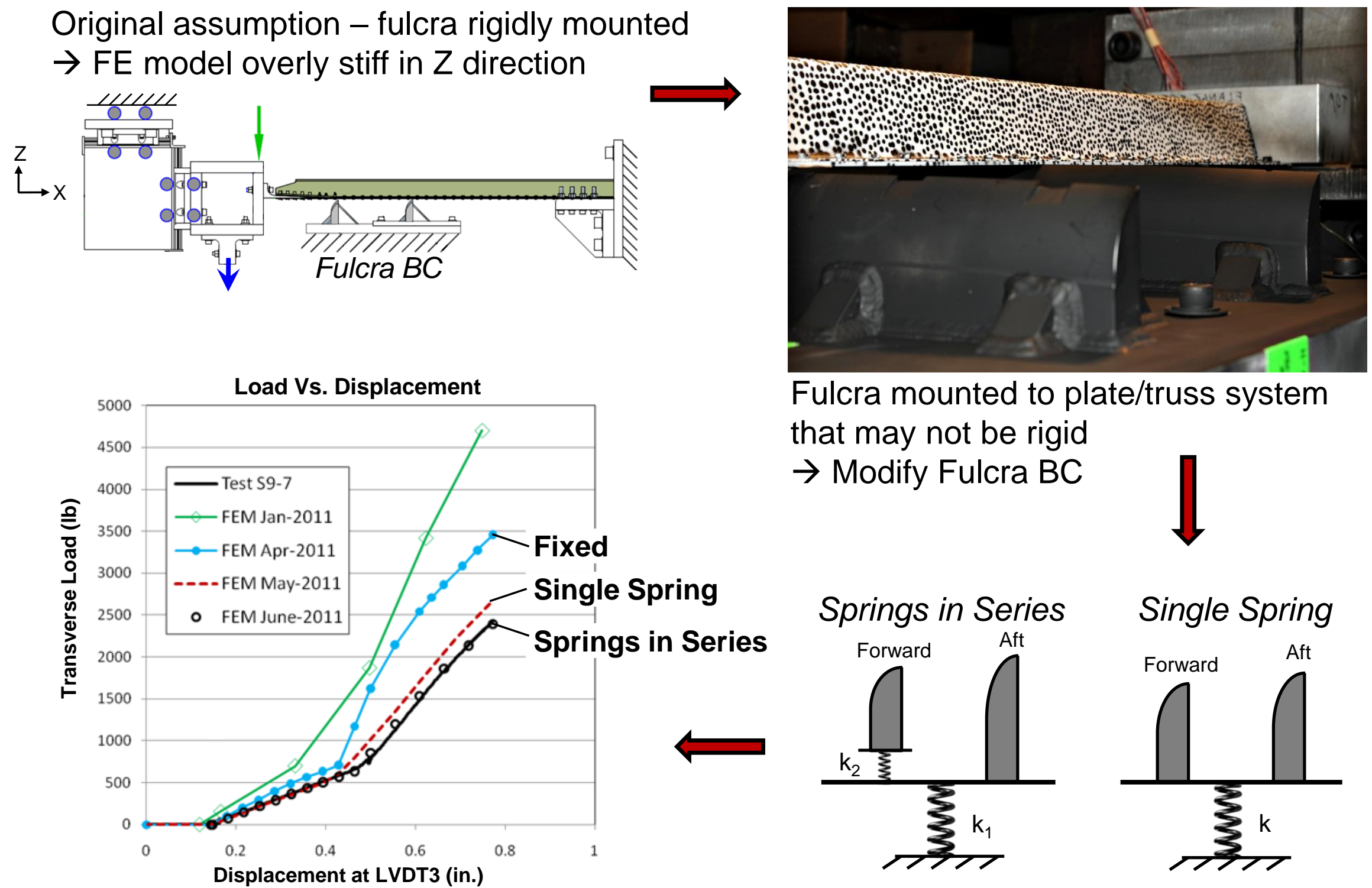

Fulcra mounted to plate/truss system that may not be rigid $\rightarrow$ Modify Fulcra BC

Springs in Series

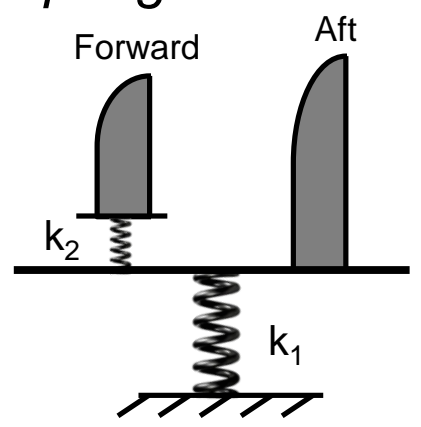

Single Spring

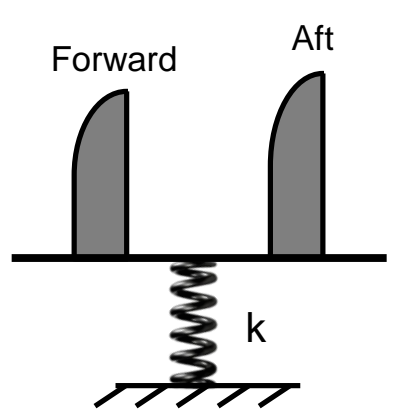




\section{S6-8 (Short) Global Load-Displacement Results}
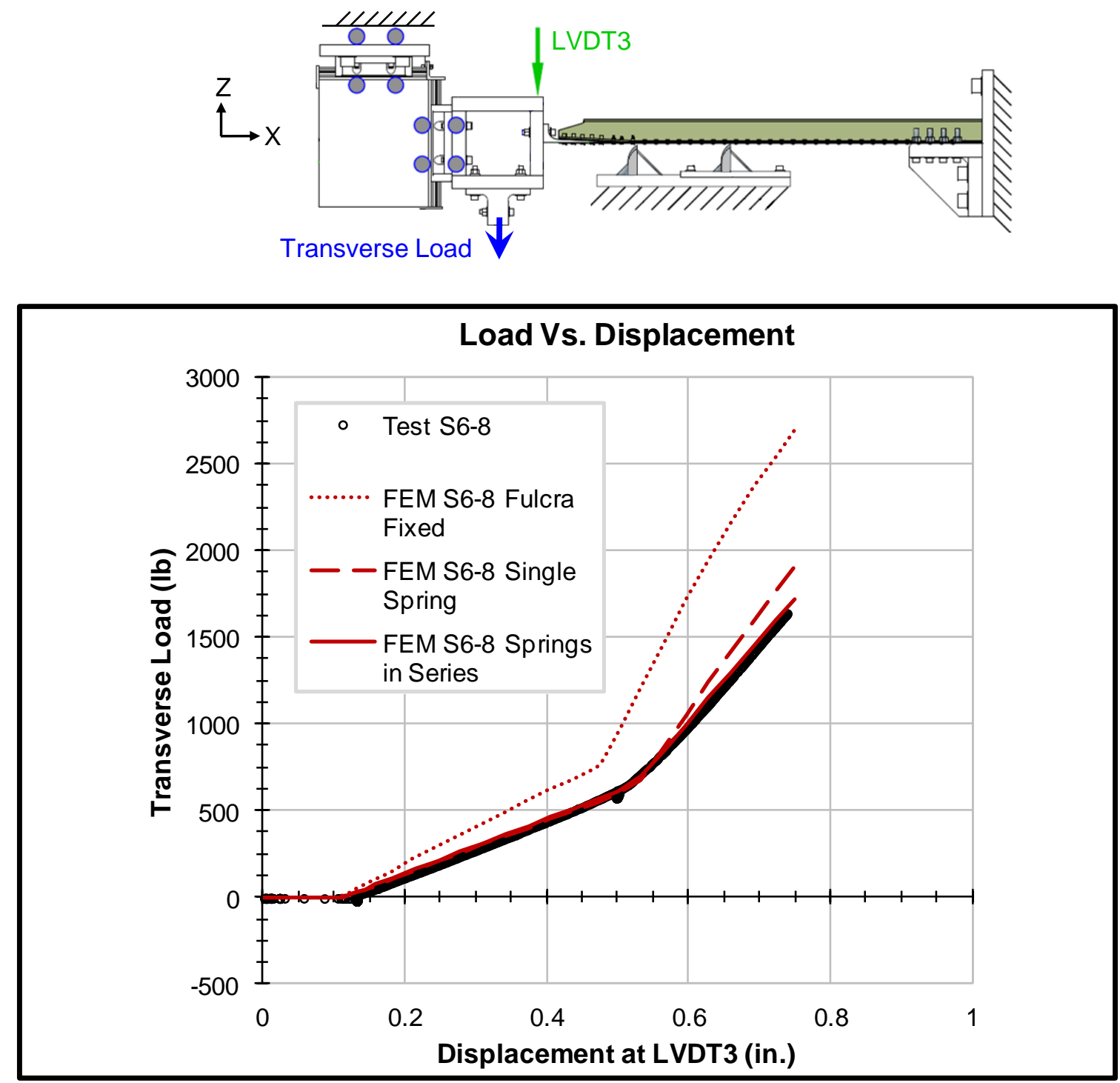


\section{Correlation Comparison}

\section{S9-7 (Long Chord)}

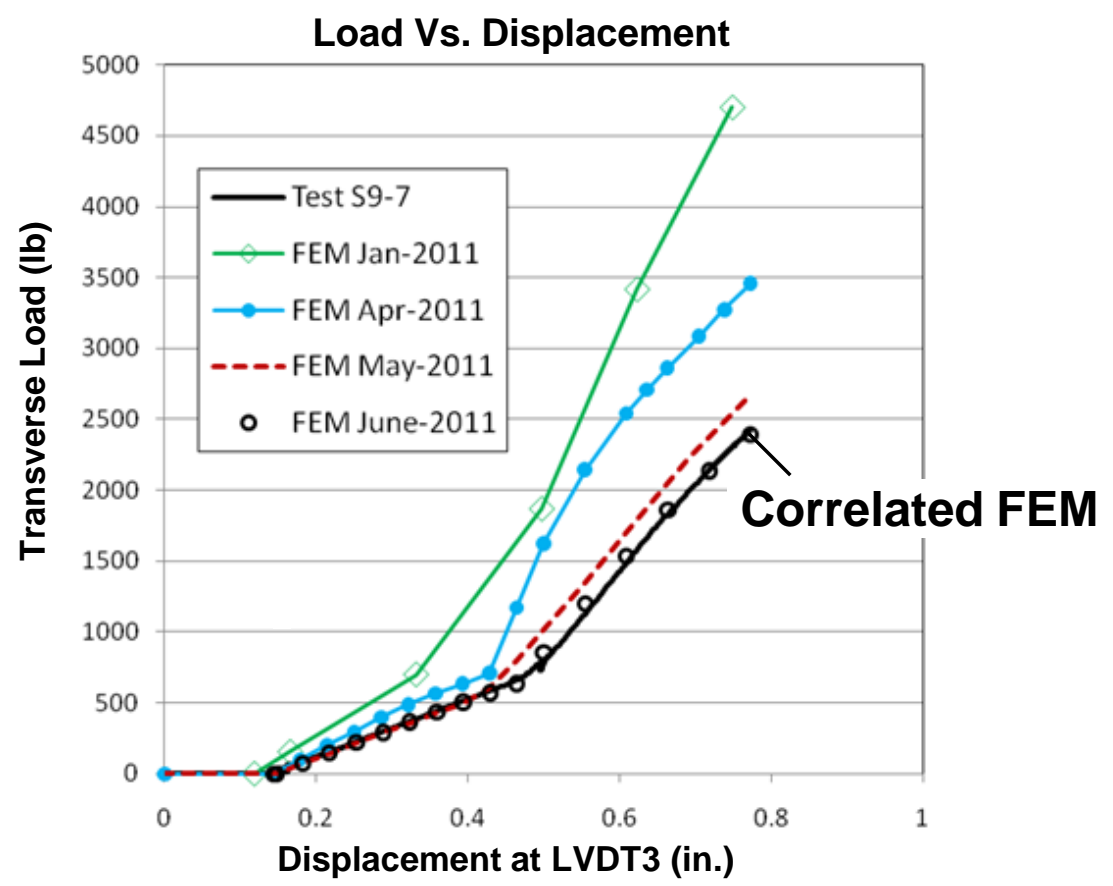

\section{S6-8 (Short Chord)}

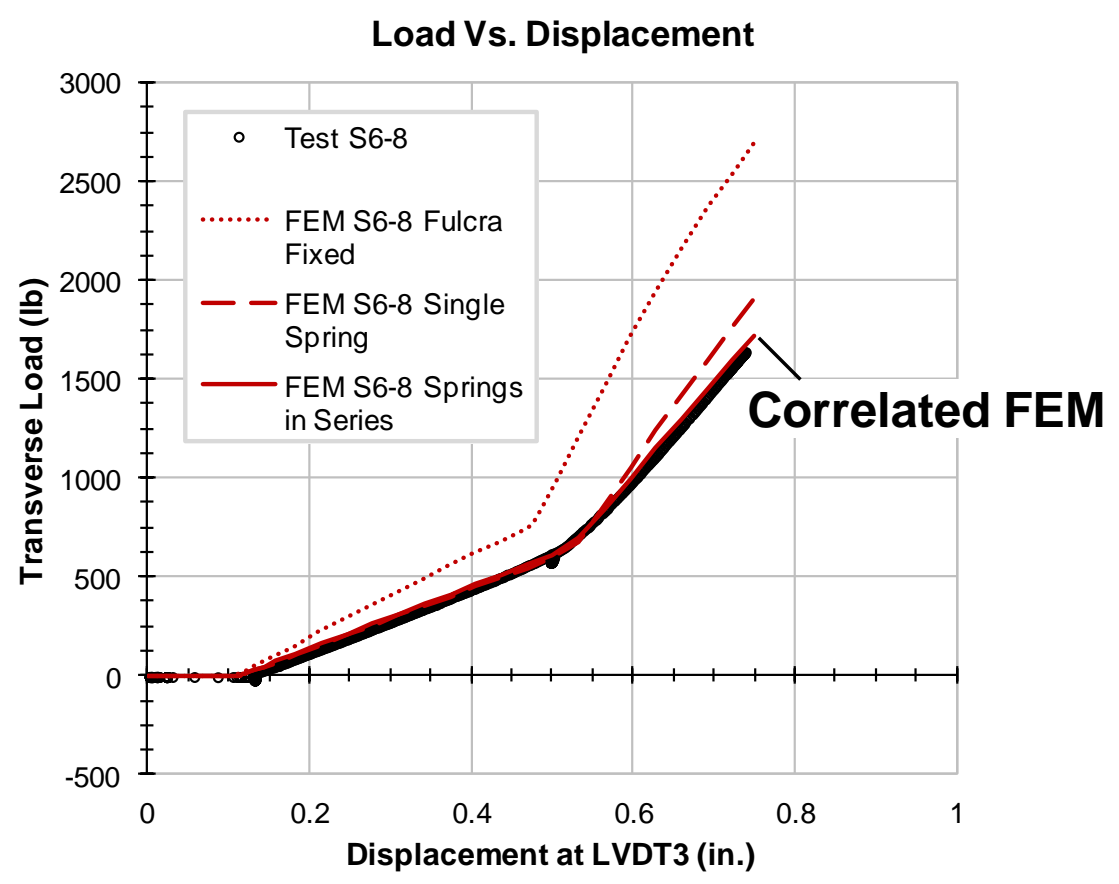




\section{S9-7 (Long Chord) Strain Gage Comparisons}

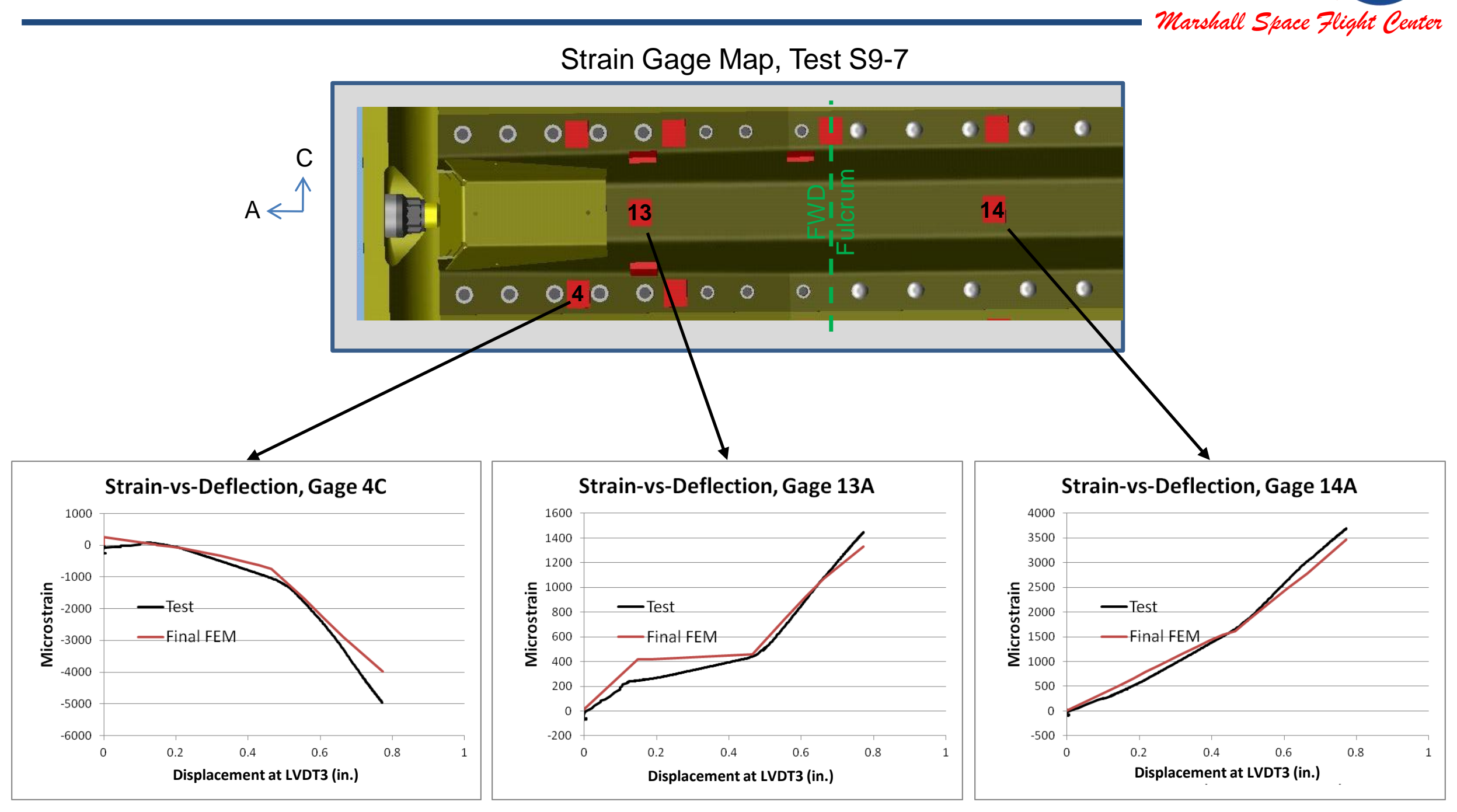




\section{S6-8 (Short Chord) Strain Gage Comparisons}

Marshall Space Flight Center

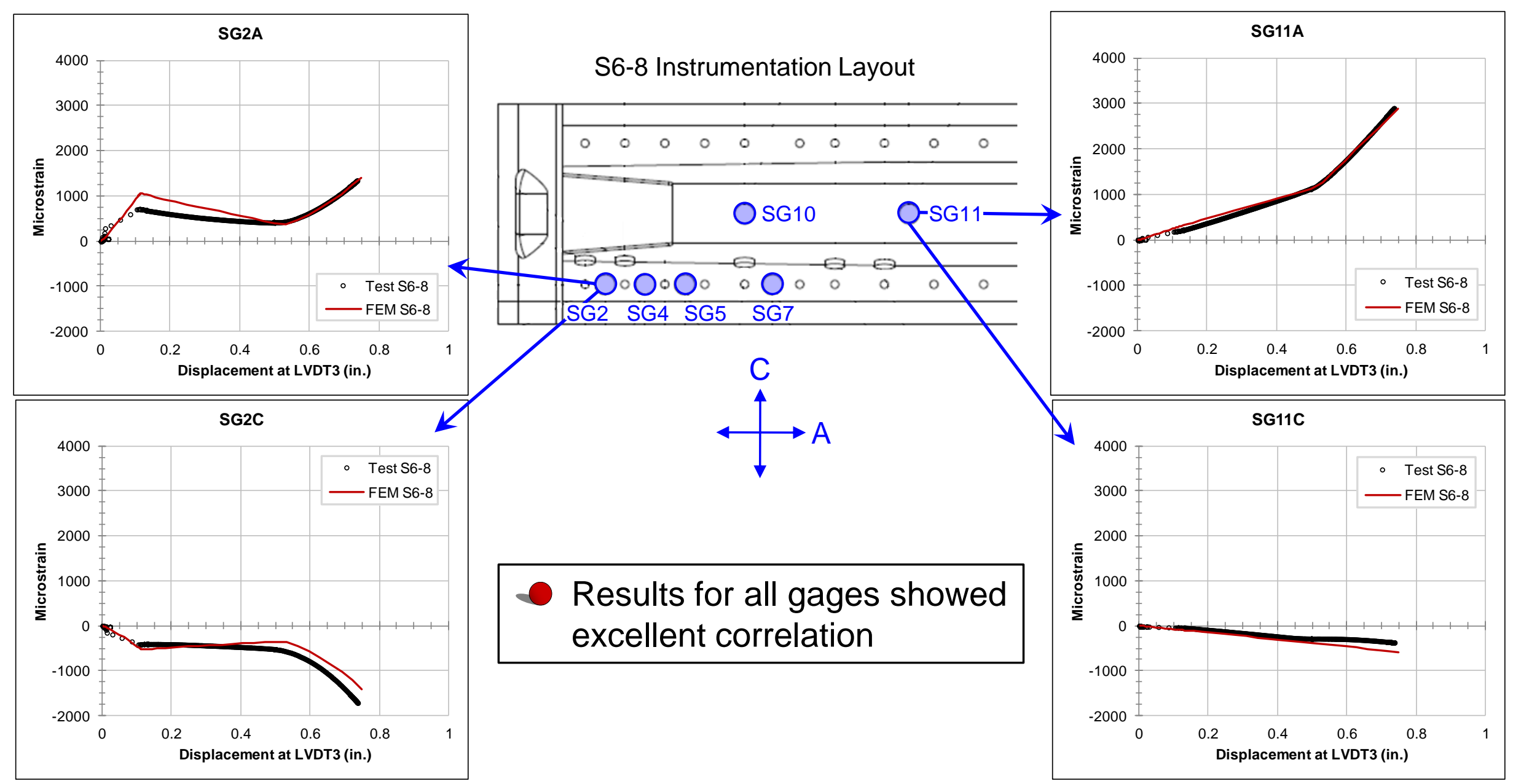




\section{S6-8 (Short Chord) Photogrammetry Comparison}

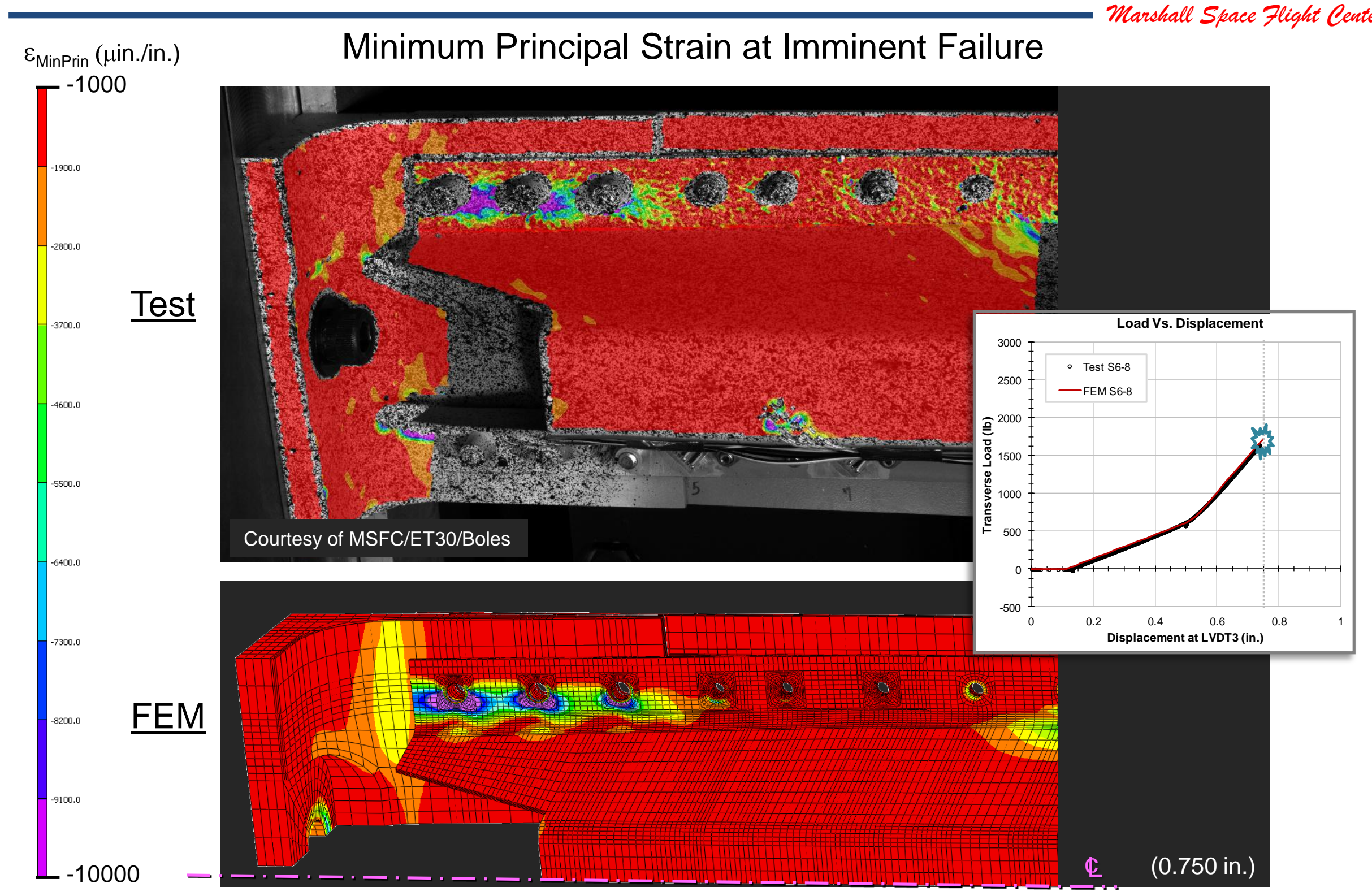




\section{Further Correlation Efforts}

- Test-analysis correlation not trivial

- Springs-in-series boundary condition worked for both S9-7 (long chord) and S6-8 (short chord)

- Boundary condition finding explored further

- Analysis using beam modeling

- Analysis of stringer with radius block modification 


\section{Analysis Using Beam Modeling}

Bending tests resemble simple beam:

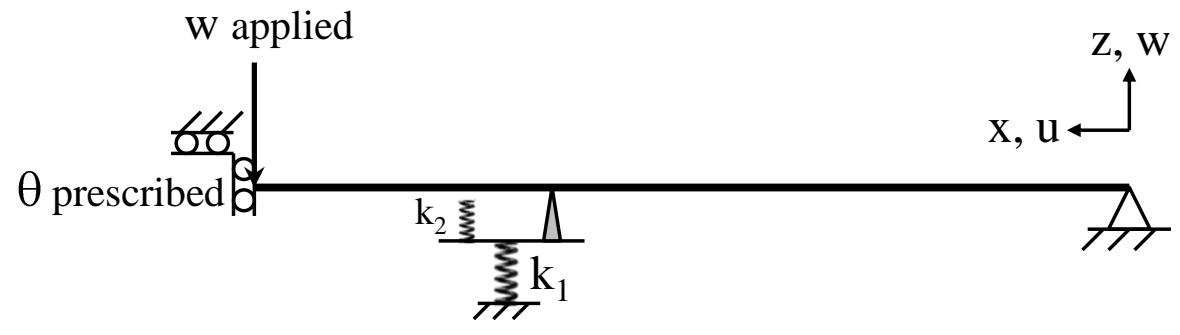

Finite element model for S6-8 (short chord):

- $201 \mathrm{D}$ beam elements

- Gap element at forward fulcrum

- Linear, elastic

- Applied displacement
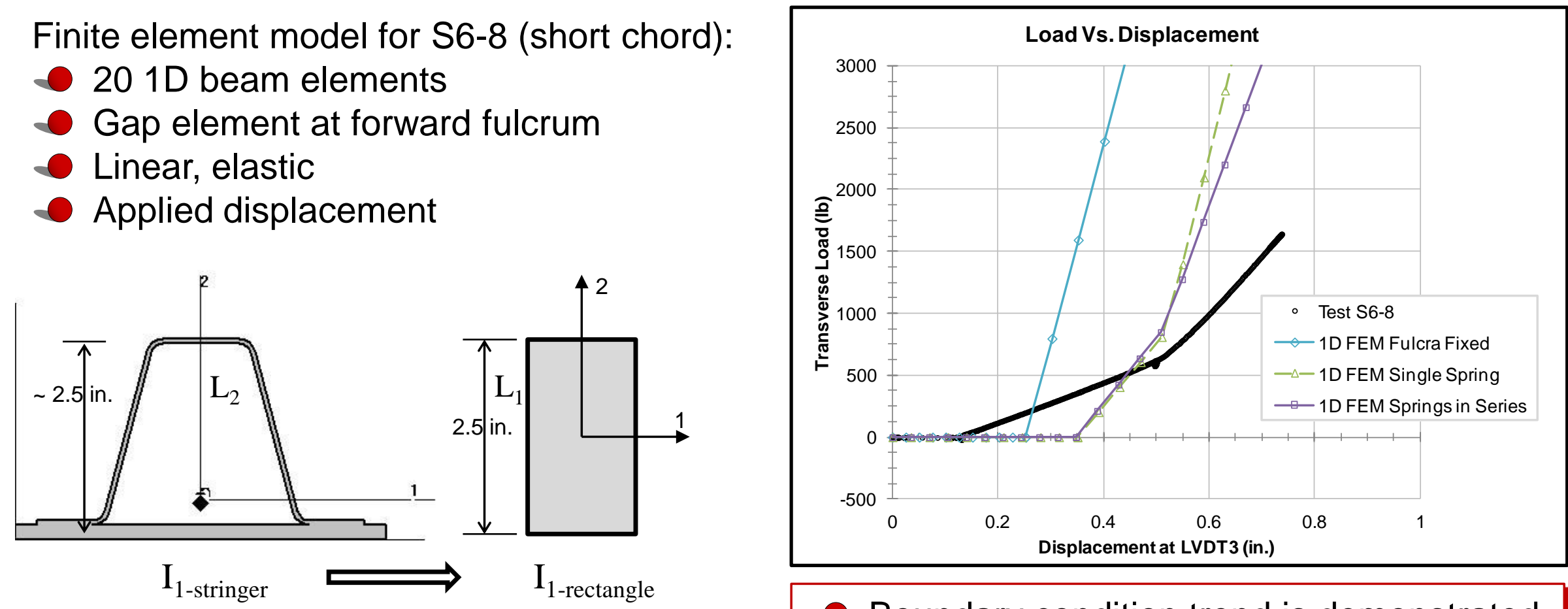

- Boundary condition trend is demonstrated 


\section{Analysis Using Beam Modeling}

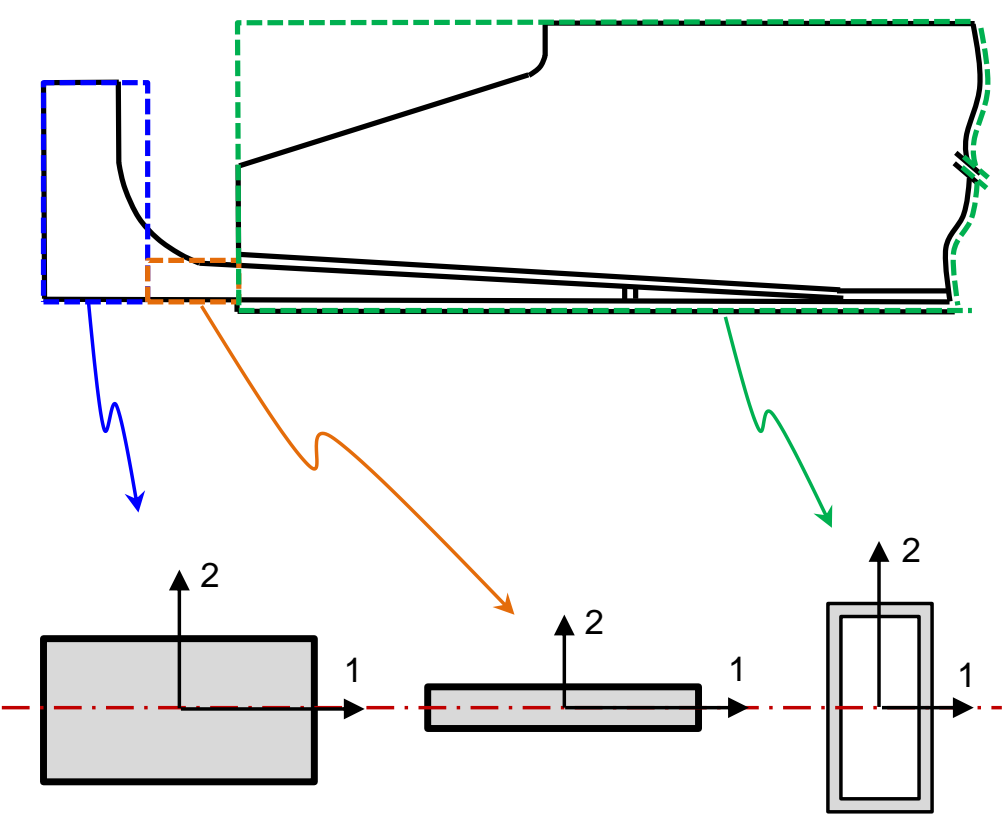

Three Cross-Sections

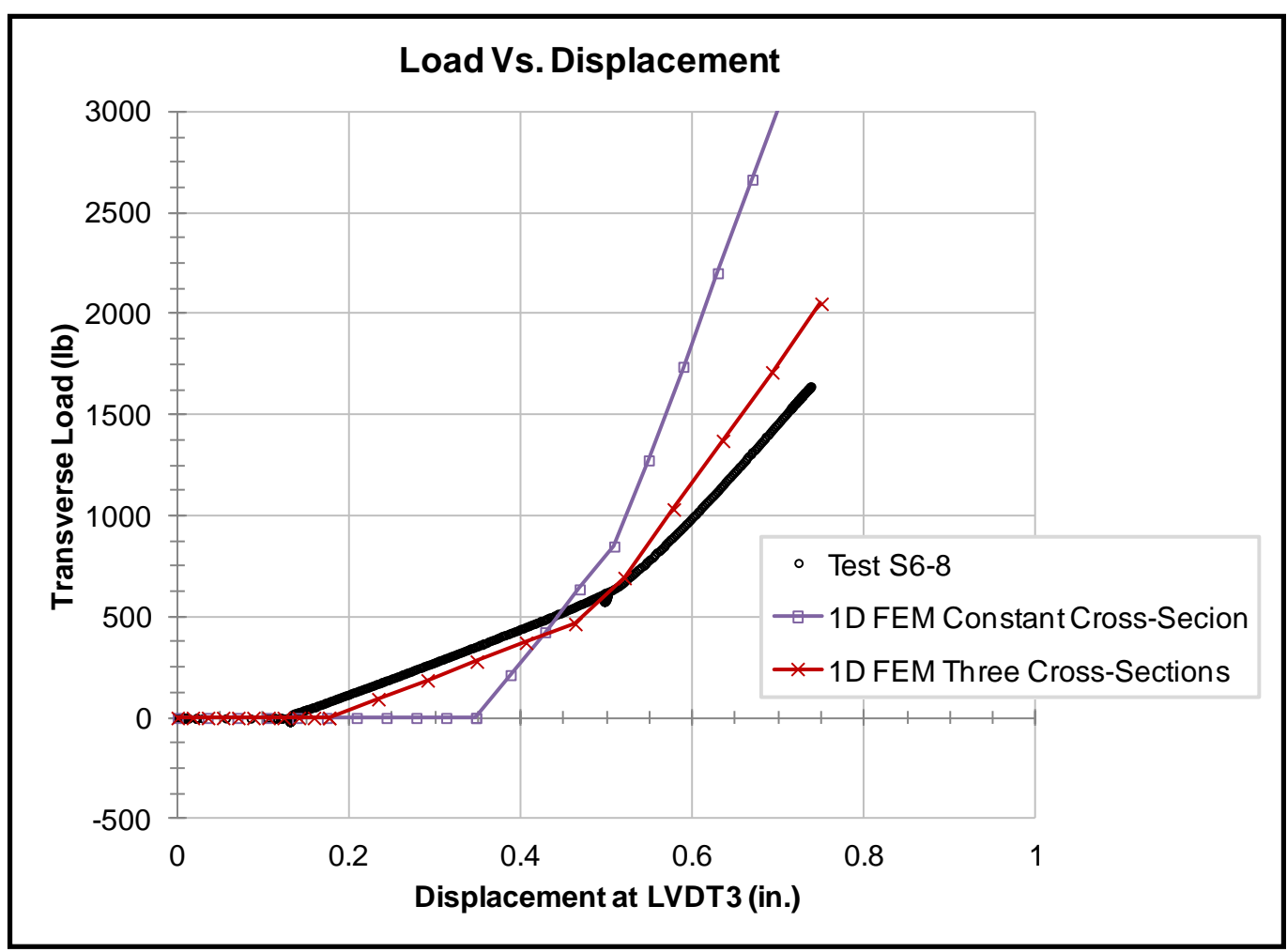

- Beam model captures global behavior well 


\section{Analysis of Radius Block Modification}

Marshall Space Flight Center

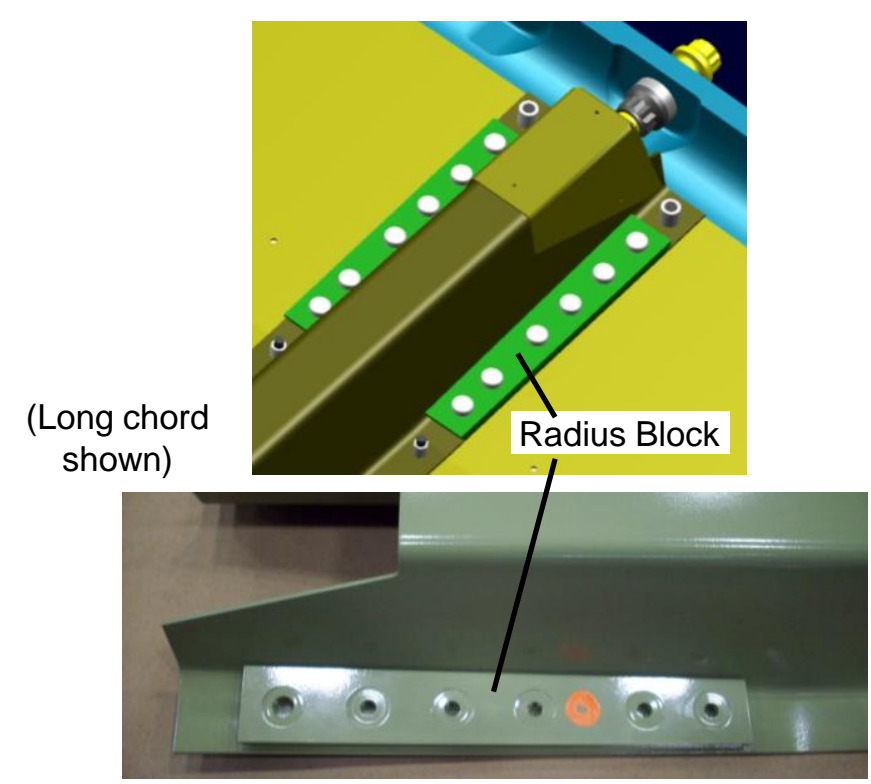

\section{Test S8-8 (Short Chord)}

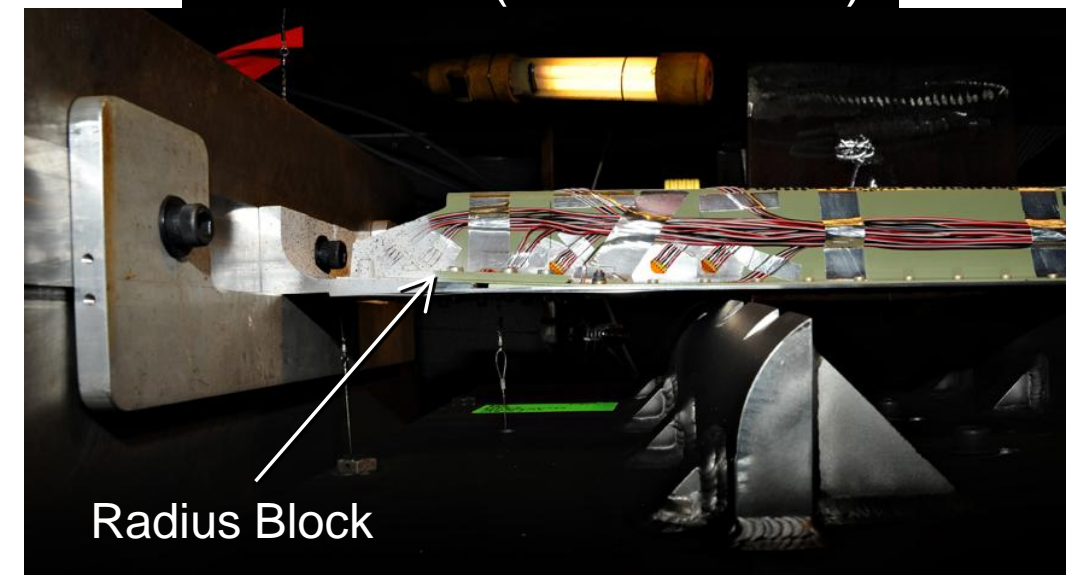

$\rightarrow$ FE Model of S6-8 Modified to Include Radius Block
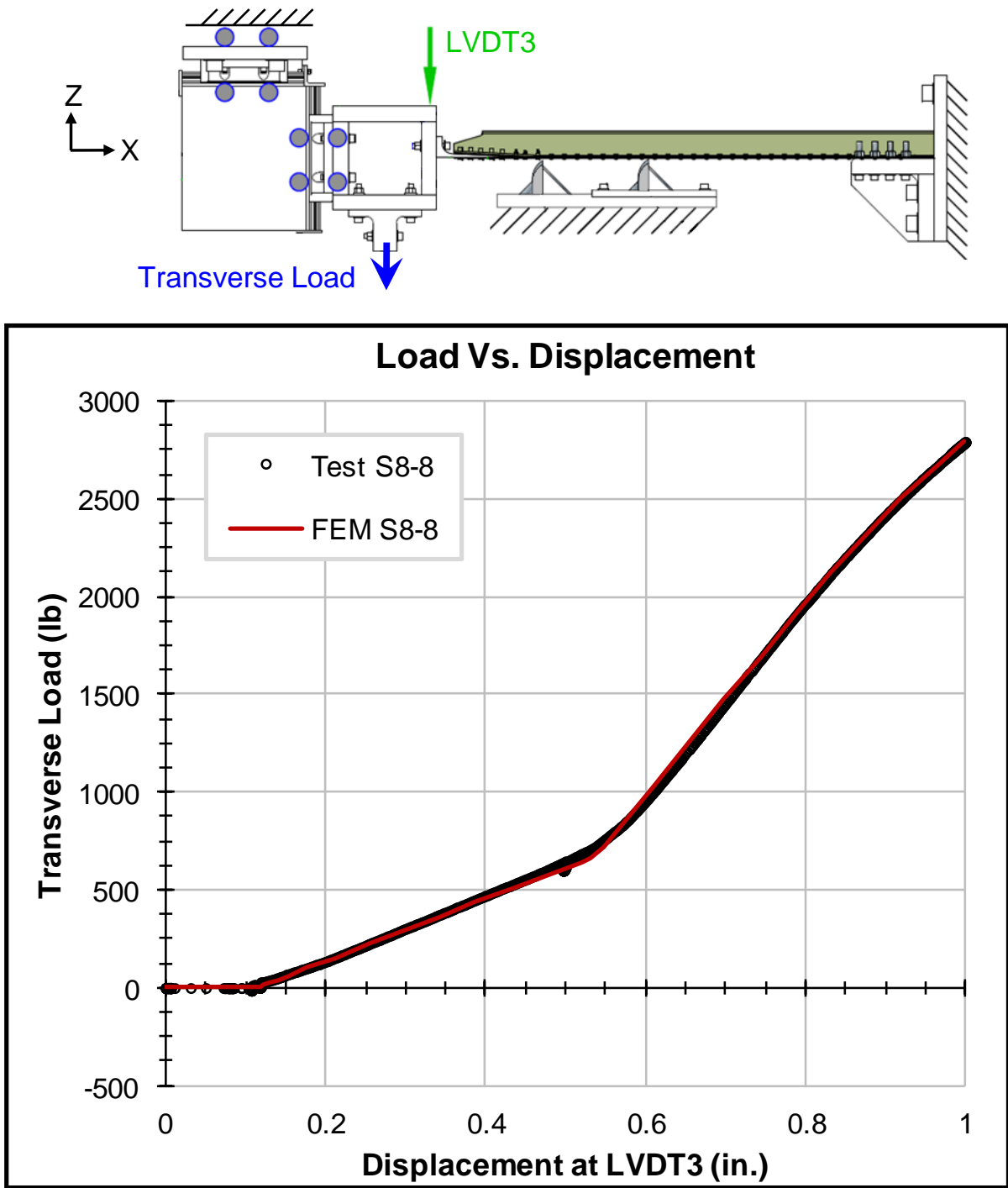


\section{S8-8 Strain Gage Comparisons}

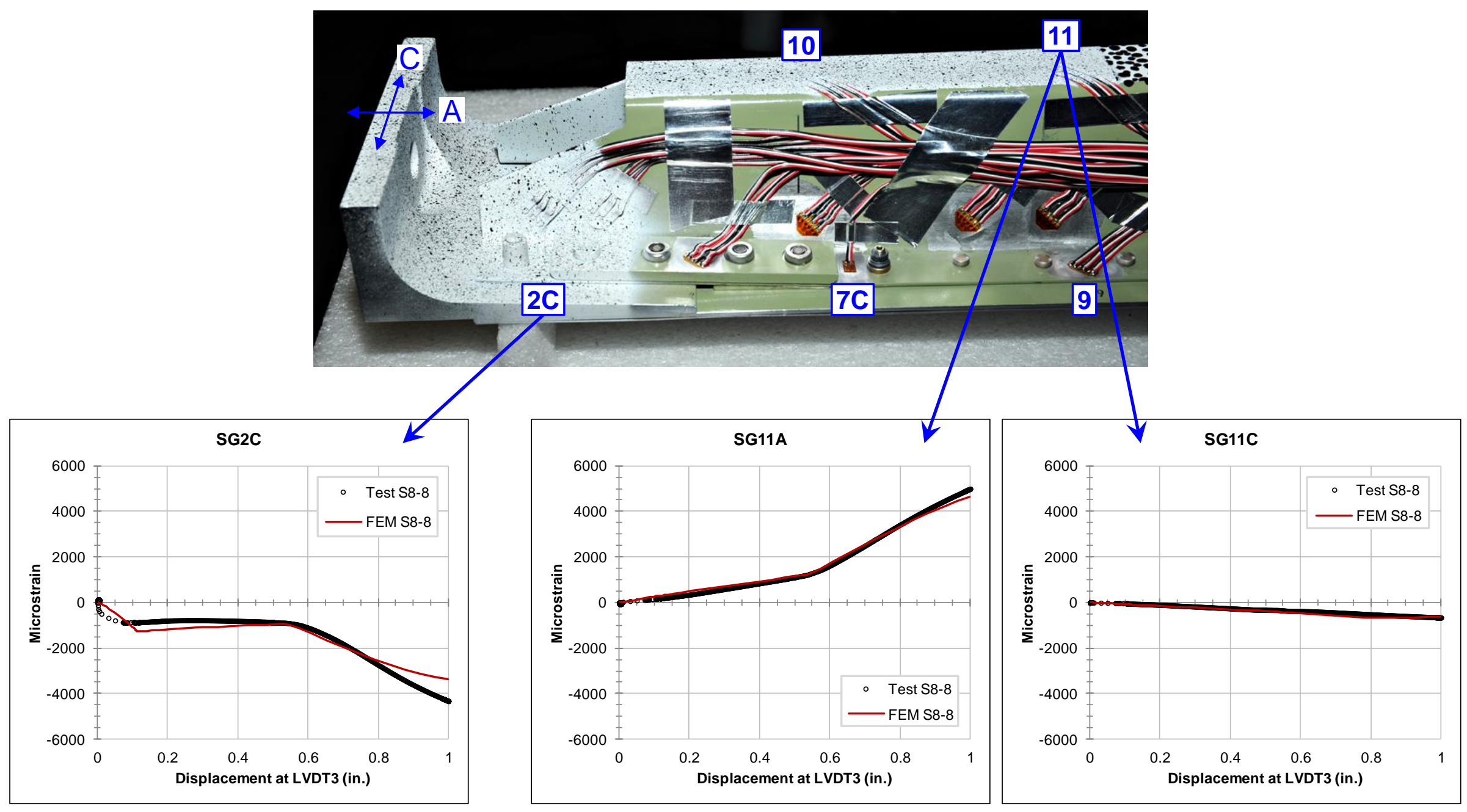

Results for all gages showed excellent correlation 


\section{S8-8 Photogrammetry Comparison}

Marshall Space Flight Center Minimum Principal Strain at 0.75 in. LVDT3 Displacement (Imminent Failure of S6-8) $\varepsilon_{\text {MinPrin }}(\mu \mathrm{in}$. /in.)
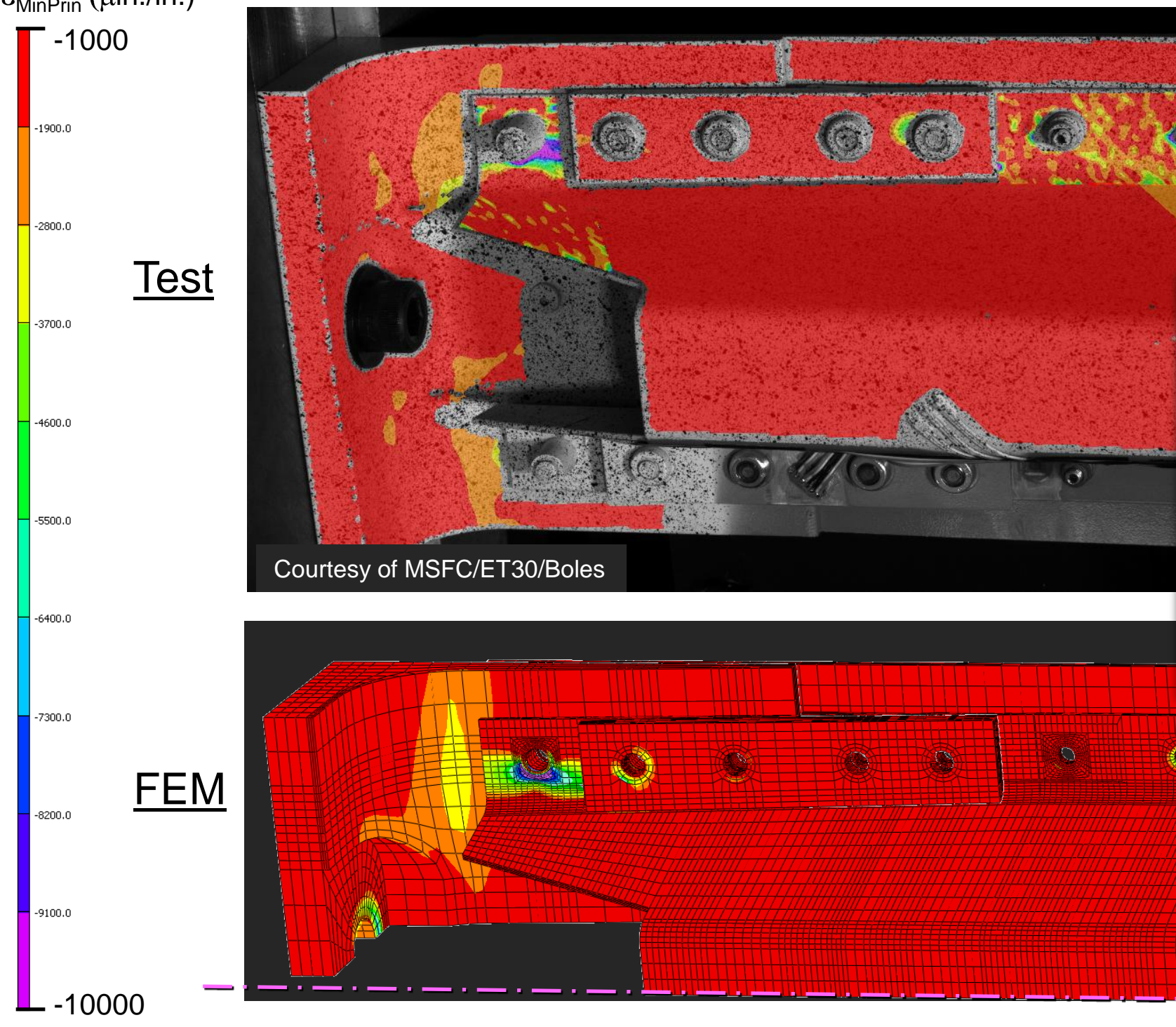

Test

Courtesy of MSFC/ET30/Boles
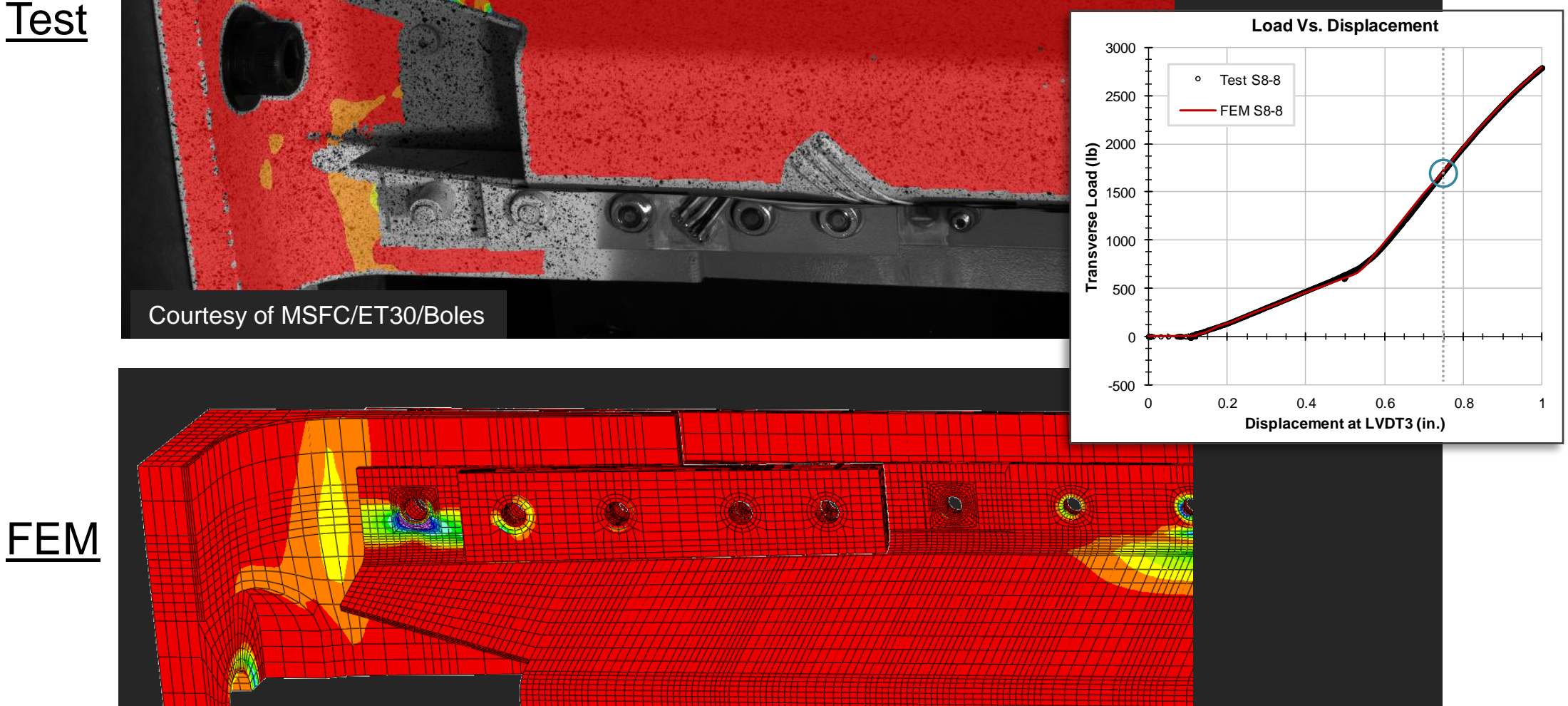

$$
-
$$




\section{Correlation Timeline}

- Test-analysis correlation completed after ET-137 flew

- Findings of test program used in flight readiness assessment to demonstrate capability of stringers with radius block modification

- Two tanks yet to fly, ET-122 and ET-138

- Both tanks modified to include radius blocks

- Correlation effort continued to improve understanding of tank behavior and effects of radius blocks

- Results available to further bolster structural verification for remaining two flights 


\section{Effect of Radius Blocks}

Minimum Principal Strain at 0.75 in. LVDT3 Displacement
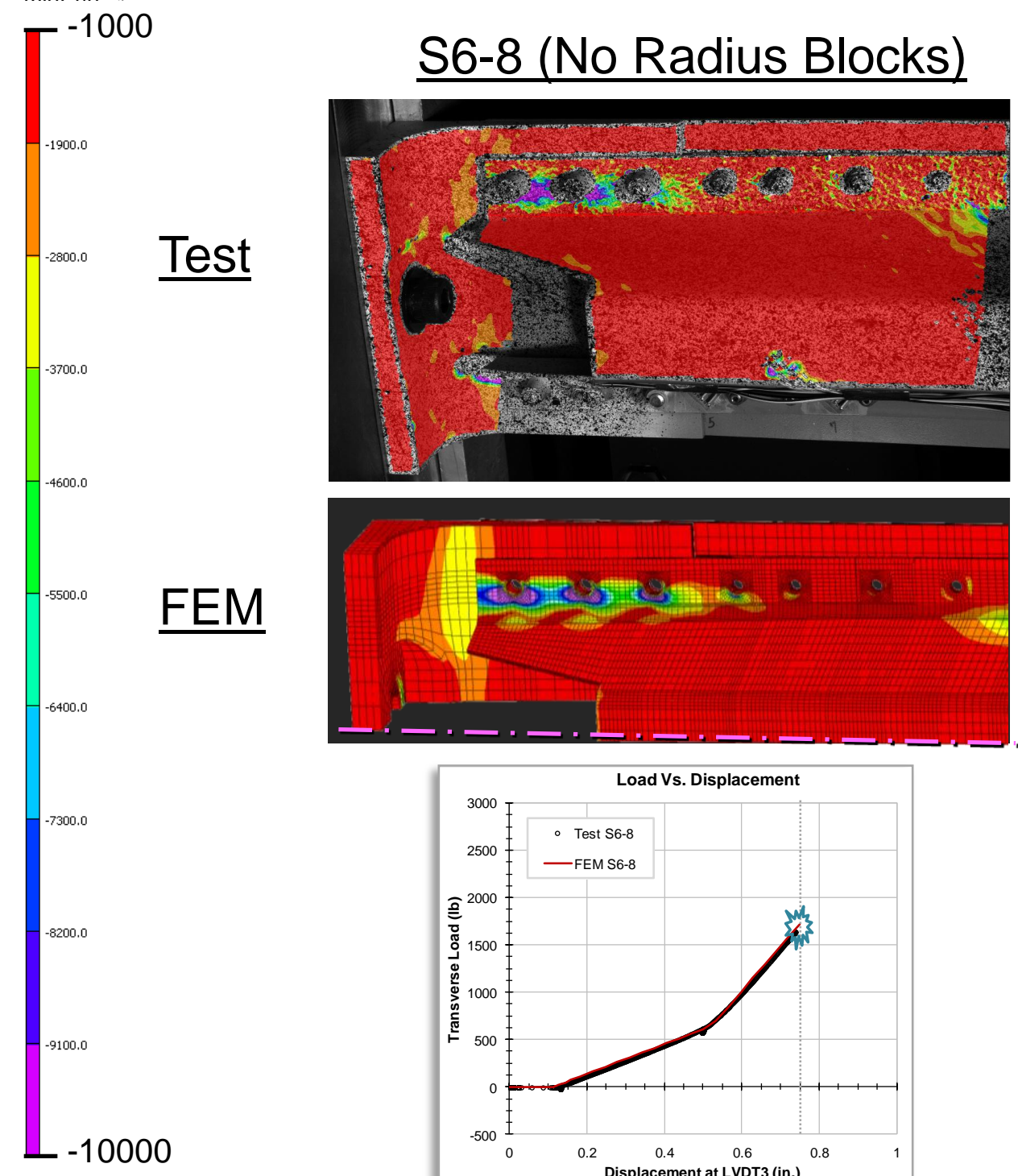

S8-8 (With Radius Blocks)
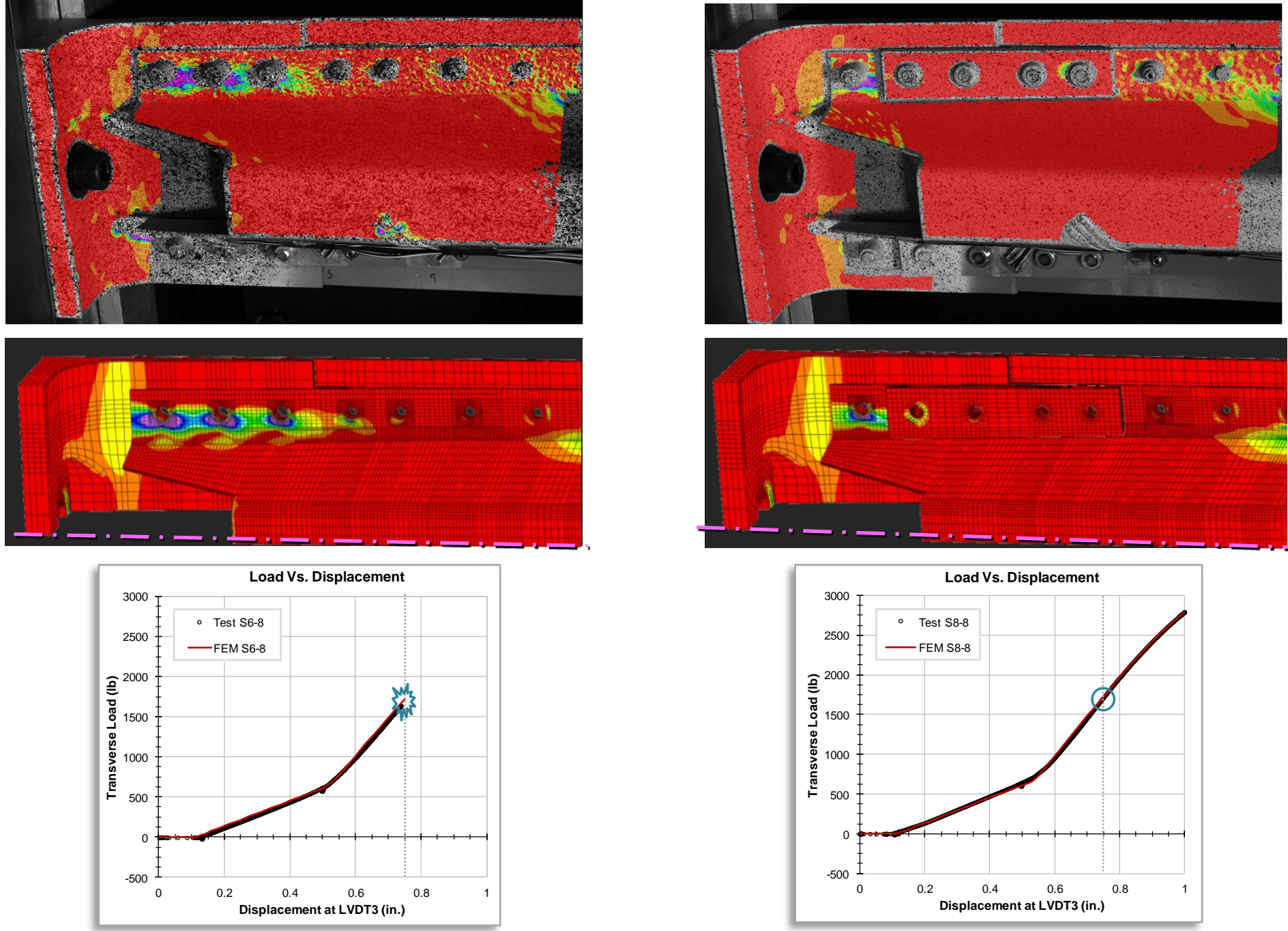


\section{Lessons Learned}

- 3D solid models created to study through-thickness behavior

- 1D models could have been used earlier to help understand global behavior

- Systematically verify boundary conditions

- BCs at forward and aft ends studied

- Degree of fixity at aft end

- Preload in test bolt

- And many more...

- BCs at fulcra peripherally studied

- Profile of fulcra

- Etc.

- Test set-up could have included LVDT at fulcra to verify rigid BC assumption

- Photogrammetry proved incredibly useful for overall picture of correlation 


\section{Summary}

- Following STS-133 launch scrub, cracks found in Intertank stringers of ET-137

- Large investigation conducted to determine root cause, establish remedy/repair, and provide data for flight readiness assessment

- Findings from single stringer bending tests used in flight readiness assessment to demonstrate capability of stringers modified with radius blocks

- Test-analysis correlation effort continued and completed after STS-137 flew

- 3D solid FE models for two different stringer configurations

- Correlation not trivial

- Correct boundary conditions identified

- Lessons learned identified

- Excellent correlation eventually obtained for stringers without and with radius blocks

- Correlation results available to further bolster structural verification of remaining ETs

- Shuttle Discovery final launch on February 24, 2011 as STS-133 with repaired and modified ET-137

- Space Shuttle Program successfully concluded in August 2011 


\section{STS-133 Roll-Out}

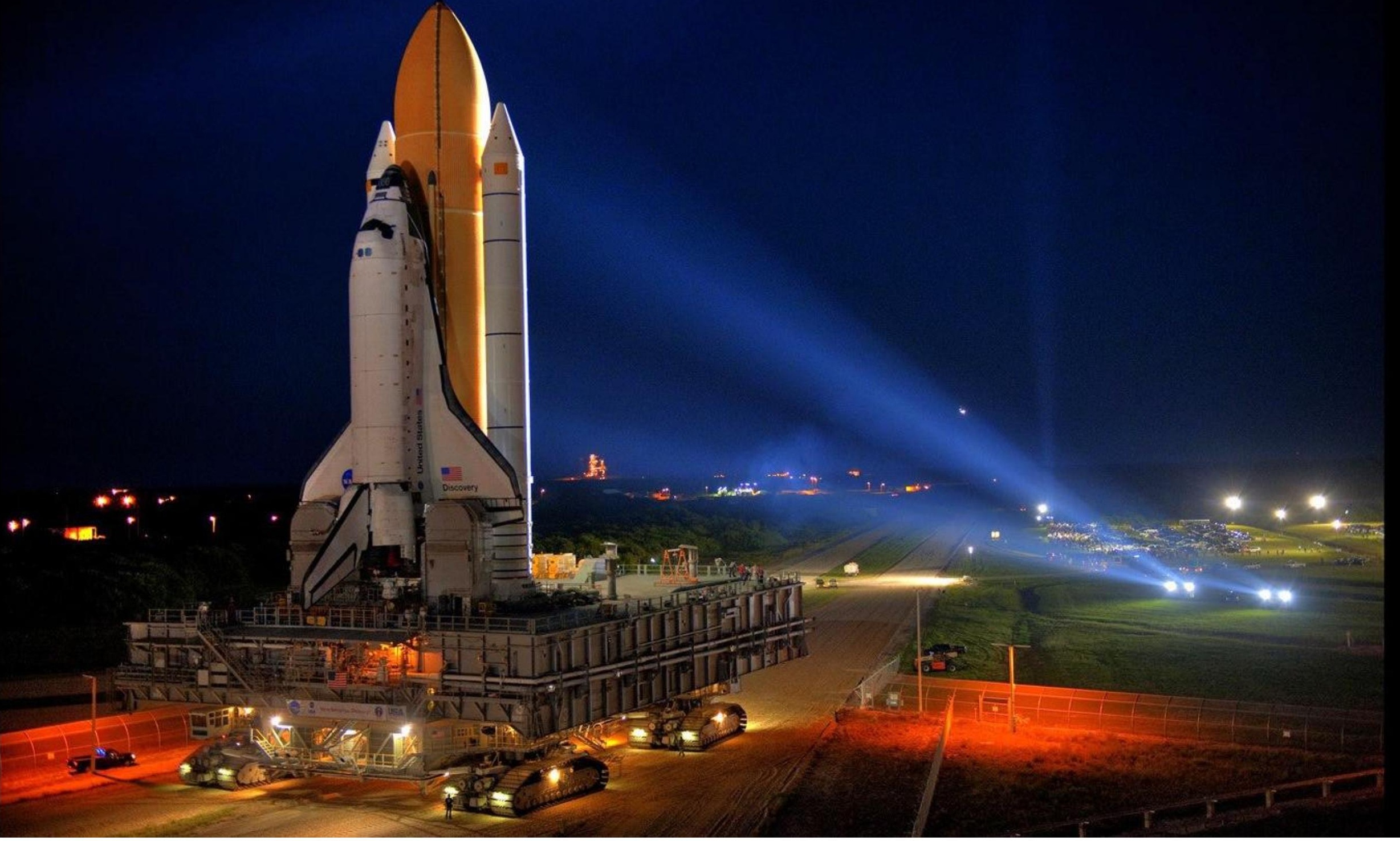

